\title{
Impact of Virtual and Augmented Reality on Theme Parks
}

\author{
by
}

Trevor Nelson

Bachelor of Commerce, Dalhousie University, April 2012

\author{
A Major Research Paper \\ Presented to Ryerson University \\ in partial fulfillment of the \\ requirements for the degree of \\ Master of Digital Media, 2016 \\ in the program of Digital Media \\ Toronto, Ontario, Canada, 2016
}

(C) Trevor Nelson, 2016 


\section{Author's Declaration}

I hereby declare that I am the sole author of this MRP. This is a true copy of the MRP, including any required final revisions.

I authorize Ryerson University to lend this MRP to other institutions or individuals for the purpose of scholarly research.

I further authorize Ryerson University to reproduce this MRP by photocopying or by other means, in total or in part, at the request of other institutions or individuals for the purpose of scholarly research.

I understand that my MRP may be made electronically available to the public.

Trevor Nelson 
Abstract

Impact of Virtual and Augmented Reality on Theme Parks

Master of Digital Media, 2016

Trevor, Nelson

Master of Digital Media, Ryerson University

Virtual Reality (VR) and Augmented Reality (AR), provide immersive experiences that are increasingly considered for implementation within Theme Parks. This paper seeks to determine the impact of virtual technologies on the Theme Parks.

The method for this paper involved interviews with industry leading experts from the Theme Park industry. The interviews were structured to determine more detailed information on how they are approaching VR/AR in Theme Park attractions.

Theme Parks need to provide guests with something they can't get at home. There are many challenges with head mounted displays (HMD) in Theme Parks, as a result, several participants pointed to Mixed Reality (MR) as a better current solution. It mixes physical spaces with digital overlays with less complicated and operationally challenging technology. New attractions using VR/AR/MR technologies need to carefully consider what content they will use, mechanics of the experience and the business case to ultimately achieve overall success. 


\section{Acknowledgements}

It has been a great opportunity for me to write on the subject of Virtual and Augmented Reality and their Impacts on Theme Parks. I have completed this study under the guidance and supervision of Dr. Kathryn Woodcock and Professor Michael Carter am very thankful for their scholarly guidance, assistance and knowledge. I would also like to thank Dr. Ali Mazalek and Dr. Michael Murphy who provided additional assistance as I completed this report.

This paper would not have been possible without the openness and kindness of the experts from the VR/AR Theme Park Community. I thank everyone very much for sparing their time and wisdom with me in the pursuit of completing this report.

Finally, I would like to thank my family for their direct and indirect support during the entire course of this project. It has been a fantastic opportunity to travel the world, meet top experts in this field and create a body of research to supplement the limited research that exists in this emerging subject area. I am very grateful for that opportunity. 


\section{Table of Contents}

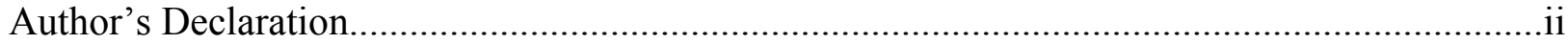

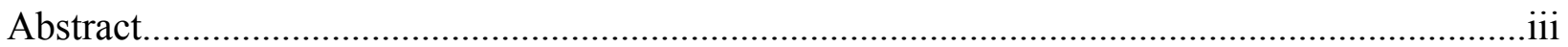

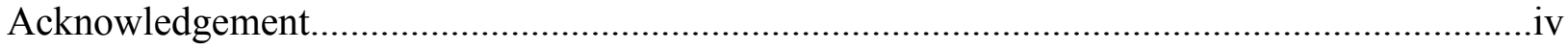

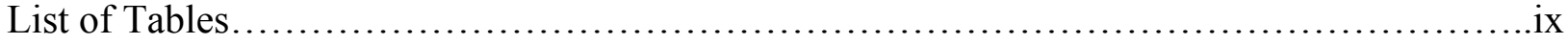

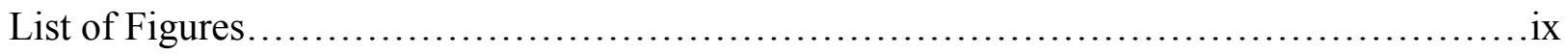

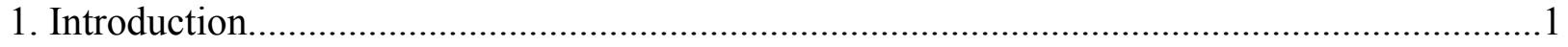

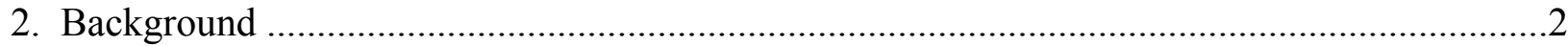

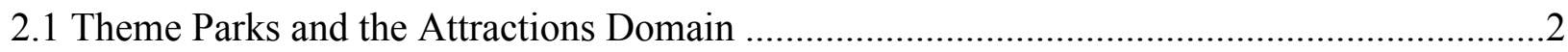

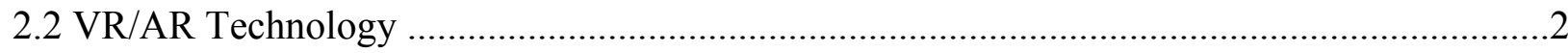

2.3 Opportunity to Match VR/AR Technology with Theme Park Attraction...................................2

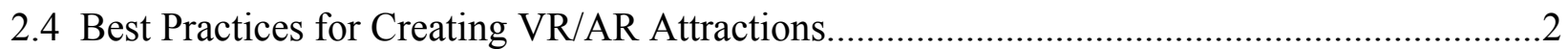

2.5 Why the connection between VR/AR attractions been made...................................................

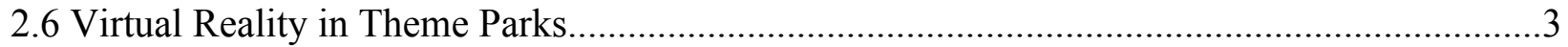

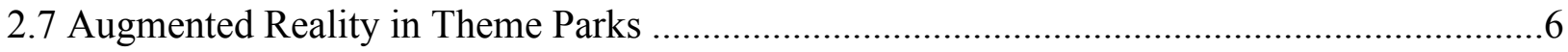

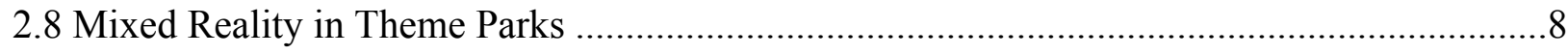

2.9 Paper Outline ..........................................................................................................

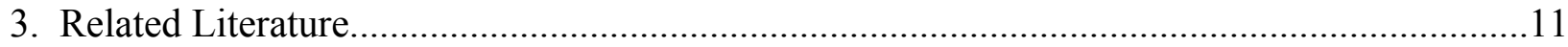

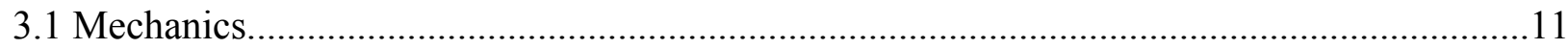

3.1.1 The Nature of Ride Motion/Vehicles...............................................................................11

3.1.2. Common Requirements for Attractions..........................................................................14

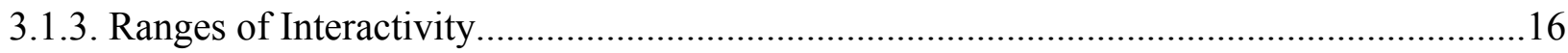

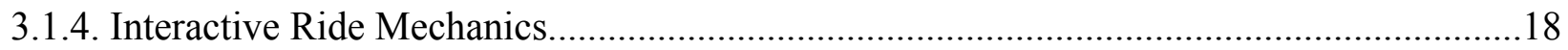

3.1.5. VR/AR/MR Technology ...........................................................................................19

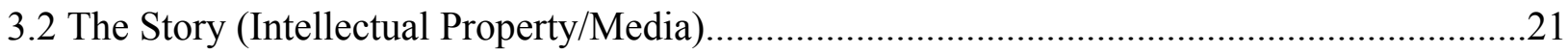

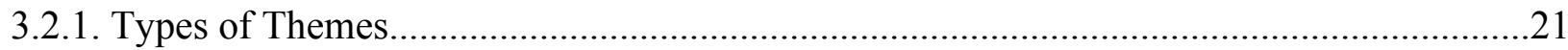

3.2.2. Importance of Good Characters, Stories and Physical Worlds............................................23

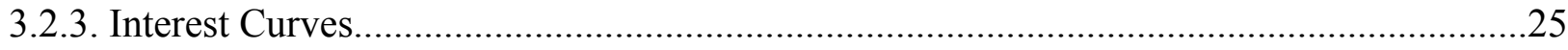

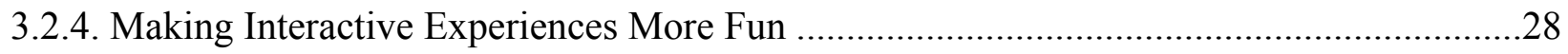

3.2.5. Understandability - Is there a clear goal?.........................................................................30

3.2.6. Branded Content vs. Custom Content............................................................................... 


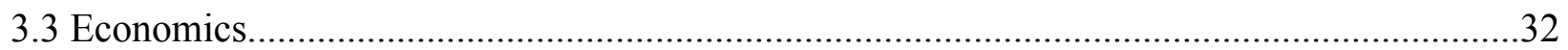

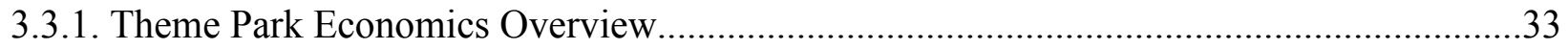

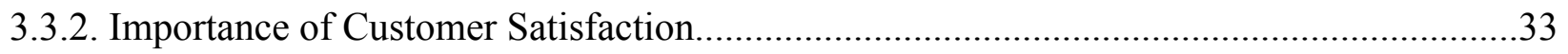

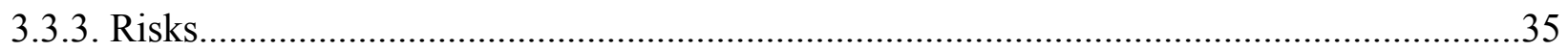

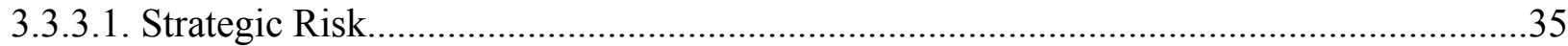

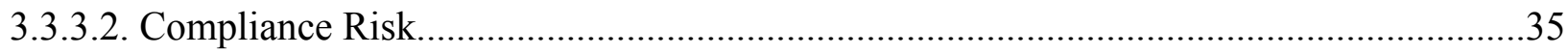

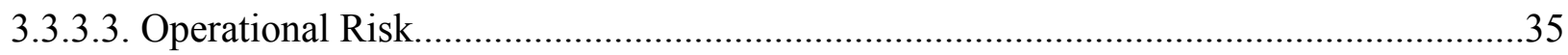

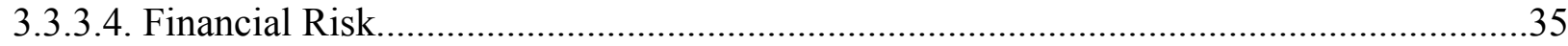

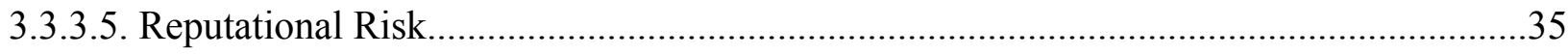

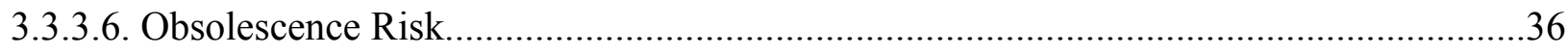

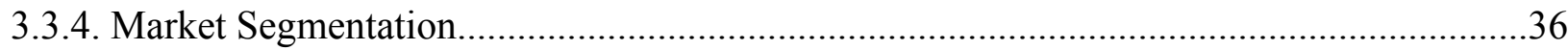

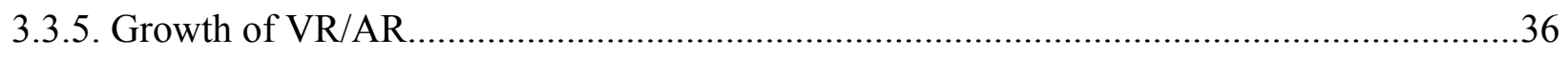

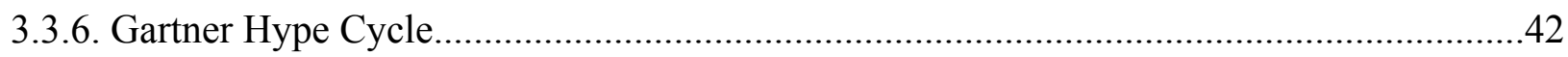

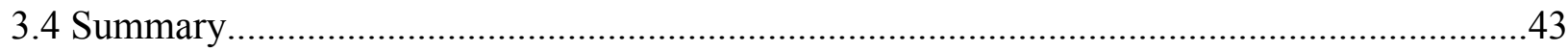

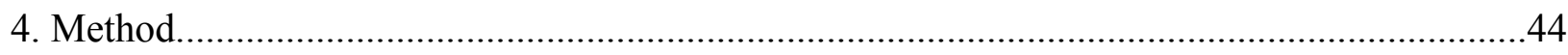

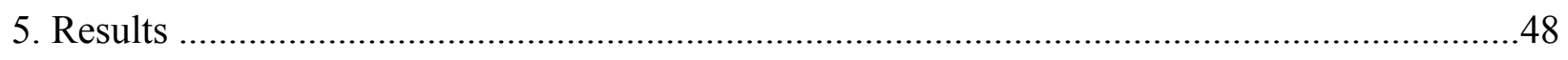

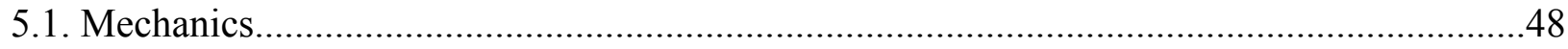

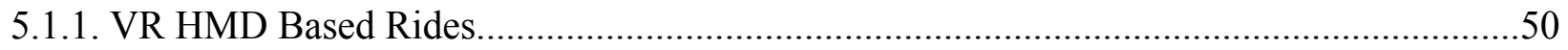

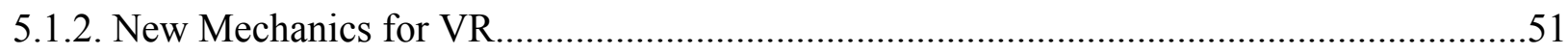

5.1.3. Combining Mature Technologies for Attraction Success.....................................................53

5.1.4. Augmented Reality is the Ultimate Goal for Theme Parks................................................53

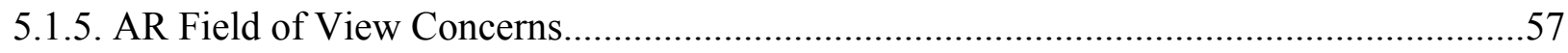

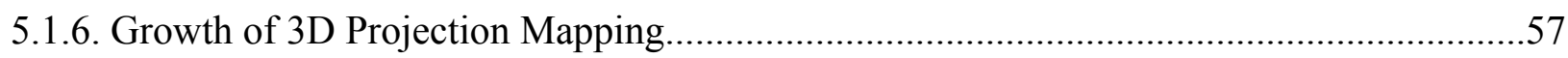

5.1.7. Growth of Free Roam VR Experiences............................................................................56

5.1.8. Importance of Physicality for Enhancing Presence.........................................................56

5.1.9. Provide an Experience that Can't be Achieved at Home.......................................................57

5.1.10. Enhancing Experiences in Lines....................................................................................

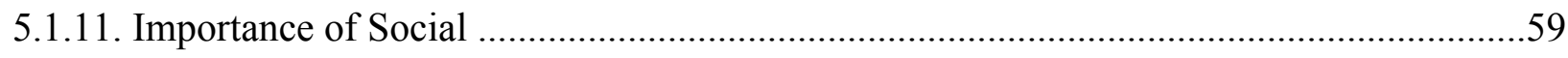

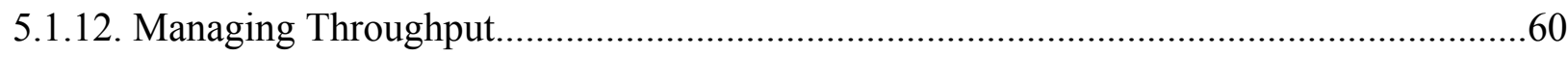

5.1.13. Leveraging Haptic Technologies................................................................................61

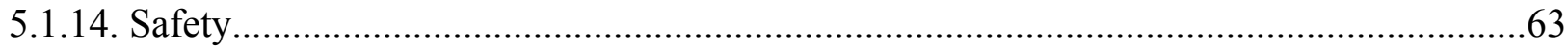




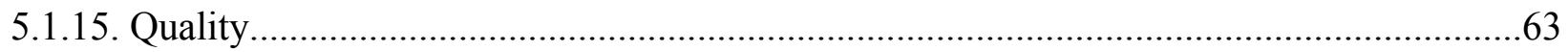

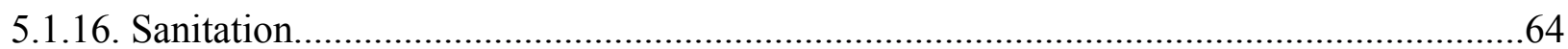

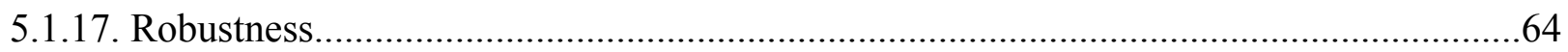

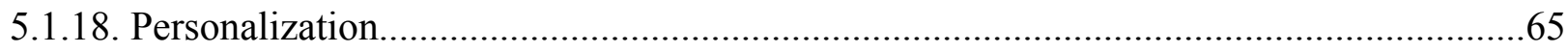

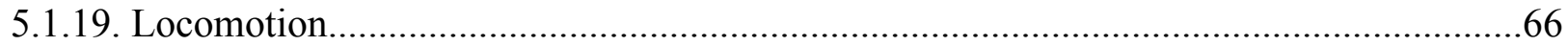

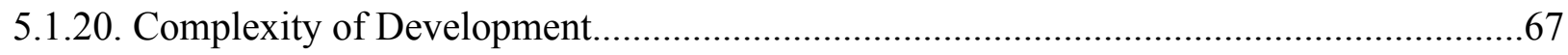

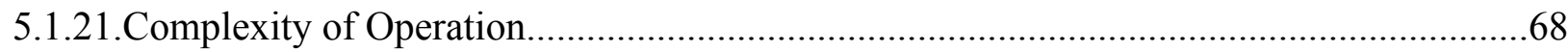

5.1.22. Enhancing the Design Process with VR Pre-Visualization...............................................68

5.1.23. VR Game Design....................................................................................................69

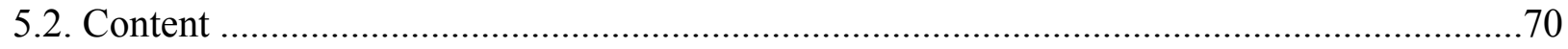

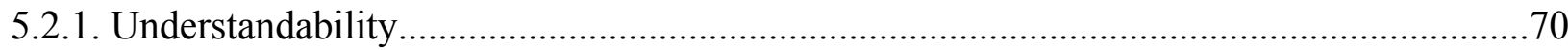

5.2.2. Attractions need to be Repeatable ................................................................................

5.2.3. Pre-Rendered vs. Interactive Experiences........................................................................71

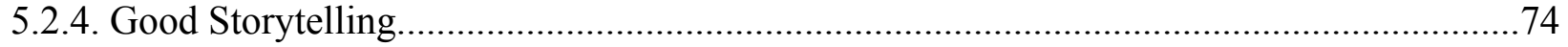

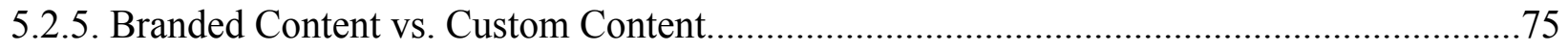

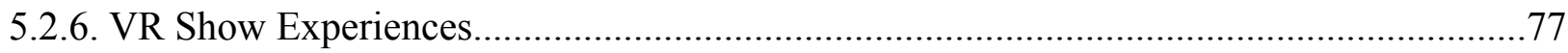

5.2.7. Trans-media Experiences................................................................................................. 78

5.2.8. Transferable Innovation in Military VR/AR Technology................................................... 80

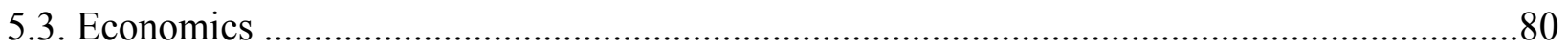

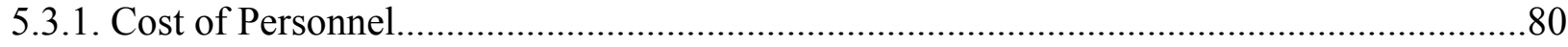

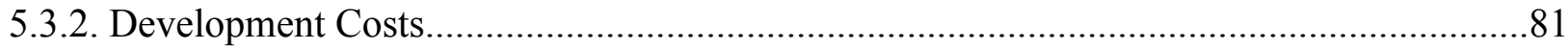

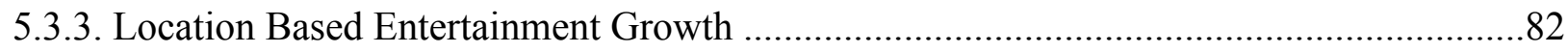

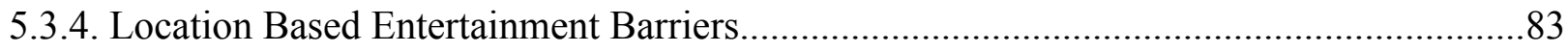

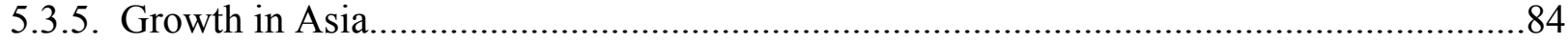

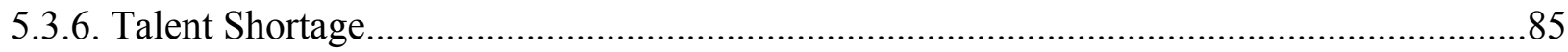

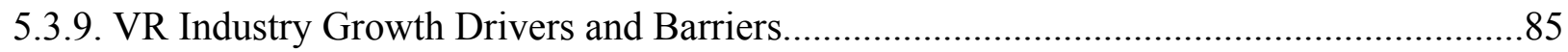

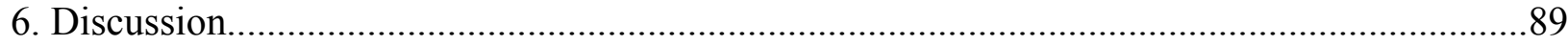

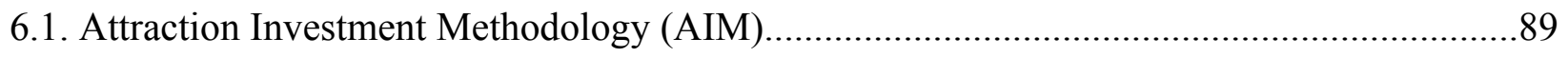

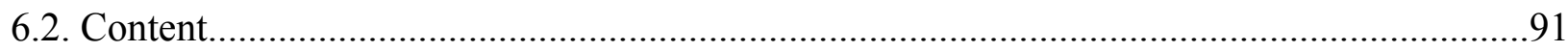

6.2.1. Attract..................................................................................................................... 91

6.2.2. Engage 


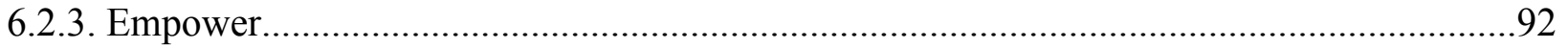

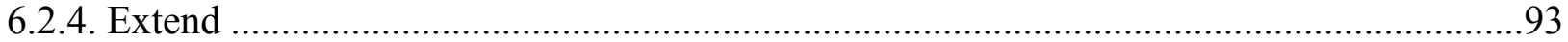

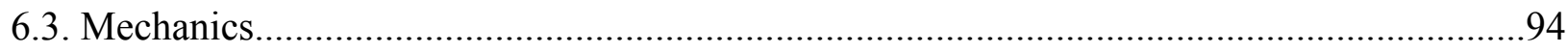

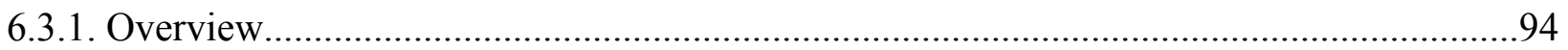

6.3.2. Ride Types that could be Enhanced with VR/AR/MR ............................................95

6.3.3. Ride Systems Most Likely to be matched VR/AR/MR Technologies.............................96

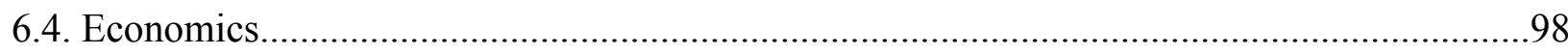

6.4.1. Theme Park Economics.................................................... 98

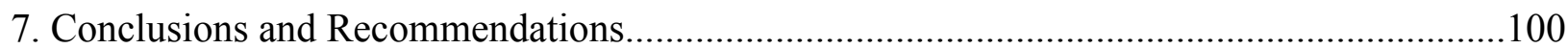

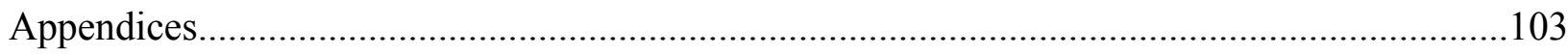

A.1. Top Theme Park Operators and Location Based Entertainment Companies .....................103

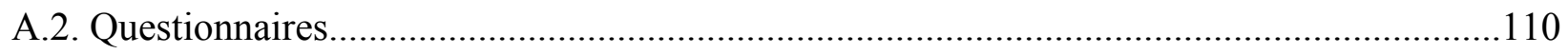

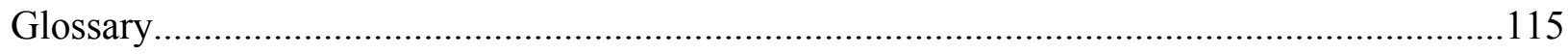

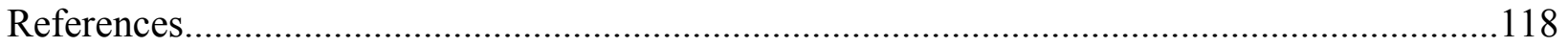




\section{List of Tables}

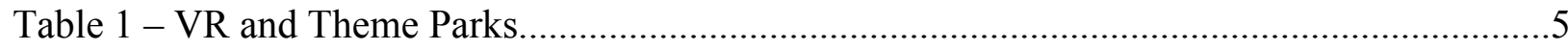

Table 2 - Current Consumer Applications of AR .............................................................

Table 3 - Four Examples of Mixed Reality Attractions using Projection Mapping.....................9

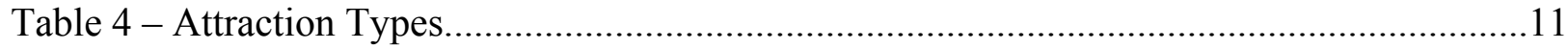

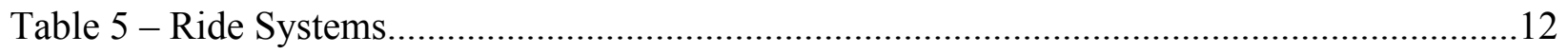

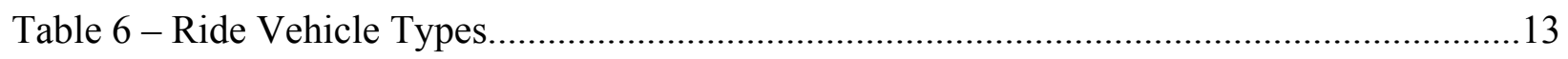

Table 7 - Typical Types of Land within a Theme Park Mix of Attractions...............................22

Table 8 - Lists of Types and Popularity of Content at Theme Parks......................................23

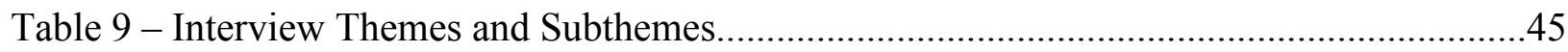

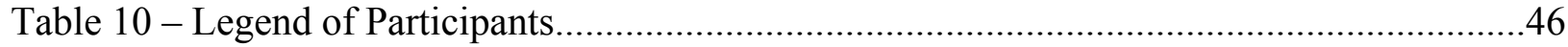

Table 11 - Drivers and Barriers for the VR Industry .................................................... 88

Table 12- Top Ten Global Theme Park Operators................................................................ 103

Table 12 - Top Theme Park Profiles and VR/AR Strategies..............................................111

Table 14 - Top VR/AR Location Based Entertainment Companies......................................117

Table 15 Typical Definitions of VR and AR Terms........................................................118

\section{List of Figures}

Figure 1-Four Types of Guest Experience for Media Based Attractions..................................16

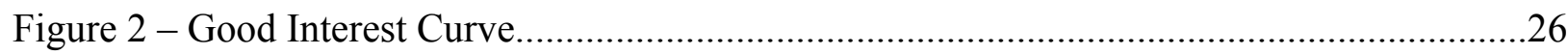

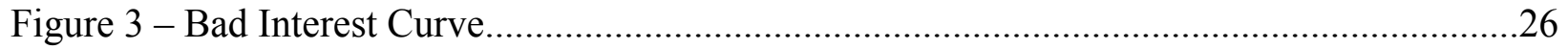

Figure 4 - Typical Interest Curve for Good Video Games.....................................................22

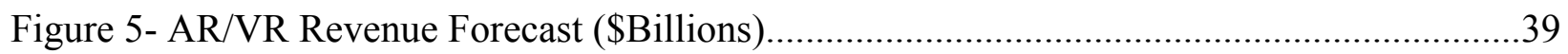

Figure 6 - VR/AR HMD Market Potential.................................................................... 40

Figure 7 - Adoption Rates of Major Technologies .........................................................4

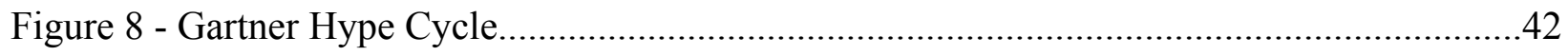

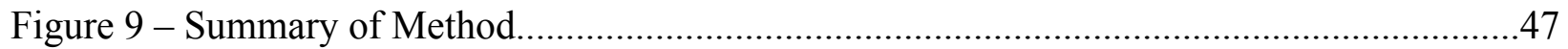

Figure 10 - Attraction Investment Model (AIM) ...................................................... 90 


\section{Introduction}

Virtual technologies, which provide computer generated immersive 360 experiences are now being increasingly being considered for implementation within Theme Parks. With increasing hype surrounding Virtual Reality, this paper seeks to determine how insiders in the Theme Park industry view implementing immersive technologies within their parks and attractions. After an initial literature review was conducted pointing to the importance of content, mechanics and economics within Media Based Attractions at Theme Parks, several questions more specifically about VR technologies in Theme Parks remained unanswered. As a result, the method for this paper involved global interviews with industry leading experts from the Theme Park industry. The subgroups included theme park suppliers, VR/AR experts, consultants and industry analysts and were structured to determine more information on how they approach VR/AR attractions.

Participants continually referred to the fact that Theme Parks need to provide guests with something they can't get at home. As increasingly powerful technologies come to the home, theme park providers need to provide a differentiated experience which draws people out of their homes to the parks. There are many challenges with HMDs in Theme Parks including increased cost of increased personel, high development cost, sanitation, safety, durability and sim sickness. As a result, several participants pointed to Mixed Reality as a better current solution as it mixes beautiful physical spaces with digital overlays without getting to wrapped up with complicated and operationally challenging technology. By focusing less on making attractions for the sake of technology and rather for enhancing the guest experience in a clever and innovative way, Theme Parks will minimize the risk of any oncoming competive technologies entering the market. This will allow them to continue to grow and remain profitable.

Growing trends include using Branded Content for business success within theme parks, offering interactive experiences within parks and extending the brand experience out of the park. Across the various ride types and systems, various opportunities exist to pair immersive technologies. Using virtual technologies with attractions enable creators to tell transport people to new imaginary worlds story while using a motion based experience which delights guests and provides an added layer of excitement. New attractions using VR/AR/MR technologies need to carefully consider what content they will use, mechanics of the experience and the business case to ultimately achieve overall success. 


\section{Background}

\subsection{Theme Parks and the Attractions Domain}

Theme Parks are large commercial tracts of land designed and developed in such a way as to attract large groups of people for purposes of entertaining them. Theme Parks must be set up spatially to allow people to move through the park efficiently across themed areas including stores, restaurants, attractions and shows. Within Theme Parks, the word Attraction describes the various experiences guests will encounter during their stay, typically in place of what the general public would synonymously refer to as a ride (Younger, 2016).

\subsection{VR/AR Technology}

Virtual Reality (VR) is a computer enabled medium for people to explore new worlds, share ideas and have new experiences within digital space. A VR experience enables a user to explore a virtual world or computer generated space by leveraging advanced technology to trick the brain into feeling immersed in a different world (Craig, Sherman, \& Will, 2009).

Augmented Reality (AR) involves taking computer generated information and overlaying them over a real time environment (Kipper \& Rampolla, 2012). The computer generated content could be text, images, video, audio or haptic information but it is superimposed over a physical view of the world. AR supplements what people can see in the real world with digital content, thus augmenting reality.

\subsection{Opportunity to Match VR/AR Technology with Theme Park Attractions}

As virtual technologies continuously improve, there are many interesting ways that a motion base ride vehicle can be paired up with various styles of VR. This paper investigates the business opportunity of creating attractions that feature VR or AR content. Given the current diversity in attraction types, there is lots of opportunity to create new attraction categories that pair existing motion based systems with VR or AR technology.

\subsection{Best Practices for Creating VR/AR Attractions}

Creating technologically advanced attractions is a complex process. This paper tries to provide some best practices and a model for companies to follow when engaged in this type of attraction development. The model was created based on interviews with top stakeholders in this space and is representative of the considerations and lessons learned they have collectively achieved in their undertakings related to VR/AR attraction development. 


\subsection{Why has the connection between VR/AR and Attractions Been Made?}

Virtual and Augmented Reality Based Attractions are a relatively new phenomenon. As a result, they have not been the topic of much academic literature. While resources exist for the Theme Park Attraction domain in general, VR/AR Attractions have only been a small subsection of that analysis to this point.

As more Theme Park developers investigate developing VR/AR attractions, formal literature and best practices would be of value to Attraction Designers as they strive to successfully create new technologically enabled attractions. As a result, this paper is designed to provide Project Owners who are considering VR/AR/MR attractions with guidance of what options are available, trends, best practices and risks.

\subsection{Virtual Reality in Theme Parks}

VR is used at Theme Park's in two major ways: internally as a design tool and externally, enhancing the guest experience. On the design end, VR has enabled a significantly enhanced mechanism to pre-visualize attractions at Theme Parks whether that is live shows, attractions, hotels, restaurants or stores. Where in the past, 2D pictures needed to be drawn by architects or experience designers, now we can virtually mock up an environment at many stages along the lifecycle of a project, enabling rapid prototyping and advanced ability to ideate and get buy in from the stakeholder group. As mentioned, VR has also been used to enhance the guest experience on attractions. This is currently taking three broad forms; VR Coasters, Arena Style VR Gaming and VR Simulators.

VR Coasters typically take existing roller coasters and combine them with synchronized HMD based virtual reality experiences. VR coasters operate a system of positional tracking sensors, mounted on the track which map across a measurable path. As the coaster moves around the path, the sensors feed into the system providing the ability to identify different stages in the path. This allows them to process the motion data in real time and provide virtual imagery to go along with the roller coaster experience. They currently use a modified Samsung Gear VR HMD to cope with the G-Forces on the roller coaster. There is also a centralized touch pad enabled system for managing the headsets and a main battery pack which keeps the units charged at all times. This system can theoretically work on any ride vehicle that moves on a fixed path, meaning it could also work on boats, automated guided vehicles, simulators and entertainment robots. 
A new market niche within VR is Location Based Entertainment. The three companies leading this market niche are The Void, VRCade and Zero Latency. These companies all strive to offer large scale Virtual Worlds that people can actually walk around and interact with. The way the technology typically works is through a backpack hoisted wireless PC ("Backtop"), head-mounted display, motion capture cameras which monitor anything inside with an optical tracker on it (i.e. headsets, guns, props, tracked body parts etc.), haptic vests which provide force-feedback (when a player is shot), high quality audio and multisensory effects. The Location Based Entertainment systems enable multiplayer track-ability, real time gameplay, haptic feedback, mapped physical spaces with digital overlay and in some cases redirected walking to provide the illusion of unlimited space within the environment. For example, props are tracked, digital walls are mapped over physical walls and doors work the same physically as they do in the virtual environment.

Much like classic Dark Rides, VR simulators create an immersive story leveraging HMD technology, typically leveraging multisensory stimulation, haptic feedback and interactivity in some cases. Elements included in a VR simulator include a motion base, a set scene, lighting, special effects and audio. A good example of HMD based VR experience is Derren Brown's Ghost Train Experience at Thorpe Park in the UK.

One of the key ways VR will be able to enhance Attractions is by using it during the design phase. By being able to pre-visualize an attraction, it can provide a digital view of the attraction before it is built. This allows designers to be more iterative and imaginative with their ideas because they can experiment with different concepts in a way that was more expensive to do in the past. Having the ability to rapidly prototype and iterate digitally along Attraction development lifecycle allows designers to adopt an agile delivery approach. This will lead to faster delivery timelines, more efficient communications between the team, cheaper development and better end experiences on the attraction. 
Table 1-VR and Theme Parks

VR Coasters




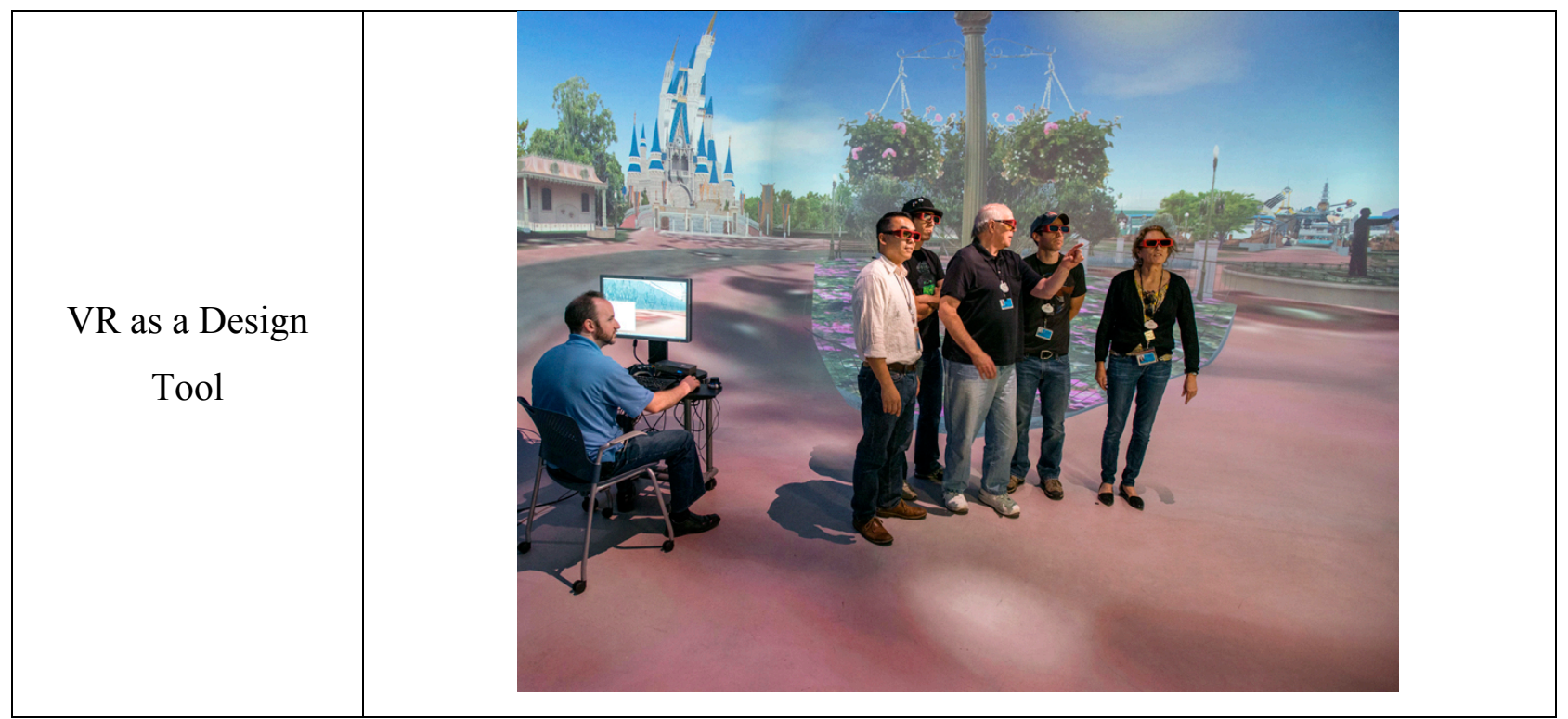

\subsection{Augmented Reality in Theme Parks}

AR at Theme Parks currently takes three broad forms: Kiosks/Periscopes/Digital Signs, Smartphone and Tablet Based AR. An example of Kiosks is a station where customers can bring things to, scan them and find out about them through augmented information on a screen. For example, at Lego Stores, customers can scan boxes and then see an augmented reality depiction of the completed toy. Periscopes can take advantage of various sightseeing points at Theme Parks and augment digital graphics over top of the physical scenery to make it more interesting.

Lastly and most importantly, Theme Parks have been using the truly social and interconnected nature of mobile phones to turn their parks into AR Treasure Hunts. Examples of this include The Battle for Cedar Point and Kim Possible's World Showcase. Though this can also be done in the consumer space as exemplified with things like Pokemon Go, Theme Parks have an interesting advantage of being able to build physical interactive objects that can interact with users' mobile phones to make physical situations like volcanoes erupting or a zombie attack as well as digital things which can happen through the smartphone's interface. Another recent example of AR technology that could be well suited to Theme Parks is subway based AR which lights up subway windows with animations based on LED lights on the tunnel walls which dynamically change to present a moving picture (Top Flash Media, 2016).

While AR in some senses is not quite ready for Theme Parks, there are some interesting available use cases which are being introduced. Holovis in cooperation with Cedar Point created 
a mobile based game called "The Battle for Cedar Point." In this game people can use their mobile phone to scan items around the park to earn points for their clan. People are told to choose random tasks on the battle map and can earn points throughout the Theme Park. The winner is announced daily at a live show called "Luminosity". This form of VR relies on the smartphone camera which overlays live digital graphics on the users' screen based on what they point the camera at. The graphics can be overlayed on an image on the phone through either geo-location of the smartphone or image recognition software.

Table 2 - Current Consumer Applications of AR

\begin{tabular}{|c|c|c|c|}
\hline Kiosks and Digital \\
Signs \\
Periscopes
\end{tabular}




\begin{tabular}{|l|l|l|l|l|l|}
\hline Subway Based AR & & & \\
\hline
\end{tabular}

\subsection{Mixed Reality (MR) in Theme Parks}

One of the great strengths of Theme Park attractions is their ability to create interesting physical spaces and combine this with media. Mixed Reality is an environment in which real world and virtual world objects are presented together within a single display (Milgram, Takemura, Utsumi, \& Kishino, 1995). In Theme Park's, this often manifests in a "Dark Ride" attraction containing interesting, indoor physical spaces, sometimes using high definition 3D screens, illusions and animatronic figures and variable lighting to enhance the guests feeling of immersion in a story world, full of surprises and entertainment (Younger, 2016). At many of the top Theme Parks around the world, this represents a big part of their capital expenditures (Younger, 2016).

Large scale, Mixed Reality Attractions often become very popular attractions at major Theme Parks, enabling operators to attract more people to their Theme Park. Trends within this market niche are the increased push towards real-time interactivity, using 3D projection mapping and pairing attractions with very cool and recognizable intellectual property. "Projection Mapping uses video projectors, but instead of projecting on a flat screen (e.g. to display a PowerPoint), light is mapped onto any surface, turning common objects of any 3D shape into interactive displays. Specialized software can be used to align the virtual content and physical objects" (Jones, 2016). This is different from a purely virtual environment because some of the physical aspects actually stand out more in the minds of guests.

Table 6 below highlights four notable examples of popular Dark Rides, including Harry Potter and the Forbidden Journey, Avatar, Toy Story Midway Mania and Pirates of the Caribbean. 
Table 3 - Four Examples of Mixed Reality Attractions

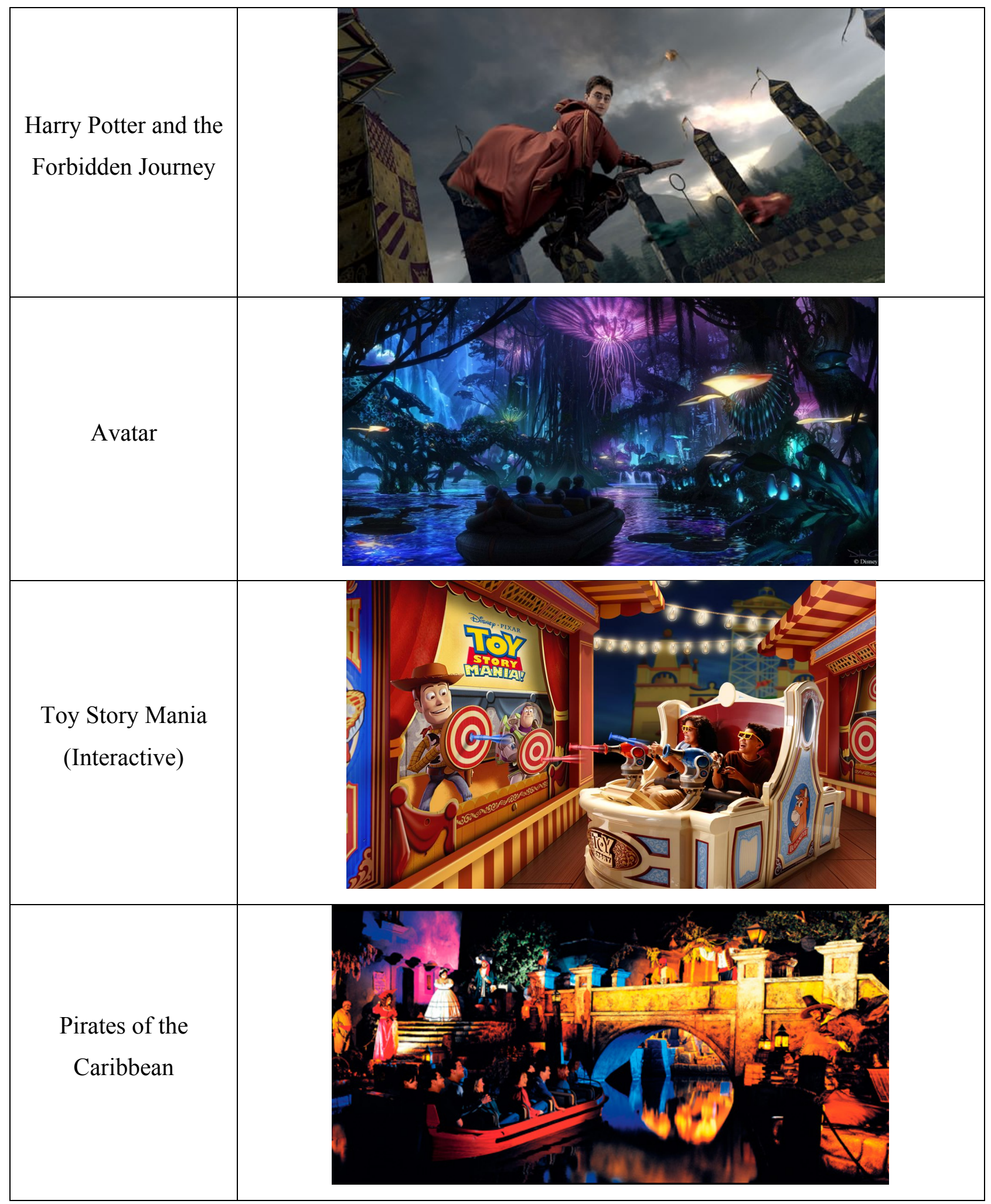




\subsection{Paper Outline}

The following section (Ch. 3) reviews the interview methodology and describes the approach taken to elicit knowledge from subject matter experts. The scope of research interviews involved identifying the attributes of $\mathrm{VR} / \mathrm{AR}$ attraction projects that are required to increase overall success by improving the nature of the ride/motion vehicle, enhancing the story and enhancing the economic aspects of introducing one of these attractions.

The subsequent section (Ch. 5) presents the Results obtained from conducting the interviews with subject matter experts. Chapter 6 contains a Discussion section that introduces the Attraction Investment Methodology (AIM). The AIM model involves integrating content, mechanics and economics to optimize the attraction development outcome. Following that, Chapter 7 provides Conclusions \& Recommendation. 


\section{Related Literature}

Since VR/AR attraction development is a relatively new and niche segment of the overall Theme Park market, the subject lacks formal academic literature. However, when scanning the various sub-components involved in creating a VR/AR attraction, there is an abundance of information available. Some of these sub-components include: Virtual Reality, Augmented Reality, Theme Parks, Attraction Design and Psychology of Entertainment Experiences. When analysing the literature surrounding VR, AR and attraction design, the three areas which became evident as separate thematic areas were Mechanics, Content and Economics.

\subsection{Mechanics}

\subsubsection{The Nature of Ride Motion/Vehicles}

There are many types of Theme Park attractions. The following table shows some of the in scope attractions which could be influenced by VR and or AR overlays.

\section{Table 4 - Attraction Types}

\begin{tabular}{|l|l|}
\hline Attraction Type & Current Description \\
\hline Dark Rides & $\begin{array}{l}\text { Dark Rides involve dark circuits inside a building that have scenic areas } \\
\text { that a motion base moves through. They involve elements of film and } \\
\text { have the overall objective of immersing the guest inside a world (Clavé, } \\
\text { 2007). }\end{array}$ \\
\hline Composite Attractions & $\begin{array}{l}\text { Composite Attractions are large-scale attractions which offer more than } \\
\text { one type of experience within the attraction leading to greater variety } \\
\text { within the experience (Younger, 2016). Examples of composite } \\
\text { attractions could include a boat ride blended with a walk through or an } \\
\text { omni-mover. }\end{array}$ \\
\hline Competition Rides & $\begin{array}{l}\text { Competition Attractions are attractions that feature friendly competition } \\
\text { between different guests involving aspects such as skill, speed, } \\
\text { knowledge or voting (Younger, 2016). This could be in the form of a } \\
\text { shooting game, a race or a water fight. }\end{array}$ \\
\hline Excursion Rides & $\begin{array}{l}\text { An excursion ride's goal is to simulate the experience of going to "a } \\
\text { faraway place" such as a safari, jungle boat ride or submarine journey. } \\
\text { While this may be indoors like a "Dark Ride", it can also sometimes be } \\
\text { outside as in the example of a Jungle experience. }\end{array}$ \\
\hline $\begin{array}{l}\text { Thrill Rides and Scare } \\
\text { Attractions }\end{array}$ & $\begin{array}{l}\text { Thrill Rides typically involve physical or psychological techniques that } \\
\text { make people's adrenaline rise through exciting situations. Often these } \\
\text { rides provide the illusion of danger but really provide a safe experience. } \\
\text { (Younger, 2016). }\end{array}$ \\
\hline $\begin{array}{l}\text { Transportation } \\
\text { Attractions }\end{array}$ & $\begin{array}{l}\text { Transportation Attractions are rides which move people around to the } \\
\text { different stations at the Theme Park. This could be a monorail, a train, }\end{array}$ \\
\hline
\end{tabular}


gondola, bus or boat ride getting people to different locations (Younger, 2016).

Attractions vary based on the internal ride system or technical attraction requirements that they offer. The following table shows the primary types of Ride System Categories as well as definitions for those categories.

Table 5 - Ride Systems

\begin{tabular}{|l|l|}
\hline Attraction System & Current Description \\
\hline Roller Coasters & $\begin{array}{l}\text { Roller coasters come in a variety of different styles. Companies like Six } \\
\text { Flags and Cedar Point have traditionally been known for being the } \\
\text { "mecca of roller coaster-oriented Theme Parks" (Clavé, 2007). }\end{array}$ \\
\hline Tracked Rides & $\begin{array}{l}\text { Tracked Ride Systems feature a ride vehicle moving along a set path or } \\
\text { track moving through a space. The types of tracked rides include } \\
\text { busbar rides, car rides, enhanced motion vehicles, omni-movers, tracked } \\
\text { robot arms, suspended rides and shooters (Younger, 2016). }\end{array}$ \\
\hline $\begin{array}{l}\text { Trackless Rides or } \\
\text { Vehicles }\end{array}$ & $\begin{array}{l}\text { Trackless Rides or AGVs are a new development within the Theme } \\
\text { Park space that allow for non-linear attractions. They typically work } \\
\text { through automation enabled through computer chips or wires embedded } \\
\text { into the floor (or Local Positioning System) which for altered routes, } \\
\text { show lengths, speeds and sequencing (Younger, 2016). }\end{array}$ \\
\hline $\begin{array}{l}\text { Production or Show } \\
\text { Attractions }\end{array}$ & $\begin{array}{l}\text { A production attraction is typically set up in a theater and has live or } \\
\text { audio-visual entertainment. They are designed to differentiate from } \\
\text { typical movie theater offerings by providing more of a multisensory } \\
\text { experience, including motion bases or having 3D Omnimax screens } \\
\text { (Younger, 2016). }\end{array}$ \\
\hline $\begin{array}{l}\text { Alternative } \\
\text { Attractions }\end{array}$ & $\begin{array}{l}\text { Currently Alternative Attractions is used as a catch-all term to describe } \\
\text { different, less categorized attractions such as walk-throughs, VR set } \\
\text { ups, Mazes, Fun Houses and augmented reality games (Younger, 2016). }\end{array}$ \\
\hline
\end{tabular}

When the ride system categories are broken down, there is a large variety of potential options that an attraction designer can make when considering the motion base for the Attraction. In total, there are many over 140 total types of attractions at Theme Parks the world (Younger, 2016). The following page shows the various Motion Vehicle Types. 
Table 6 - Ride Vehicle Types (Younger, 2016)

\begin{tabular}{|c|c|c|c|c|c|c|c|}
\hline \multirow{2}{*}{$\begin{array}{c}\begin{array}{c}\text { Tracked Ride } \\
\text { Systems }\end{array} \\
\text { Busbar Rides }\end{array}$} & \multirow{2}{*}{$\begin{array}{l}\text { Water Ride } \\
\text { Flume Ride }\end{array}$} & \multirow{2}{*}{$\begin{array}{c}\begin{array}{c}\text { Real World } \\
\text { Transportation }\end{array} \\
\text { Animals }\end{array}$} & \multirow{2}{*}{$\begin{array}{c}\begin{array}{c}\text { Roller } \\
\text { Coasters }\end{array} \\
\text { 4th Dimension } \\
\text { Coaster } \\
\end{array}$} & \multicolumn{2}{|c|}{ Flat Rides } & \multirow{2}{*}{$\begin{array}{c}\begin{array}{c}\text { Alternative } \\
\text { Attractions }\end{array} \\
\text { Animal Exhibit }\end{array}$} & \multirow{2}{*}{$\begin{array}{c}\begin{array}{c}\text { Show } \\
\text { Attractions }\end{array} \\
\text { Films }\end{array}$} \\
\hline & & & & Air Diver & Pagoda & & \\
\hline Car Rides & Lake Boats & Canoes & Bobsled Coaster & Baloon Race & Parachute Tower & Arcade & 3D Movies \\
\hline EMV Rides & Log Flume & Gondolas & $\begin{array}{c}\text { Floorless } \\
\text { Coaster }\end{array}$ & Bayern Kurve & Pendulum & $\begin{array}{c}\text { Augmented } \\
\text { Reality Game }\end{array}$ & $\begin{array}{c}\text { Animatronic } \\
\text { Movies }\end{array}$ \\
\hline Omnimovers & River Rapids & $\begin{array}{c}\text { Hot Air } \\
\text { Balloons }\end{array}$ & Inverted Coaster & Booster & Rock \& Roll & Carnival Games & $\begin{array}{c}\text { Animatronic } \\
\text { Encounters }\end{array}$ \\
\hline Shooters & $\begin{array}{l}\text { Shoot-the- } \\
\text { Shoots }\end{array}$ & Trains & Flying Coaster & Bouncer & Rocket Swing & Exhibit & $\begin{array}{c}\text { Character } \\
\text { Experiences }\end{array}$ \\
\hline $\begin{array}{c}\text { Tracked Robot } \\
\text { Arms }\end{array}$ & Submarine Ride & Mono Rails & $\begin{array}{c}\text { Motorbike } \\
\text { Coaster }\end{array}$ & Breakdance & Rocking Tug & Fun House & \\
\hline \multirow[t]{31}{*}{ Trackless Rides } & Tow Boat Ride & River Boats & $\begin{array}{c}\text { Powered } \\
\text { Coaster }\end{array}$ & Bumber Cars & Rock-o-Plane & Gardens & \\
\hline & $\begin{array}{c}\text { Tracked Water } \\
\text { Ride }\end{array}$ & Sailing Boats & SFX Coaster & Carousel & Roundabout & Madhouse & \\
\hline & & Stage Coaches & $\begin{array}{l}\text { Sit Down } \\
\text { Coaster }\end{array}$ & Chaos & Sky Swatter & Maze & \\
\hline & & Trams & $\begin{array}{l}\text { Spinning } \\
\text { Coaster }\end{array}$ & Condor & Sky Wheel & Meet \& Greet & \\
\hline & & $\begin{array}{l}\text { Helicopter } \\
\text { simulation }\end{array}$ & Standup Coaster & Crazy Wave & Slingshot & Petting Zoo & \\
\hline & & $\begin{array}{c}\text { Plane } \\
\text { Simulation } \\
\end{array}$ & $\begin{array}{c}\text { Suspended } \\
\text { Coaster }\end{array}$ & Cuddle Up & Spin Out & Playground & \\
\hline & & & Pipeline Coaster & Dancer & Spinner & Playthrough & \\
\hline & & & Water Coaster & $\begin{array}{l}\text { Dancing } \\
\text { Pavilion }\end{array}$ & Super Looper & Puzzle Maze & \\
\hline & & & $\begin{array}{l}\text { Wild Mounse } \\
\text { Coaster }\end{array}$ & Disko & Super Nova & Robot Arm & \\
\hline & & & Wing Coaster & Double Inverter & Swing Tower & Scare Maze & \\
\hline & & & & Drop Tower & Swinging Ship & Simulator & \\
\hline & & & & $\begin{array}{c}\text { Eccentric } \\
\text { Wheel }\end{array}$ & Tagada & Sports & \\
\hline & & & & Enterprise & Tea Cups & Walkthrough & \\
\hline & & & & Ferris Wheel & Tagada & & \\
\hline & & & & Flic Flac & Tilt-a-Whirl & & \\
\hline & & & & Flipper & Top Scan & & \\
\hline & & & & Flying Saucers & Top Spin & & \\
\hline & & & & Flying Scooters & Top Star & & \\
\hline & & & & Giant Slide & Topple Tower & & \\
\hline & & & & Gravitron & Tornado & & \\
\hline & & & & $\begin{array}{c}\text { Half Pipe } \\
\text { Coaster }\end{array}$ & Tourbillon & & \\
\hline & & & & Helter Skelter & Trabant & & \\
\hline & & & & Inverted Ship & Tristar & & \\
\hline & & & & Jet Skier & Tumble bug & & \\
\hline & & & & Launch Tower & Twist \& Splash & & \\
\hline & & & & Lindy Loop & Twister & & \\
\hline & & & & Magic Carpet & Umbrella & & \\
\hline & & & & $\begin{array}{c}\text { Observation } \\
\text { Tower }\end{array}$ & Waveswinger & & \\
\hline & & & & Octopus & Whip & & \\
\hline & & & & Orbiter & Witching Waves & & \\
\hline & & & & & Zipper & & \\
\hline
\end{tabular}




\subsubsection{Common Requirements for Attractions}

Before looking at particular categories of Theme Park attractions, it is important to note the common requirements or considerations that need to be taken into account before developing a Theme Park attraction. These considerations include choosing the story or theme, type of experience, capacity, space, costs, target audience and type of attraction within the attraction mix (i.e. does it balance out within the other attractions at the park). From a requirements perspective, four key goals must be achieved: fun, safety, robustness and high throughput.

At their core, attractions need to be fun. If attractions aren't fun, no one would go on them. One of the best parts of an attraction designer's job is to ensure that the ride that they are creating is fun. This can mean different things for different demographic audience makes ups especially when looking at the thrill ride category of attractions. While some people may prefer an intense rollercoaster, others may be intimidated by it, made uncomfortable by riding it and not want to ride it again. Elements which can add to the fun include; immersing people, allowing them to get better at something and providing a social experience (Lazzaro, 2004: P. 3-6). Additionally, ensuring that the guests' interest in the experience is mapped out and that if follows an upwards progression with chances for people to relax will help to enable a repeatable, fun and engaging Theme Park experience (Schell, 2014: P. 281).

Throughput is a measure for how many people a Theme Park attraction can entertain per hour. This is one of the most critical requirements of a Theme Park attraction because if an attraction can't handle a high volume of people per hour, there will be long lines, unsatisfied customers and people will get so annoyed with the attraction that they might not come back to the Theme Park, ultimately risking the Theme Park's survival.

Within the context of VR rides, and under safety, there is a major hygienic issue of keeping the HMDs clean. Due to issues such as transmittable diseases, it is crucial to keep the headsets or glasses sanitary if many people are going to be sharing them. Significant measures currently go towards keeping things like 3D glasses and HMD units sanitary and free of transmittable germs which could cause infections. This can mean using closed foam and wiping it down every time (which has implications for throughput and operating costs) or letting users wear something that covers the parts of their faces that are exposed which can be weird looking or uncomfortable. Also regarding motion on the ride, it has to be clear that the ride will not 
injure anyone or make anyone sick. Also, there needs to be restrictions on the types of people who can ride a certain ride (height and weight and health for example).

Another key safety issue with HMD based rides, is that a guest's vision will often be blocked from seeing their physical surroundings. As more robust AR headsets come out, this problem may soon become a thing of the past, however when considering the high quality HMDs currently available, there needs to be measures taken to mitigate this safety risk. Many of the free-roam and arena based games have found innovative solutions to this problem and with time, it will disappear but it is something that a ride designer needs to be cognizant of.

The attraction also needs to be robust. Within the context of VR based rides, this could mean that the headset needs to be able to be used a lot throughout a day and still work. There needs to be centralized systems in place for monitoring and managing the various technological equipment. Also, there needs to be maintenance procedures in place to ensure that if equipment breaks down, it is replaceable. "Technologically advanced rides are controlled by redundant industrial computers, constantly monitoring the condition and location of ever coaster train through hundreds or thousands of sensors built into the track. If any one of the sensors reports a fault and there is not $100 \%$ agreement reported by all the sensors as to the every train's location, then all the trains are stopped in a safe place" (Clave, 2007).

In addition, it is important to remember that Theme Parks are harsh environments for technology to be used in. For example, in addition to the large volume of unpredictable people going through an attraction, other considerations which need to be addressed are weather, climate, topography, local demographics and culture (Clave, 2007).

Another critical aspect involved with safety is that training of employees is a critical part of an attractions safe operating procedures. Employees are trained through formal training courses, certifications and experience to know what to do in every type of uncertain situation (Clave, 2007). Ride operators must practice running the rides without passengers hundreds of times and pass a certification test before they can officially operate a ride (Clave, 2007). Additionally, at companies such as Six Flags, they drill their employees with multi-purpose tests where operators need to be able to anticipate various types of emergency situation and respond to them successfully before they are able to work within the Theme Park. 


\subsubsection{Ranges of Interactivity}

A model was created to categorize virtual experiences across the dimensions of existence (defined by existence within the virtual world) versus influence (defined by interactive influence within a story). Research has found that all virtual experiences all fall onto a Punnett square and can either be "observant/active", "observant/passive", "participant/active" and "participant passive" (Dolan \& Parets, 2016). While this research model was created in response to the new wave of VR, it can also nicely categorize the different types of interactive attractions available at Theme Parks today. While there are more examples which fit in each of the four corners of this Punnett square, this section highlights four key examples of each experience type available at Theme Parks today.

Figure 1 - Four Types of Guest Experience for Media Based Attractions

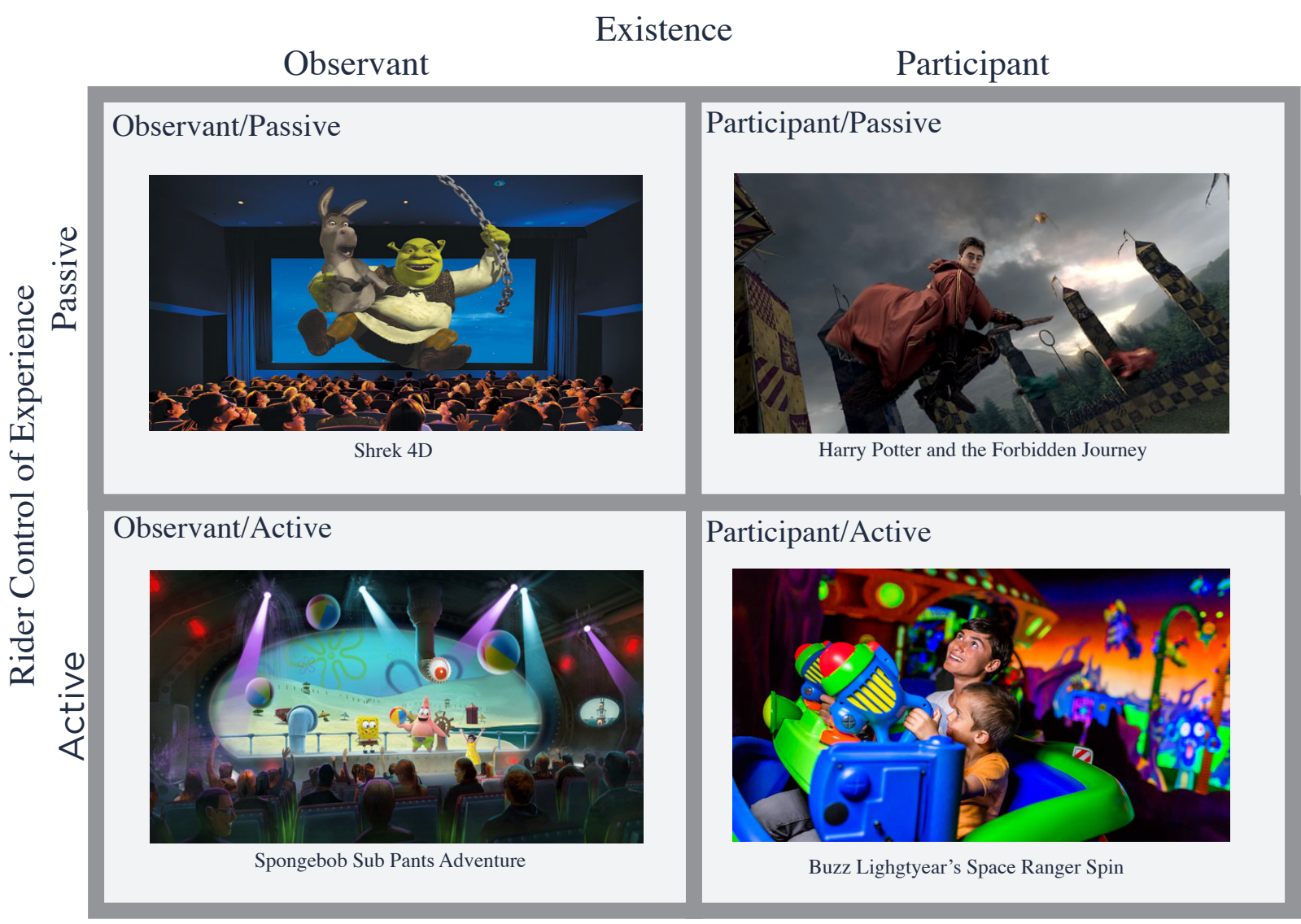


Interactive rides at Theme Park are still a relatively new and constantly changing concept. Currently there are four models of interaction that exist. The observant active model can best be explained as the popular "choose your own adventure" model of narrative. In Theme Parks today, there are ways that they can create this in a 4D theater based show. Super 78 Studios in LA helped to create Sponge Bob Subpants Adventure. Sponge Bob Subpants Adventure is an interactive experience where guests go on an undersea voyage in a 128 passenger 4D theater. In the Adventure, a live actor controls the Sponge Bob character and manipulates what he talks about based on how the audience responds to it. The actor pushes buttons on a central controller which kick off different sequences of activity dynamically based on how the audience reacts. It is interesting because it is $3 \mathrm{D}$, reactive to the audience and it gets people having fun and feeling like they have agency over the outcome of the story.

Another category of virtual experiences is Observant and Passive. Some forms of 4D theaters contain highly immersive and entertaining experiences however, the audience is not able to affect the outcome of the narrative. They are more a passive observant. Theme Parks have been using 4D theaters for many years as an attraction to entertain guests. As a result, some of the earlier theaters are not as reactive to the audience due to technology limitations at the time. Observant Passive experiences are the standard form of filmed content that people already know well. The audience doesn't exist in the story's universe and does not have agency over the events which occur. Instead they watch the narrative unfold in a set way with the author having complete control over the narrative.

Participant Active is when the viewer both exists in the world as a character or story device, and has influence over the experienced story. The universe acknowledges and addresses Existence, as the viewer interacts with the world and is bound by its laws and underlying story. This is one of the more complicated types of attractions to create and is still relatively new within the Theme Park industry. One example is Buzz Lightyear's Space Ranger Spin. The goal of this ride is to fire lasers to defeat Zurg in an interactive space battle. This ride features an innovative onboard joystick that can spin the cruiser a full 360 degrees as well as a cannon blaster that shoots at targets to collect points. After the experience, players are ranked based on how many points they got earning them the title of "Space Cadet" or "Galactic Hero". 
Participant Passive is the final type of virtual content type. It is a relatively new form of story in which the viewer exists in the world as a story device, but the story does not ask anything of the viewer. This is sometimes seen in TV shows or movies "when the protagonist breaks the fourth wall to open up a line of dialog to (not with) the audience". For instance, an interesting example in popular culture today is in House of Cards when Frank Underwood addresses the audience as a story device within his world. In the world of Theme Parks, an example is The Wizarding World of Harry Potter. In this ride, the individual audience members feel as if they are accompanying Harry on a flying broom adventure around Hogwarts. The participant cannot affect the outcome of the experience, however, they are participating on the flying broom adventure with Harry.

\subsubsection{Interactive Ride Mechanics}

Videogame design can provide valuable guidance and insight when designing an interactive attraction as they share a lot of the same mechanics. As the Theme Park industry pushes towards offering interactivity in their parks, the design methodology from game design can be leveraged to help successfully create interesting gameplay and repeatable game mechanics.

The main mechanics of any game are: (1) Space, (2) Objects, Attributes and States, (3) Actions, (4) Rules, (5) Skill and (6) chance (Schell, 2014). Every game needs to take place in some kind of space. Spaces can either be discrete or continuous, can be two dimensional or three dimensional and have bounded areas that are either connected or not (Schell, 2014). "When you can think of your space in these pure abstract terms, it helps you let go of assumptions about the real world, and it lets you focus on the kinds of gameplay interactions you would like to see"(Schell, 2014).

Objects are anything within the space such as characters, props, tokens scoreboards or anything that can be manipulated through gameplay. The objects attributes refer to it's current position in the game space (Schell, 2014). For example, in a racing game, maximum speed is an attribute while current speed is the state that the object may be in.

Actions are the "verb of game mechanics" (Schell, 2014). They determine what the player can do within gameplay. Rules are said to be the most fundamental mechanic within a game. Rules involve all the previously mentioned mechanics such as the space, the objects, 
actions, consequences of those actions, constraints of a particular actions and finally - the goals of the game (Schell, 2014). Having VERY clear goals is paramount to making any game good. Goals must be concrete, achievable and rewarding (Schell, 2014).

The next mechanic is skill. Skill is the mechanic that is required from the player to battle through and enjoy the process of playing a game. Most games actually require several skills but they all fall into three main categories: physical skills, mental skills and social skills. Physical skills are required when you need to get good at manipulating a controller, mental skills could be things like memory work, puzzle solving skills or observation while social skills in games could be things like reading an opponent, influencing someone or psyching an opponent out (Schell, 2008). The final game mechanic is chance. Chance is an integral game mechanic using all previously mentioned mechanics and adding an important and interesting element of uncertainty to the game play (Schell, 2014). Uncertainty leads to surprises that is a key underpinning of a fun gaming experience.

A game designer needs to carefully consider and balance the probabilities inherent in the gameplay experience. They add chance to involve randomness and risk into the gameplay. "Risk and randomness are like spices. A game without any hint of them can be completely bland, but put in too much and they overwhelm everything else" (Schell, 2014).

A video game or interactive experience must be in balance. Balancing a game means adjusting the elements of the game until it delivers the right experience. It is more of an art than a science and something that designers need to be very cognisant of. Similar to a recipe for a meal, it is important to understand what and how much and many of the ingredients you need to use. "A skilled chef can make the simplest of recipes a delight to eat for the same reason a skilled game designer can make the simplest of games a delight to play - they both know how to balance the ingredients" (Schell, 2014). Game balancing looks at elements such as fairness, challenge vs. success, gameplay choices, skill vs. chance, competition vs. cooperation, freedom vs. controlled experience, rewards, simple vs. complex and detail vs. imagination (Schell, 2014).

\subsection{5. $V R / A R / M R$ Technology}

VR is a computer enabled medium for people to explore new worlds, share ideas and have new experiences. A VR experience enables a user to explore a virtual world or computer generated space by leveraging advanced technology to trick the brain into feeling immersed in a 
different world. VR “tracks the user's position and action and provides synthetic feedback to one or more senses, giving the feeling of being immersed or being present in the simulation" (Craig et al., 2009).

In VR, one or more of the user's senses must be provided with artificial (computer generated) stimuli. Typical VR simulations typically involve at least visual stimuli but often aural stimuli are also provided. Also, skin sensation and force feedback that are typically called haptic or touch feedback can be used. Other possible sensory outputs from VR experiences include vestibular (balance), olfaction (smell) and gustation (taste) feedback (Craig et al., 2009).

Augmented Reality (AR) involves taking computer generated information and overlaying them over a real time environment (Kipper \& Rampolla, 2012). The computer generated content could be text, images, video, audio or haptic information but it is superimposed over a physical view of the world. AR supplements what people can see in the real world with digital content, thus augmenting reality.

AR typically comes in two main forms "see-through" AR displays and Monitor Based AR Displays (Milgram et al., 1995). See-through AR displays are "characterized by the ability to see through the display medium directly to the world surrounding the observer, thereby achieving both the maximal possible extent of presence and the ultimate degree of real space imaging (Milgram et al., 1995). Monitor based AR displays refer to display systems where computer generated images are either "analogically" or digitally overlaid onto live or stored video images (Milgram et al., 1995).

Mixed Reality refers to attractions that use 3D projection mapped screens mixed into physical environments. These physical environments involve scenic sets and often other sensory experiences such as audio, scents and touch. There are other types of mixed reality under the overall definition however within Theme Parks, this is currently a common form of it.

Three key factors that differentiate different types of Mixed Reality environments are Extent of World Knowledge (EWK), Reproduction Fidelity (RF) and Extent of Presence Metaphor (Milgram et al., 1995). Extent of World Knowledge is defined as how much we know about objects and the world in which they are displayed. This can be shown as a spectrum on the low end having a world un-modeled in the display to the high end where the world is completely modeled. In other words, the contents of the images and the location of those contents is known (Milgram et al., 1995). Reproduction fidelity refers to the "relative quality with which the 
synthesizing display is able to reproduce the actual or intended images of the objects being displayed. Reproduction Fidelity refers to both real and virtual objects (Milgram et al., 1995). The final factor is Extent of Presence Metaphor which is the extent to which the observer is intended to feel "present" within the displayed scene (Milgram et al., 1995).

\subsection{The Story (Intellectual Property/Media)}

\subsubsection{Types of Themes}

A theme must provide the identity of a park. It will provide a cohesive narrative, marketability, media presence, a spatial way of organizing the park and typically involves animation (Clavé, 2007). The following table shows the different types of themes used at Theme Parks (Wong \& Cheung, 1999). 
Table 7 - Typical Types of Land within a Theme Park mix of Attractions (Wong \& Cheung, 1999)

\begin{tabular}{|c|c|}
\hline Type & Attributes \\
\hline Adventure & $\begin{array}{l}\text { Excitement and action } \\
\text { Frightening } \\
\text { Mysterious } \\
\text { Thrill Rides }\end{array}$ \\
\hline Futurism & $\begin{array}{l}\text { Advances in society and technology } \\
\text { Discovery } \\
\text { Exploration of science and technology } \\
\text { Laser } \\
\text { Robot } \\
\text { Scientific } \\
\text { Science Fiction }\end{array}$ \\
\hline International & $\begin{array}{l}\text { Flavours of the World } \\
\text { International village } \\
\text { Miniature replicas } \\
\text { Scenic spots } \\
\text { World expositions } \\
\text { Animals }\end{array}$ \\
\hline Nature & $\begin{array}{l}\text { Animals } \\
\text { Floral displays } \\
\text { Horticultural gardens } \\
\text { Landscaping } \\
\text { Marine life } \\
\text { Natural wonders } \\
\text { Ocean } \\
\text { Wildlife }\end{array}$ \\
\hline Fantasy & $\begin{array}{l}\text { Animation } \\
\text { Cartoon characters } \\
\text { Childhood enchantment } \\
\text { Children's play park } \\
\text { Fairy tale } \\
\text { Magic } \\
\text { Make believe } \\
\text { Myths and legends }\end{array}$ \\
\hline History and Culture & $\begin{array}{l}\text { Aboriginal } \\
\text { Authentic } \\
\text { Cultural heritage } \\
\text { Ethnic appeals } \\
\text { Gold rush } \\
\text { Historical ambience }\end{array}$ \\
\hline Movie & $\begin{array}{l}\text { American Wild West show } \\
\text { Comedy } \\
\text { Motion picture } \\
\text { Show business }\end{array}$ \\
\hline
\end{tabular}




\begin{tabular}{|l|l|}
\hline Contents & Degree of Accord (on a scale of 1-5) \\
\hline Interactive adventure & 4.18 \\
Fantasy and mystery & 3.82 \\
Movies and TV shows & 3.69 \\
Science fiction/futuristic & 3.60 \\
Space & 3.45 \\
Nature/ecology & 3.44 \\
Educational & 3.32 \\
Seasonal themes & 3.20 \\
Sports & 3.11 \\
Storybook themes & 3.06 \\
Food & 3.06 \\
Science & 3.00 \\
Cultural and demographic diversity & 2.92 \\
History & 2.73 \\
Transportation & 2.68 \\
Ethnic themes & 2.67 \\
\hline
\end{tabular}

\subsubsection{Importance of Good Characters, Stories and Worlds}

Characters are a critical part of a Theme Park experience because they have the power to bring the experience to life. In an attraction they are the life-blood of the story. Dark Rides typically display characters as either video content, voice overs, 2D painted flats, mechanical figures and animatronics. Typical characters in Theme Park attractions include humans, animals, robots or aliens.

While there can be many characters involved in the world of an attraction, a designer needs to determine what role the audience should be playing. Sometimes an attraction designer will want to make the guest feel like the main character or hero, but there are also other interesting character structures that could be used taking a page out of the world of Massively Multiplayer Online Games or movies with lots of cool characters in them. Going forward, with digital technologies such as AR and VR, designers will be able to use avatars to represent different people riding an attraction. As a result, they may need to determine what type of characters people should play within an attraction's world.

As online and offline worlds blend, elements from character can be lifted from the Video Game world into the Theme Park world. "Korean online games usually operate with a different business model from American and Japanese games. They feature cash shops, where players can 
essentially invest real money in their characters, making them more powerful. This creates a "pseudo-fund" of cyber money, online currency interchangeable amongst online gamers. In such a community, one is commonly judged by the strength of one's character; thus players are eager to invest in improving their characters" (Wi, 2009).

Good characters are only good when they are part of an interesting story. Story is one of the other critical elements in a successful attraction. A good story will be able to weave the experience into an interesting and engaging narrative that grips the various guests. Another key element of attraction design is including a lot of interesting physical or digital details which draw the guest's eye and immerses them in the story.

Music is a key tool in conveying emotion in a story. It can cue a guest how to feel (happy, sad, edgy, nervous etc.) or add a layer of excitement to an experience. Additionally, if the attraction is based off a popular film (i.e. Harry Potter, Star Wars), that music can be used to further remind guests that they are immersed within that movie world. As well, theme music can be re-recorded and weaved in and out of new musical content allowing a composer to control their emotional response to a story (Younger, 2016).

When looking at the current media landscape and Theme Parks in particular (which are sometimes directly tied to mass media conglomerates) more and more, we are seeing worlds as the foundations for many of the successful media franchises of modern day. Taking worlds such as Pokemon, Star Wars and Harry Potter as examples, people are very attracted to becoming part of these worlds (Jenkins, 2006).

"More and more, storytelling has become the art of world building, as artists create compelling environments that cannot be fully explored or exhausted within a single work or even a single medium. The world is bigger than the film, bigger even than the franchise - since fan speculations and elaborations also expand the world in a variety of directions. As an experienced screenwriter told me "When I first started, you would pitch a story because without a good story, you didn't have a good film. Later, once sequels started to take off, you pitched a character because a good character could support multiple stories. And now, you pitch a world because a world can support multiple characters and multiple stories across multiple media" (Jenkins, 2006). 


\subsubsection{Interest Curves}

Show producers have long known about a concept called "Interest Curves". Designers need to ensure that their entertainment has the proper progression to sustain the attention and interest of an audience. Different mediums such as movies, plays, video games and Theme Park attractions all generally differ in the total length of time. However, they all share a common goal of sustaining consumer interest to ensure that there is an overall progression where they gradually build up with bigger and bigger routines until a grand finale that exceeds expectations before letting the audience come down a bit to collect their thoughts, share experience with guests around them and generally reflect on the overall experience (Schell, 2014).

The next table displays how a guest's interest level changes based upon the attraction design. The experience or story is produced to increasingly peak the guest's interest before a grand finale. After which the audience is left some time to reflect and come down from the experience. Though different attractions have different climaxes and progressions designed into them, it is important that there is a general upwards progression, otherwise, an audience might get bored, think about something else or physically want to leave the attraction. If you look at it in segments, right out of the gates, you want a hook which is something that will exceed guests' expectations (at around the two-minute mark) (Schell, 2014). Next it is important to have interest continually rise, temporarily peaking at different points and occasionally dropping a bit to points (like five and seven minute marks) only in anticipation of rising again (at the eightminute mark). After the story has resolved, the guest will hopefully leave desiring more from the experience. This is signified by their interest not going back down to zero. Attraction Designers often understand this emotional state that a guest is left in and often purposefully put a gift shop at the end of an attraction. This is to capitalize on the guests' excitement levels in hopes that they may purchase a souvenir to remember the experience with. 
Figure 2 - Good Interest Curve (Schell, 2014)

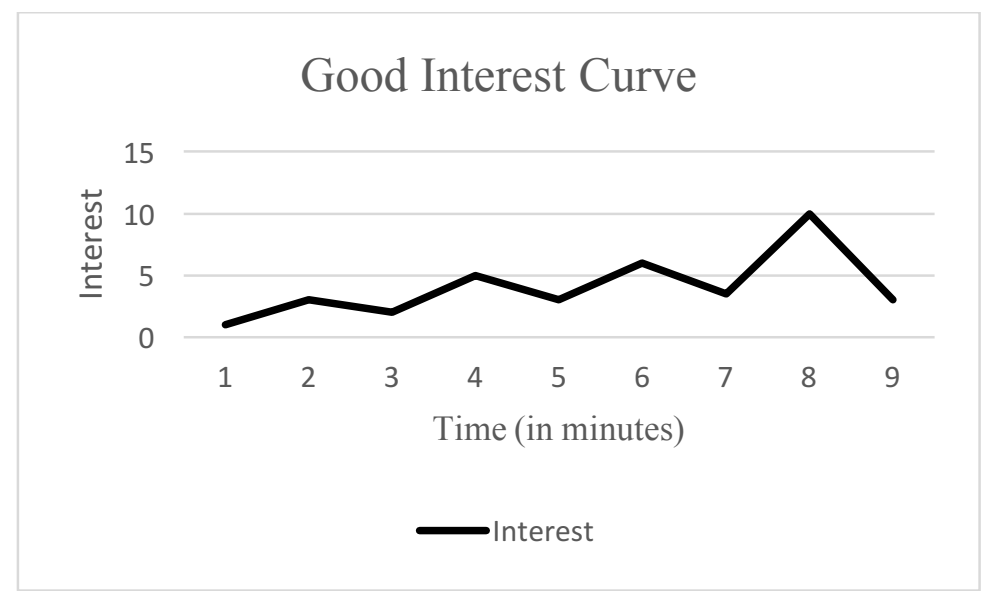

The following graph provides an example of an interest curve for a less successful entertainment experience. As can be seen at the two-minute mark, the attraction has failed to successfully hook the audience or grab their attention. Though there is something interesting that happens at the three-minute mark, it doesn't last. Next, at the five minute mark, interest is effectively lost in the attraction and at this point the guest either "changes the channel, leaves the theater, closes the book or shuts off the game (Schell, 2014). Though something interesting may have happened at the six-minute mark, it eventually wanes down to a point of nothingness at nine minutes. By that point, the guest would have already probably given up on the experience altogether.

Figure 3 - Bad Interest Curve (Schell, 2014)

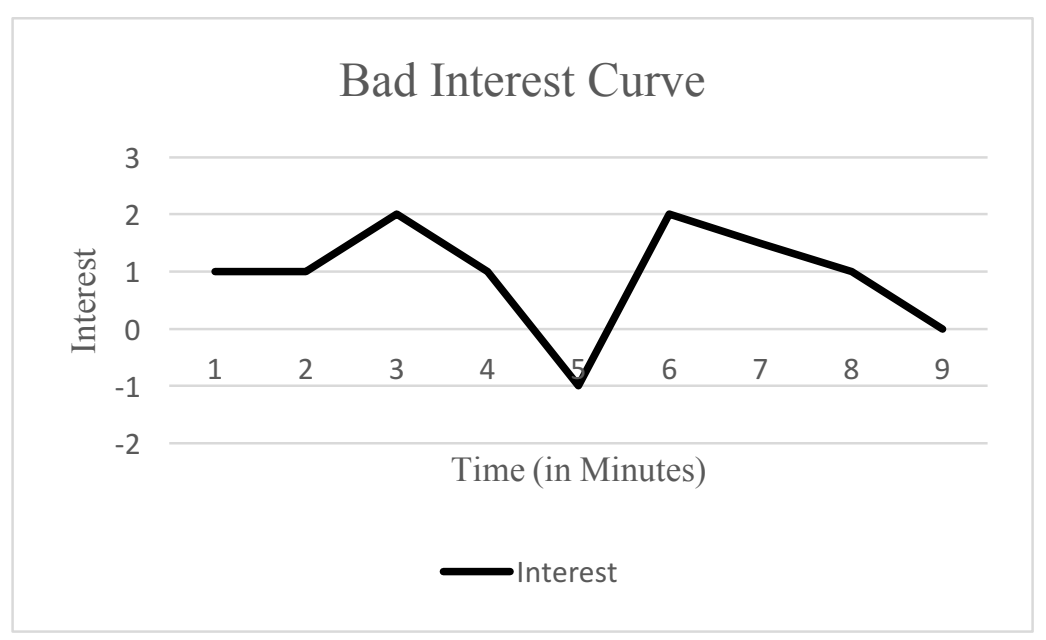


By physically charting the expected interest levels of an experience, problems can be discovered and fixed (Schell, 2014). Also, it is good to map actual interest levels of the audience, against expected levels of the entertainment. By being aware as a designer of the audiences' actual interest levels throughout an experience, they can create better experiences. Not all people experience attractions the same. Designers need to be cognizant of how different demographic groups approach their content. As a result, becoming better at either appealing to broader audiences or satisfying their target audiences.

When comparing this concept to a longer term Theme Park experience or a day at the park, the concept of "fractal interest curves" can be used to gamify a person's overall experience at a Theme Park. Since good video games are designed to sustain a person's interest and attention over a long time, a fractal interest curve can show what that would look like (Schell, 2014).

Figure 4 - Typical Interest Curve for Good Video Games ((Schell, 2014)

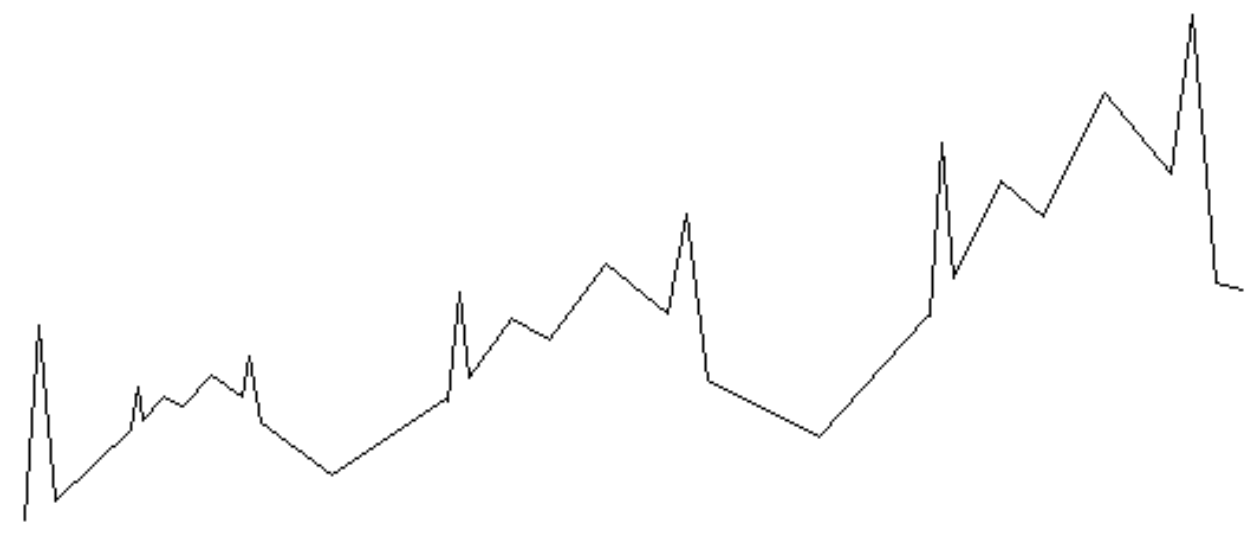

Fractal means that "each long peak can have an internal structure that looks like the overall pattern" (Schell, 2014). Further, the individual peaks can be broken down to show many different layers of gradually increasing interest curves. The different layers that can be typically seen in video games are:

1. The Overall Game

2. Each Level

3. Each Challenge 
When considering how a Theme Park planner plans a guest's overall experience at a Theme Park, it is useful to consider the fractal curves which videogame designers employ to consistently keep people more and more hooked on their games. Similarly, in a Theme Park setting, you want people to be experiencing a positively increasing interest curve throughout their stay at the Theme Park. If the experience slopes sideways or even downward for too long, that will lead to negative experiences, people to leave the park, not return or not spend money during their current stay in the park.

\subsubsection{Making Interactive Experiences More Fun}

When creating interactive Theme Park attractions, it is important to first have an understanding of why people play video games. By measuring peoples' emotions through interactive videogame experiences, there are a lot of lessons which can be passed on to designers of interactive Theme Park experiences. A study called "The 4 Keys to Fun" was completed which involved studying different gamers playing some of the most popular games and measuring their emotions during gameplay to determine what made certain experiences more enjoyable than others (Lazzaro, 2004).

Social is by far the most important key, making up for more enjoyment than the other three keys combined (Lazzaro, 2004). It involves creating opportunities for player competition, cooperation, performance and obstacles. "Playing games in social contexts intensifies player emotions and adds content. People playing in groups for this study demonstrate substantially more signs of emotion than those playing on their own" (Lazzaro, 2004). Interestingly the study found that by putting players in the same room, they had more emotional displays, more energetic responses and different types of interactions (Lazzaro, 2004). People will often play games they don't even like just so they can spend time with their friends because this gives them a channel to make wisecracks, have rivalries and use teamwork and camaraderie to accomplish shared goals. Multiplayer games should have both competitive and cooperative parts to offer a variety of emotional responses. People reported having emotion from competition, showing others how to do things within the game, feeling like an expert and saving the day (Lazzaro, 2004).

Another key is the internal experience key that is how a game makes a player feel. As a player plays the game, they produce emotions or internal sensations of excitement or relief. 
Emotions can come from visceral experiences, behavioural reactions to elements within the experience, cognitive reactions from ideas memories or associations about the gaming experience or from social interactions with others playing the game (Lazzaro, 2004). An example of emotion coming from visceral experiences is the screeching of tires in a racing games or the sensation of falling, fire or spiders (Lazzaro, 2004). The study reported many adults that didn't enjoy the sensations coming from graphic violence, blood and gore (with some refusing to play games with these elements). People generally preferred games with friendly interaction and art (Lazzaro, 2004). This excited more positive emotions in players. Having this sort of openness created through fun music, bright colors and zany obstacles makes games more approachable for casual gamers which is a similar "catch all" demographic to most Theme Park audiences.

People can have different cognitive experiences when moving through a game or experience. People's experiences can be influenced by ideas and memories that come to them as they experience something. Also after playing, people like to reflect on the experience that can add enjoyment to the overall equation. As well, this can be influenced by things like music playing in part of a game which can evoke a certain mood association (Lazzaro, 2004).

The next key is the challenge and strategy key that involves unlocking emotions from meaningful challenges, strategies and puzzles. For many gamers, overcoming obstacles is why they play. As well, being rewarded with progression and success in the game makes these players feel accomplished. These players often play to see how good they are, to beat the game, overcome multiple obstacles or use strategy to win. This type of fun is seen as the most obvious source of player emotion but also one which requires a fair bit of balance to get right (Lazzaro, 2004). It may seem obvious that people like mastery and controlling things, but on the way to that, there can also be frustration. For example, players can sometimes get frustrated if they cannot see what they need to do next in an experience. Also, in competition, while one person's satisfaction can come from winning, that can often mean their opponent's demise in defeat. This can lead to poor overall satisfaction levels in the context of an interactive ride experience where you can't play it again and again necessarily. As a result, to achieve this key, it is important to remember that optimal game experiences fill player attention, offer clear goals, achievable tasks, immediate feedback and a sense of control (Lazzaro, 2004). Instead of having a winner take all 
situation, it can be good to allow all guests in the experience the opportunity to go from frustration to enjoyment of success (Lazzaro, 2004).

The next key is the immersion key which involves grabbing attention with ambiguity, incompleteness and detail (Lazzaro, 2004). The immersion key brings out a sense of curiosity in the player. Ambiguity, incompleteness and detail all come together to make a living world that captures the player's attention and holds their interest. Players who like the immersion key say that they like exploring new worlds with other people, being excited and having a sense of adventure, finding out what happens in the story and feeling like them and their character are one. To achieve this key, it is important to create beautiful immersive environments in attractions that inspire emotions (such as beauty, horror or humour). This key enables people to enjoy the experience without having to focus on pursuing goals. Instead they can just passively enjoy the powerful and emotion evoking to create interesting experiences.

These are all important things to remember when designing attractions as people like to go to Theme Parks as a social outing with family and friends. Almost all of the reasons people like playing videogames together apply directly to people enjoying going to interactive Theme Park attractions together. As rides become more interactive in the future, some of these positive outcomes from group game play should be remembered and incorporated into interactive ride experiences. Though people especially those in groups can be "unpredictable", it is important to weigh that against the extreme benefits gained by designing experiences to become more social.

\subsubsection{Understandability - is there a clear goal?}

A key element of engagement is not overcomplicating the narrative content. With increasingly immersive and interactive narrative structures in attractions, it is important that the narrative doesn't ask too much of the guest.

If an Attraction is interactive, the interactive interface or controller needs to be incredibly intuitive. "Intuitive user interfaces are crucial for interactive Theme Park rides. To ensure the high throughput that Theme Parks demand, we shouldn't waste the guests' time acclimating them to the story, interface, or game rules" (Schell, J Shochet, 2001). For example, in the Pirates of the Caribbean attraction at Disney Quest in Orlando, "Pirates uses simple, obvious interfaces like a steering wheel to steer and actual cannons to point and shoot virtual cannonballs. We decided to make the helm and cannons active while the guests board the ship. This gives 
them a few seconds to fire off a test shot or try a turn on the wheel to acclimate to the interface before the pressure of the actual game begins" (Schell, J Shochet, 2001).

While interactive games should be easy to learn, they should be hard to master. An example is the Korean Game Fortress 2, which is based off tank warfare. "Fortress 2's strength was that while it was simple to learn, the game was deceptively complex. While it seems like a simple point and shoot game, the location and angle of the opponent's tank played a major factor in the effectiveness of a shot, and the game required diverse strategies to be successful" (Kim et al., 2003). "Koreans prefer games wherein angle and strength can be controlled. Billiards is a prime example. It has simple rules but no one refers to it as a simple game. This is what we wanted. We began developing with a complex game with simple rules in mind" (Kim et al., 2003). Frustration with an interface can drastically decrease a person's enjoyment of a game. "Players report abandoning games because of interface difficulties. Steep learning curves cause people to play less or not at all. The success players enjoy most comes from overcoming meaningful obstacles. In short, challenge is more rewarding when the frustration comes from pursuing an important game goal" (Lazzaro, 2004).

\subsubsection{Branded Content vs. Custom Content}

Theme Park attractions typically offer either custom or branded content. Many of the top Theme Park companies feel that using branded content such as a blockbuster movie as the supporting content for a themed attraction can deliver incredible financial success. The Wizarding World of Harry Potter was announced over seven years ago at Universal Studios, Islands of Adventure Theme Park in Florida and was greeted with huge success. This was followed up by an expansion of various parks around the world including Universal Studios Hollywood, Universal Studios Osaka and recently announced, Universal Studios Beijing. Due to the high demand for the Wizarding World of Harry Potter, the new ones are larger and offer “demand-based ticket pricing systems" to prevent overcrowding (MacDonald, 2016).

Theme Parks also often use product placement within the various themed lands and attractions. Since the early days at Disneyland, Walt Disney in many cases relied on corporate partnerships and financing deals to bring some of his attractions and themed worlds to life. For example, The Carousel of Progress at Walt Disney World was jointly supported by General Electric and offered a branding opportunity for their company to display some of their values to 
the guests attending Disney World. Similarly, Space Mountain was sponsored by RCA and enjoyed a co-branding through that attractions futuristic experience (Younger, 2016). More recently, Ferrari World is a great example of an entire Theme Park which is based off of a very popular brand that allows consumers to experience the brand through a day at the park.

Theme Park's offer a compelling opportunity for companies to get people subliminally thinking about their brands. "A viewer's anti-advertising 'defenses' are lowered at the cinema, thereby offering brands an opportunity to communicate that may be very competitive. Brand awareness can be concretely reinforced. The more the brand is seen or heard, the better the chances that it will be remembered" (Lehu, 2007). The key thing when considering advertising through a Theme Park attraction is to ensure it is done tastefully. "The brand must be able to enjoy a genuine process of symbiotic integration: such a close relationship with the film's story, or more generally with the environment in which it is to appear, that it's presence will seem natural. Branded entertainment should be for the brand, an opportunity to write actual stories, integrating its identity and its personality, respecting its characteristics and promoting the stimulation of an emotional link between it and the individual" (Lehu, 2007).

\subsection{Economics}

\subsubsection{Theme Park Economics Overview}

The total Amusement and Theme Park Industry in 2015 earned \$32 Billion in Revenue in 2015. (Global Industry Analysts, 2015). Due to the highly competitive nature of the industry, "Entertainment related technology is increasingly becoming imperative for the success of a theme park" (Global Industry Analysts, 2016).

The various themed lands and attractions at Theme Park need to adhere to a business case or they won't last. "Fundamentally, the Theme Park is a system comprising various entertainments intended to draw guests to it, charging them an entrance fee, and then hold their attention for an optimum duration, gaining income from food, beverage, and merchandise sales across their stay" (Younger, 2016).

Per capita spending is a key to the Theme Park's business model. It can be broken down into yield which is like the ticket price and secondary spend which is whatever they spend inside the park (i.e. food and beverage, merchandise, hotels and ancillary attractions). 
One of Theme Parks' major goals is to make money. Some of the revenue streams currently available to Theme Park operators are admissions, retail, food and beverage, hotels, ancillary attractions, sponsorships, ticketed and corporate events and lessees (Younger, 2016).

Theme Parks have various ways of increasing revenue. These include: increasing number of visitors, increasing per capita spending, increasing the length of peoples' visit, increasing their frequency of visitation and through cannibalization (Younger, 2016).

When considering the creation of a new attraction, whether VR, AR, MR or none of the above, it requires significant investment. A proposal for a new attraction must promise that it will bring more people to the park or generate more per capita spending within the park. A new attraction at a Theme Park must pass a feasibility stage. Considerations in this stage include development costs, operating costs, maintenance costs, training costs, market conditions and target demographics. If it's an existing park, other considerations include income derived from the attraction, net operating expenditure per number of Visitors and Net cost of marketing per number of visitors (Clavé, 2007).

Though it varies by park, typically around 50\%-60\% of visitor spend at Theme Parks typically comes from entrance fees while the remainder comes through consumption within the park. Another important form of revenue for parks is sponsorship and rents. In the year 2000, Walt Disney World in Orlando reached $\$ 738$ million, $22.7 \%$ of its total revenue through sponsorship and rent (Clavé, 2007).

Theme Park operating expenses typically represent up to $80 \%$ of total sales (Clavé, 2007). Salaries are the largest part of costs with some parks representing up to $50 \%$ of total costs (Clavé, 2007). Maintenance and repair costs are typically a steady cost item. Marketing expenditure is more variable and typically associated with a new attraction or land at the park (Clavé, 2007). Insurance is another category of importance. Insurance is an essential expenditure due to the risks deriving from the use of attractions. "Given the repercussions in the media and effect on demand that any incident has, parks tend not just to adopt extreme safety measures but also to take out insurance against any possible lawsuits and claims" (Clavé, 2007).

\subsubsection{Importance of Customer Satisfaction}

Attraction Designers need to focus on delivering a very high level of customer satisfaction. Customer satisfaction can be defined as the feeling a customer has that a product 
has met or exceeded their expectations (positive disconfirmation). Dissatisfaction results if performance such as product performance or employee performance falls short of those expectations (negative disconfirmation). Companies which neglect to pay attention to their customers' satisfaction face severe consequences including: customer complaints, negative word-of-mouth, switching, loss of sales, declining market share and potential bankruptcy (Boshoff, 2006).

As guests move through a Theme Park, there are a number of ways for them to achieve satisfaction within the park. Equally, there are many things that can detract from a guest's satisfaction. In a study of guest satisfaction at several Theme Parks, it was found that the most important variables were the quality of entertainment options, restaurants, bathroom facilities, rides, retail, communication, facilities, location and price level (Boshoff, 2006). Looking specifically at rides, people expect to feel safe and secure while on the ride, feel safe and secure while near or around the rides but also to have an enjoyable experience when riding the ride. In addition, people enjoy good variety within the rides that they can choose from. The entertainment must also be entertaining, authentic and cater to both children and adults (Boshoff, 2006).

A Theme Park experience is mainly consumed by visiting guest attractions and shows. For a successful Theme Park visit, a guest will have typically been able to experience around 10 attractions or entertainment experiences throughout in an 8 hour day (Torrado A, 1995).

Parks typically have one major attraction for every two minor attractions at each themed land. "Therefore, the high capacity attraction with big drawing capability should be equal to two lower capacity attractions with smaller powers of attraction. For example, at Paramount Parks, for each intense, highly emotional attraction, whose capacity is 1500 people per hour, a capacity of 2000 people per hour is planned on a smaller, family-oriented attraction" (Rebori, 1993). The goal is for the visitor to move through "nodes" within the various themed lands not too quickly but also not too slowly (Clavé, 2007). 


\subsubsection{Risks}

\subsubsection{1. $\quad$ Strategic Risk}

Theme Park clients are sometimes seen as being somewhat risk averse when it comes to adopting new technologies. The Chinese and FEC markets tend to be more pro risk because the risks are less expensive to take than in Theme Parks.

\subsubsection{Compliance Risk}

Theme Park Attractions need to be accountable to external reviewers who monitor things such as safety, cleanliness and working operation of rides. An attraction needs to meet and continue to operate based on strict internal and external standards and oversight. If a ride uses premature or unsafe technology as the basis of their solution, they risk not meeting compliance standards that could jeopardize the entire investment in a new attraction.

\subsubsection{Operational Risk}

Attractions increase the operational overhead at a park. Parks need better employees to manage such high tech equipment and trouble shoot potential issues that arise. In addition, the amount of employees that you need to hire per guest goes up which reduces profitability if the attraction can't bring out lots of new people or get people spending more or bot.

\subsubsection{Financial Risk}

The cost of building attractions with the newest technology adds up very quickly. When considering how you want to maximize the per capita spend per square foot at a park, if a new attraction takes up a lot of space and doesn't add that much revenue to the top line in terms of marketability or increased visitors, or increased visitor spend, that might be a risky business model that might not hold up over the long term or even mid term. If an attraction can't bring out more people or get more people to spend more at the park, then it will likely not be a profitable investment for the park.

\subsubsection{Reputational Risk}

Theme Parks have to be incredibly careful with managing their reputation. In such a global industry, a problem that happens on one side of the world can travel fast through 24/7 internet and social media. In such a global industry, a problem at one park isn't just a problem at that park, it is a problem for all the parks around the world. If parks can't get people out to their park because people think they're boring or unsafe, then that park risks everything. 


\subsubsection{Obsolescence Risk}

One of the major risks with investing in VR or AR is that it will become stale the moment it is released to the public. With consumer technology advancing at such a rapid rate, any planning that a Theme Park designer will be doing today for a ride that won't be built for 3-5 years will risk implementing instantly obsolete technology.

\subsubsection{Market Segmentation}

There are several types of "Theme Parks" including destination, regional, urban and niche parks. Destination parks for example would be Disney or Universal Studios that draw people from around the world. They are "subject to economic, social and political variations affecting the consumer's willingness to travel" (Clavé, 2007). Regional parks are designed to attract guests from 100 to $200 \mathrm{~km}$ away. The principle operators of Theme Parks within this category are Six Flags, Cedar Fair and Merlin Entertainment. Theming in these parks is typically not as pronounced as at destination parks. Local parks are parks created for people in the immediate geographic area. Niche parks are small, recreational areas that receive less than one million visitors per year. These types of parks typically have far less attractions and no very expensive attractions because their low guest throughput precludes any major investments in iconic attractions. These types of parks can either be in urban or suburban areas.

\subsubsection{Growth of $V R / A R$}

Though VR is often touted by media as being the way of the future, it is actually not the first time people have held these assumptions. VR also had a boom in the 90s and another wave of innovation starting in 1965. First, in 1968, Ivan Sutherland created the first head mounted display called the "The Sword of Damocles", however being the first of it's kind it was limited in what it could do (Yang, 2016) (Yang, 2016). The next important development was in 1972, computer graphics were born with innovations such as texture mapping (adding patterns to 3D objects) and z-buffering (technology in 3D graphics which determine what parts of 3D objects are visible). Next, in the 80 s computer graphics experienced considerable growth through companies like SGI who no longer exist. Innovations during that time include panoramic video. In 1993 CAVE (Computer Augmented Virtual Environment) systems were born and around the same time Disney created Disney Quest and Imagineering Labs. Next in 1994 a company called Virtuality introduced the first commercially available VR system. By 1995, other entrants came into the market such as Sega and Nintendo with HMD based offerings. However, directly after 
this the market had a falling out. SGI went bankrupt, Disney Quest announced that they wouldn't be rolling out new locations and Sega VR and Nintendo Virtual Boy didn't sell well (Yang, 2016).

Though VR wasn't ready for the consumer market in the 90s, the entire market didn't disappear. Many employees from SGI, a company that restructured in the late 1990's, went on to companies like Nvidia and 3D graphics software companies Alias and Autodesk. As well, as military spending for VR technologies continued. and companies still used VR as an internal design tool. Additionally, the smartphone and digital media industries experienced unprecedented growth and innovation leading to a more connected and information rich world. Faster and more efficient rendering technologies became available for the Video Game market and Motion Capture technology developed considerably as a tool for movies, gaming and television production (Yang, 2016). These advances in technology and use would set the scene for a refreshed market for VR with a renewed chance at success today.

In 2012, Oculus Rift put out a Kickstarter to develop their platform, and the quality of experience they were able to provide, renewed hope for the previously beaten down industry. This led to Facebook's acquisition of Oculus for $\$ 2$ billion in 2014. Currently, more and more people are seeing the potential of VR technology and what it might be able to deliver.

According to Mark Zuckerberg, founder of Facebook, "Mobile is the platform of today, and now we're also getting ready for the platforms of tomorrow. Oculus has the chance to create the most social platform ever and change the way we work, play, and communicate. The history of our industry is that every 10 or 15 years, there's a new major computing platform, whether it's the PC, the web, or now mobile. History suggests that there will be more platforms to come, and whoever builds and defines these platforms will not only shape all of these experiences that our industry builds, but also benefit financially and strategically" (Orland, 2014).

Most of the top technology companies have invested large amounts in developing the medium including Google, Facebook, Microsoft, Sony, Hewlett Packard, HTC, Intel, NVIDIA and Samsung among others (Murphy, 2016). Additionally, if the market gets big enough, other technology giants pursuing the wait-and-see strategy may jump in.

The success of VR and AR technology is still going to be highly tied to consumer appetite for adopting VR but even modest demand for the medium will make it a compelling market to follow. As well, as consumer technologies such as smartphones and distribution 
channels such as Facebook and YouTube make VR more accessible to people, more will try it. However, to ensure it stays relevant to consumers, the content will need to be compelling, hold peoples' interest or the market will risk losing the consumers' interest and attention and not be able to get it back.

There is a difference between quality levels for different VR sub-types. With Head Mount Based VR, there is low end (Google Cardboard), mid end (Gear VR) and high end (HTC Vive, Sony PSVR and Oculus Rift) (LEK Consulting, 2016). While the capabilities are always changing, currently, Cardboard experiences are typically passive 360 videos. Mid End Gear VR experiences are typically sit down interactive experiences, sometimes with a controller. At the high end with platforms like HTC Vive and Oculus, it is typically run off a gaming PC, room scale VR (meaning you can walk around a small area), with 2 controllers and a higher fidelity interactive experience.

Alongside VR, AR is also a very interesting technology to watch and arguably going to be more disruptive and broader in terms of the use cases that it can provide. While AR on headmounted displays (or glasses in the future) is still believed by many industry insiders to have the most potential to change the future of Theme Park rides, it is currently not ready.

Games like Pokemon Go have been launched to mobile platforms showing the power of Mobile Based Augmented Reality. Interestingly, the AR technology in question is over seven years old but the power of how they used it was really what made it interesting. Pokemon Go has the power to unite people, get them playing, and even has some of the broader business benefits associated with many currently existing mobile apps (viral spreading, advertising, GPS enabled services, communication) (Etherington, 2016).

Investment in Virtual Reality technology is growing rapidly. VCs invested $\$ 1.7$ billion in the 12 months leading to March 2016 and \$1.2 billion of that was in the first quarter of this year alone. There are already $4 \mathrm{VR} / \mathrm{AR}$ unicorns (companies valued at over one billion dollars). Those companies are: Magic Leap, Oculus, Blippar and MindMaze. Additionally, VR Venture Capital Alliance, lead by HTC (with 27 total investment companies involved) has \$10 Billion in funding for VR related startups (Matney, 2016). This is in addition to HTC Vive's previously announced \$100 million Vive X Accelerator Fund (Matney, 2016).

Opinions on the viability of VR/AR seem largely positive according to a Tech Crunch Article written on May 24, 2016. Accel principle, Kobie Fuller states that "AR/VR is the next 
phase of computing, where it's not a question of if, but when" (Merel, 2016). DCM General Partner, Jason Krikorian stated that VR and AR can enable "new experiences not possible before." Jason Ball, the Managing Director at Qualcomm Ventures stated "AR/VR is the new User Experience and User Interface for everything, but it will take time.” Colopl Next CEO Shintaro thinks that "VR and AR will become the bedrock of almost every industry" (Merel, 2016).

In a positive forecast conducted in April 2015, they stated that "Augmented/Virtual Reality will hit $\$ 150$ billion (in revenue) disrupting mobile by 2020”. A year later in January 2016, Digi-Capital revised their forecast to lower the number to $\$ 120$ billion (Merel, 2016). Digi-Capital argues that there AR will take on use cases which are universally relevant across industries much like smart phones currently are (Merel, 2016).

Figure 5 - AR/VR Revenue Forecast (\$Billion) (Merel, 2016)

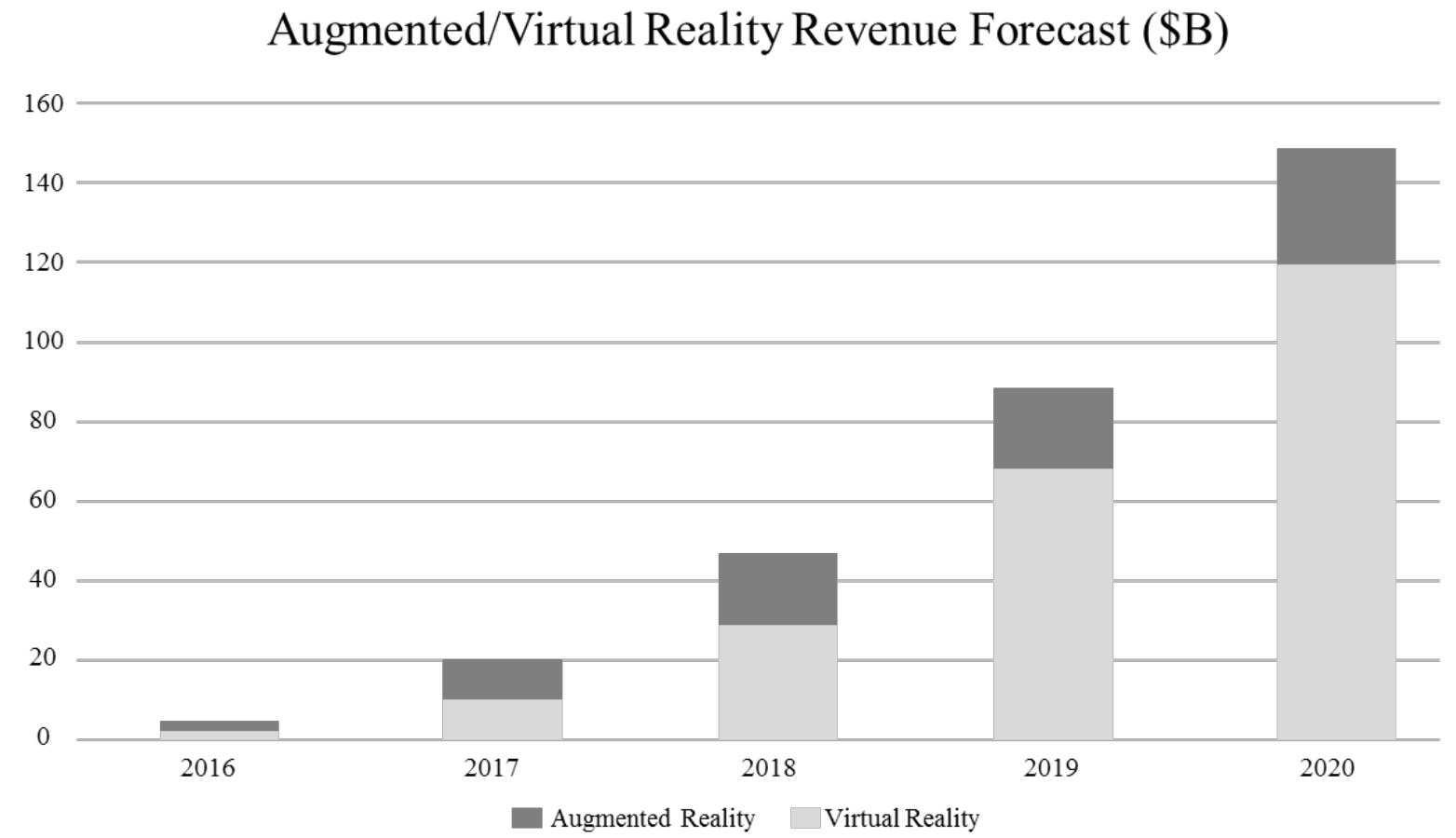


In the following study (shown in figure 6), three forecasted scenarios for the future size of the VR industry are shown. The "delayed uptake" case estimates that VR will become a \$23 billion market by 2025 , the "base case" states it will reach $\$ 40$ billion by 2025 , while the "accelerated uptake" case says it will reach $\$ 182$ billion by 2025 . The delayed uptake is based on HMDs "gaining popularity as tech improves but that adoption is still hampered by battery life and mobility." The "accelerated uptake" case predicts a \$182-billion-dollar market (containing $\$ 110$ billion from hardware and $\$ 72$ billion from software). This scenario is more aggressive assuming that the technology evolves into a "broader computing platform" much like how we view mobile today. In the delayed uptake scenario, they still predict a \$23-billion-dollar market (with $\$ 15$ billion from hardware and $\$ 8$ billion from software). This scenario predicts issues such as latency, display, safety and privacy will hamper growth. In the "base case" example, they predict that the technology doesn't move past the video gaming market. These predictions all compare to notebooks at $\$ 111$ billion, desktops at $\$ 62$ billion and video game consoles at $\$ 14$ billion (Ranj, 2016). Below, is a graph showing a visual representation of the future market in 2025.

Figure 6 - VR/AR HMD Market Potential (Ranj, 2016)

\section{Augmented/Virtual Reality Revenue Forecast (\$B)}

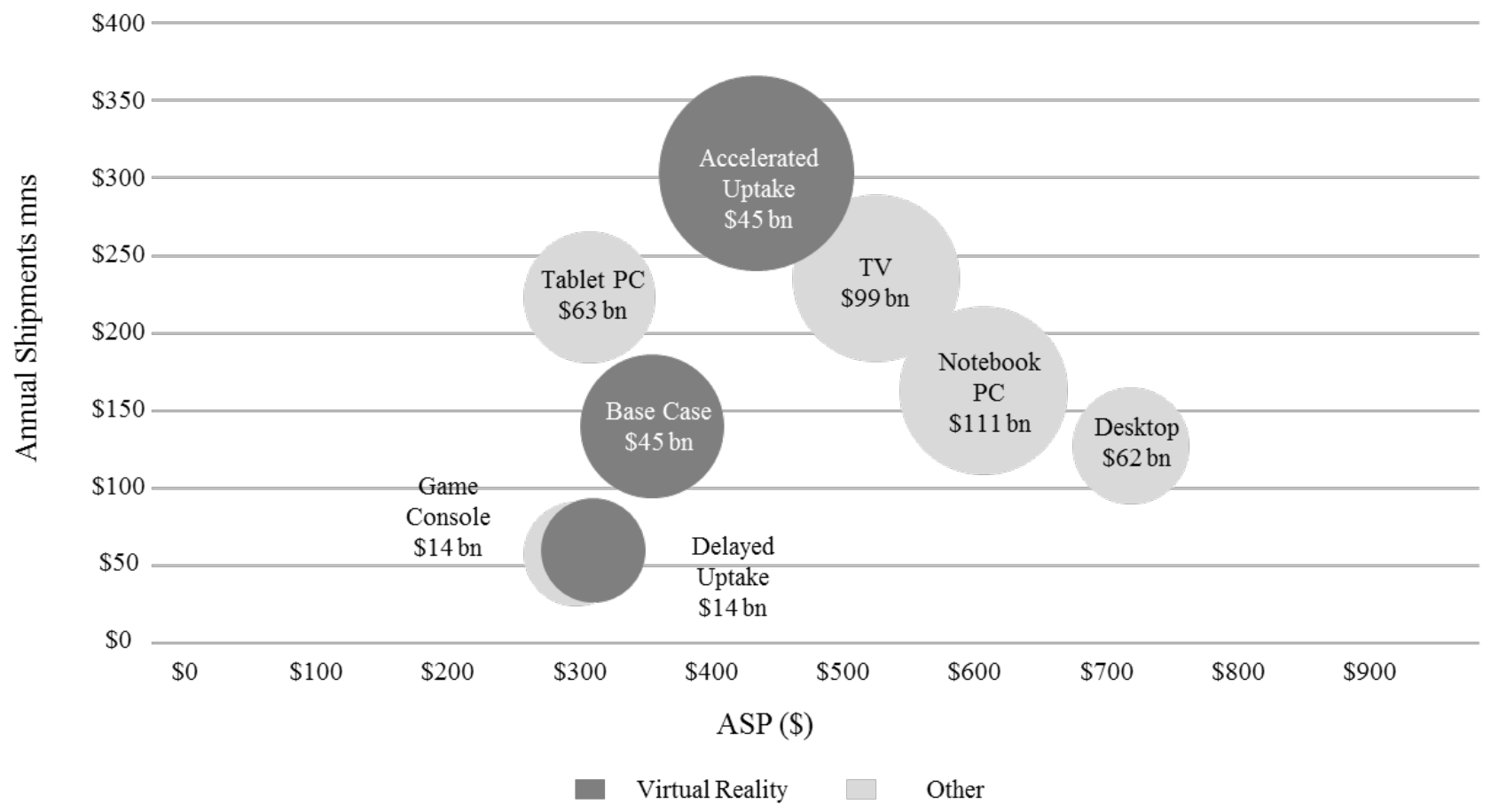


Currently, some analysts believe lack of supply and public awareness are the reasons that VR will only have a $\$ 3$ billion dollar year this year (Llamas, 2016). By 2020, they predict a \$40.3-billion-dollar market once there is more content and adoption. In 2016, HTC Vive and Oculus Rift are set to ship 1.1 million devices this year even though there have been issues with distribution (Llamas, 2016). Additionally, Samsung reportedly cannot keep up with demand of their 35 million Gear VRs that have already been ordered for this year (Llamas, 2016). Another key player in the consumer VR market is Sony who has created the Playstation VR. They are said to be the industry's "dark horse" because there is a lower barrier to entry with no need for the consumer to own an expensive (\$1500 to \$2000) gaming PC. They just need a Playstation 4. Additionally, the PSVR is approximately half the price of the Oculus Rift at \$399. Sony also has relationships with retailers which will prevent them experiencing similar distribution issues to HTC or Oculus.

Top technologies typically follow an exponential adoption curve (Super Data Research, 2016). Below, there is a prediction of what realistic adoption levels may be over the next 5 years. As it is not a mass medium but rather a specialized medium, Super Data predicts that by 2020, approximately 15\% of households will own a VR device (Llamas, 2016).

Figure 7 - Adoption Rates of Major Technologies (Llamas, 2016)

\section{Major US Technology Adoption Rates by Household}

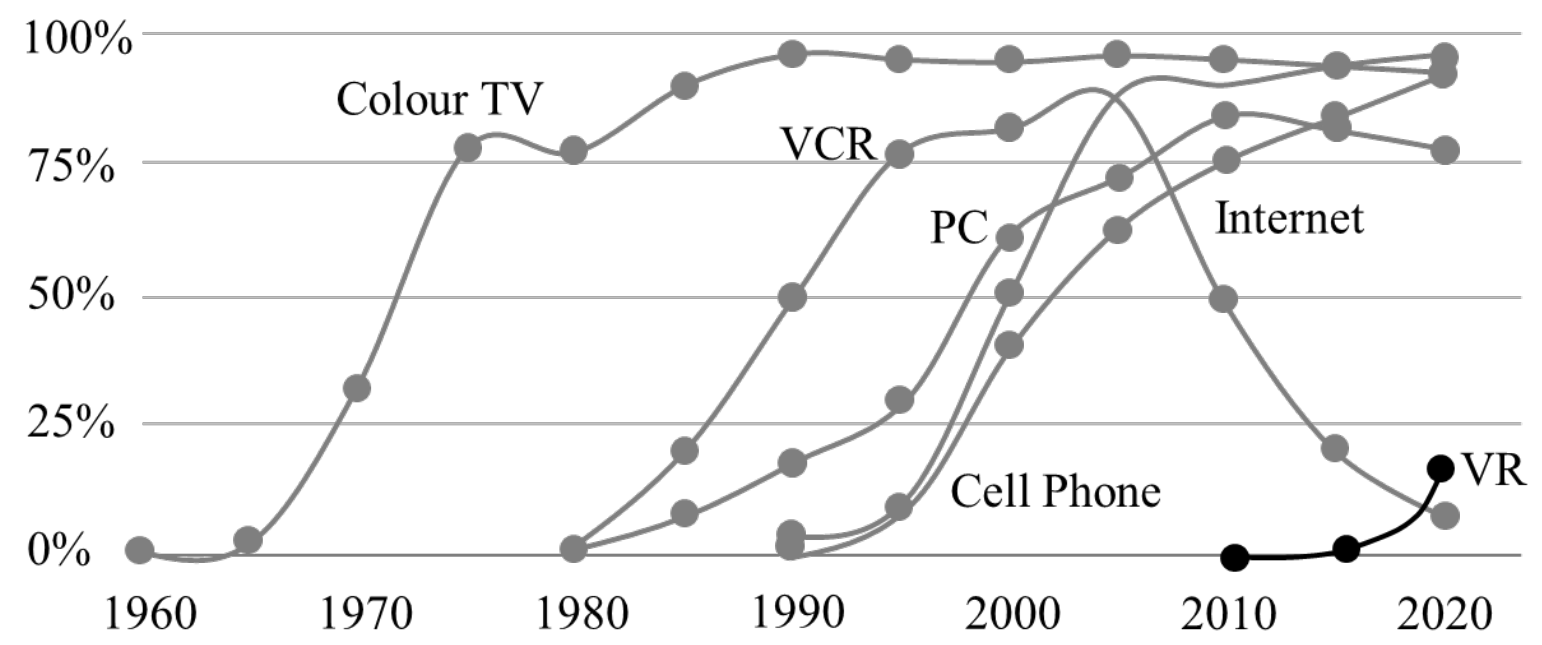


The continued growth and innovation of overall VR industry is going to be highly tied to consumer appetite for adopting Virtual Reality. As consumer technologies such as smartphones make VR more accessible to people, more will try it. However, to ensure it stays relevant to consumers, the content will need to be compelling, hold peoples' interest or the market will risk losing the consumers interest and attention and not being able to get it back.

\subsubsection{Gartner Hype Cycle}

Gartner Research has created a model to help understand the hype surrounding different technologies. Typically, each technology goes through a similar cycle regarding how people view the technology and Gartner has named this the "Gartner Hype Cycle". The Gartner Hype Cycle represents the number of people talking about the technology on the $\mathrm{Y}$-axis against time on the X-axis. Gartner believes that every technology goes through five phases of hype, as outlined in Table 8 below.

Figure 8 - Gartner Hype Cycle (Forni \& Vandermeulen, 2016)

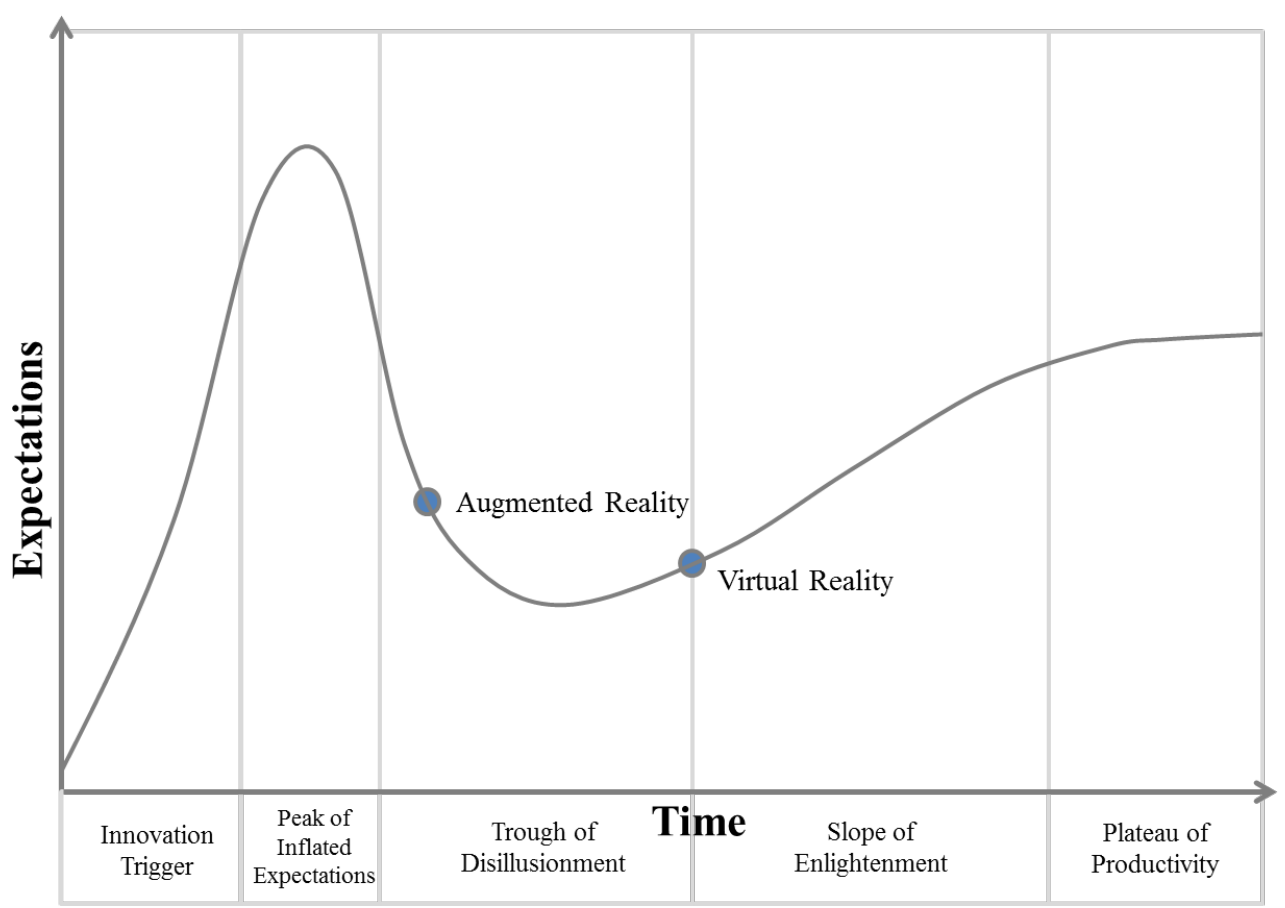

The five stages along the Gartner Hype Cycle include: the innovation trigger, the peak of inflated expectations, the trough of disillusionment and the slope of enlightenment. It is useful to understand the points where VR and AR fall on this cycle because this ensures that decisions are based off of analysis and calculated risk NOT hype. 
Currently, AR is about to hit bottom of the trough of disillusionment while VR is entering the slope of enlightenment. VR is currently in the upswing of the slope of enlightenment. This can be characterized by the fact that it is getting more prominent on the consumer stage and being successfully used in more industrial use cases.

\subsection{Summary}

Though information is readily available about the Theme Parks and Experience Design, finding peer reviewed academic literature specifically related to the VR/AR Attraction business case is more challenging. This created the need to fill in gaps in information through research interviews with people with specific involvement in the area. While a lot of information could be gathered through online publications, information regarding things like VR/AR/MR development, best practices and peoples' opinions are often not published in online publications. These gaps became the focus for the research interviews. The method for gathering data will be covered in the following chapter. 


\section{Method}

The purpose of conducting interviews was to learn from experts about how VR/AR technologies could best be leveraged by Theme Parks. Interviews focused on a mixture of discussion topics centered around three key themes including: the importance of content, what made for good VR/AR attraction/game mechanics and economic considerations. The interviews were designed to elicit information based on the gaps in knowledge from the lack of academic literature available on the topic.

The method of gathering contacts included personal outreach, attending industry conferences (such as International Association of Amusement Parks in Orlando in November 2015 and Shanghai in June 2016 and Attractions and Silicon Valley Virtual Reality in May 2016), networking on Linkedin as well as through trade associations such as Themed Entertainment Association (TEA). The interviewee sample group included a cross-section of people from industry in North America, Europe, Asia and the Middle East, thus providing a unique, global perspective. Several companies were visited in the completion of this report. Some of the cities which were visited include: San Jose, San Francisco, Los Angeles, Shanghai, Beijing, London, Tokyo, Orlando and Wels.

The literature and background research pointed to a number of variables and subvariables which may be important to discuss with thought leaders in the industry. Those variables and sub variables are shown below. 


\begin{tabular}{|c|c|c|}
\hline Mechanics & Content & Economics \\
\hline 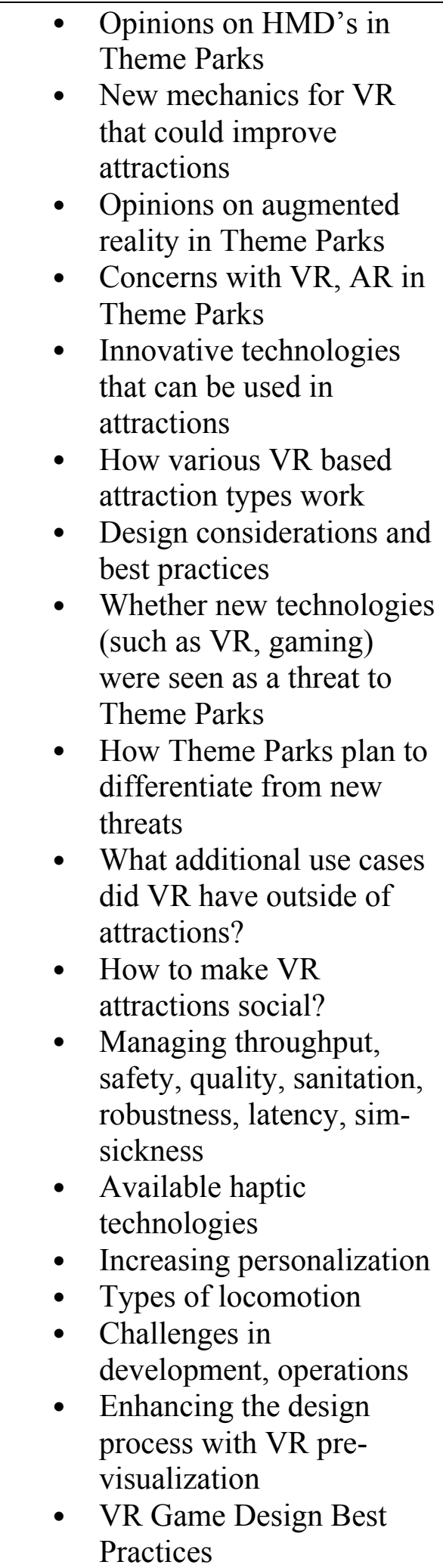 & $\begin{array}{l}\text { - Understandability } \\
\text { - } \text { Repeatability } \\
\text { - } \text { Steractivity } \\
\text { - } \text { Brandelling Content vs. } \\
\text { - } \text { Custom Content } \\
\text { - experiences } \\
\text { - Transmedia } \\
\text { experiences } \\
\text { - Innovative uses of } \\
\text { VR in other sectors } \\
\text { that could apply to } \\
\text { Theme Parks }\end{array}$ & $\begin{array}{l}\text { - } \text { Cost of personnel } \\
\text { - } \text { Development cost } \\
\text { - } \text { Maintenance } \\
\text { Location Based } \\
\text { Entertainment } \\
\text { leveraging } \\
\text { partnerships to } \\
\text { accelerate growth } \\
\text { - } \text { Location Based } \\
\text { Entertainment in } \\
\text { - } \text { struggles in the 90s } \\
\text { - Trowth in Asia } \\
\text { Talent shortage }\end{array}$ \\
\hline
\end{tabular}


There were three general questionnaire templates, each pertaining to a specific subgroup within the study, including: "Theme Park Attraction Manufacturers and Operators", "Industry Analysts" and "VR/AR Experts". To get the most value from each interview, some research questions were personally tailored based on the subject matter that the particular interviewee knew best. The interview templates can be found below in the Appendix. All interviews were approximately one hour. Twelve of the interviews were held in person and the other nine were held on skype. All interviews were held between the months of May and August in 2016. Most interviews were designed to learn from people with VR/AR subject matter expertise, about what types of virtual technology experiences their companies create and to get their opinion on various topics within the Theme Park or VR/AR industry. Questions were open ended. All interviews were recorded and transcribed at a later date and analyzed for common themes. The legend of participants can be found in the table below with codes masking participant names to maintain anonymity but still provide context as to the type of person saying something.

Table 10 - Legend of Participants

\begin{tabular}{|l|l|}
\hline Description & Code \\
\hline Creative Technology Executive & $\mathrm{A} 1$ \\
Leading Location Based Entertainment Company & $\mathrm{A} 2$ \\
Leading Location Based Entertainment Company & $\mathrm{A} 3$ \\
Entertainment Technology Executive (Theme Parks) & $\mathrm{A} 4$ \\
Entertainment Technology Executive (Theme Parks) & $\mathrm{A} 5$ \\
Entertainment Technology Executive (Theme Parks) & $\mathrm{A} 6$ \\
Entertainment Technology Executive (Theme Parks) & $\mathrm{A} 7$ \\
Entertainment Technology Manager (VR Industry) & $\mathrm{A} 8$ \\
Entertainment Technology Executive (Theme Parks) & $\mathrm{A} 9$ \\
Entertainment Technology Executive (Media Industry) & $\mathrm{A} 10$ \\
Entertainment Technology Executive (Theme Parks) & $\mathrm{A} 11$ \\
Entertainment Technology Executive (VR Theme Parks) & $\mathrm{A} 12$ \\
Entertainment Technology Executive (VR Theme Parks) & $\mathrm{A} 13$ \\
\hline Professor and Gaming Executive (VR Industry) & $\mathrm{B} 1$ \\
Mobile Gaming Executive and VR Evangelist & $\mathrm{B} 2$ \\
VR Gaming Executive & $\mathrm{B} 3$ \\
VR/AR Gaming Executive \& Consultant to Theme Parks & $\mathrm{B} 4$ \\
\hline Entertainment Technology Industry Analyst & $\mathrm{C} 1$ \\
Entertainment Technology Industry Consultant & $\mathrm{C} 2$ \\
VR News Publication Editor & $\mathrm{C} 3$ \\
VR/AR Industry Consultant & $\mathrm{C} 4$ \\
VR Focused Venture Capitalist & $\mathrm{C} 5$ \\
\hline
\end{tabular}


Figure 9 - Summary of Method

Issue: How can Theme Parks implement VR and AR into attractions to make them more compelling than in home VR and AR experiences?

\section{Literature Review:}

Conducted primary research and attended conferences related to theme parks and VR/AR

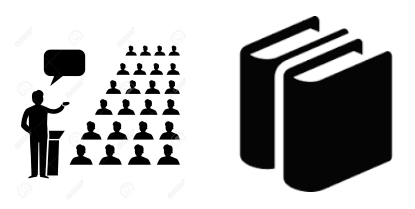

Initial search suggested several factors might be most important to study further:

1. Theme Park Attraction Design 2. Economics of Theme Parks

3. Psychology of Entertainment 4. Mechanics of VR/AR Experiences

5. VR/AR Projections

6. Related Industy Analysis

\section{Method:}

Interview recruitment used a snowball approach to identify and approach subject matter experts in:

VR/AR Experts (in Tech and Gaming)

Themed Park

Attraction

Manufacturers and Operators
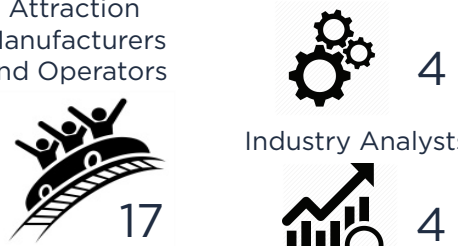

Industry Analysts

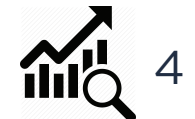

Global study included visits to related businesses and conferences in the following geographic locations:

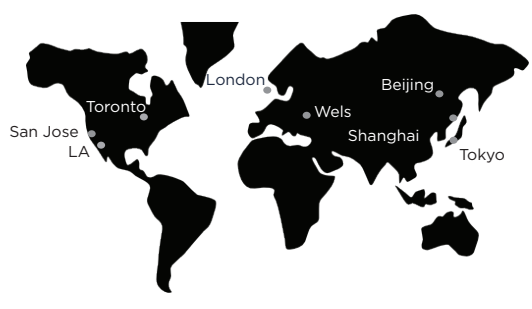

Conducted, Recorded and Analysed Interviews

Results:
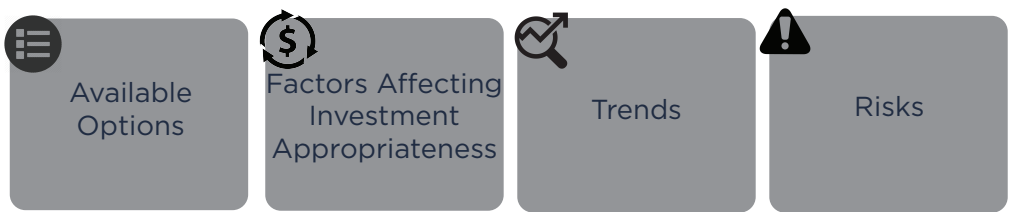


\section{Results}

All interviews validated the hypothesis that three key themes govern the decision making of most top Theme Park and VR/AR stakeholders. While the strategies of the various "Theme Park Attraction Manufacturers and Operators" may vary based on their experiences, backgrounds and business strategies that they have pursued over the past years, certain factors are concrete factors which affect everyone involved in the VR/AR attraction industry. These include common requirements such as achieving robustness, safety, managing throughput, quality of display and sanitation. As the interviewees alluded to a variety of VR, AR and MR Theme Park projects, considerations of what designers and executives found to be important varies project by project. The following sections go into more depth of what some of those considerations and opinions are within technological future of Theme Parks.

\subsection{Mechanics}

\subsubsection{VR HMD Based Rides}

When asked whether people thought VR Head Mounted Displays were appropriate to use in attractions, it led to a mix of responses. While on the one hand people expressed positivity around the innovative VR coaster strategy, ultimately there are a lot of issues that makes using them in the park a big challenge. As a result, many people thought that Attraction Designers should not get caught up in the hype surrounding VR coasters and invest in a "passing fad". As the headsets improve in quality, people expressed optimism for HMDs to improve experiences across the various ride categories that currently exist including roller coasters, simulators, pirate ships, entertainment robots and AGVs. Additionally, nearly all respondents expressed the most excitement about the potential to eventually use AR Headsets in the park, believing the current VR HMDs to be a migratory step towards an AR based future. This is due to things such as increasing social elements,

- "The whole [Leading Attraction Vendor] VR Coaster system is the beginning of something because it can turn an old steel coaster into a new concept. Take something like [Leading European Theme Park], stick a couple of Samsung's on it and you've got a brand new ride. A ten-year-old ride that you were thinking of pulling out, you've totally given it a new lease of life. Especially with the financial crush that's on them. Not all of them have deep pockets to keep buying new roller coaster every couple of years" -C2 
- "One of the troubles with VR and Theme Parks still, even though technological advances have made it more practical (tracking systems work better, they're lighter, more comfortable, its cheaper so from a price point it can make sense), there is still a throughput issue with virtual reality experiences in Theme parks. It (throughput) is going to be the limiting factor" $-\mathrm{B} 4$

- The advances in VR technology certainly has opened up some great opportunities in terms of the quality of the displays and the cost of the displays. It gives you a price performance that really makes it attractive for us to explore using it in the parks. There's still tons of issues that need to be figured out before we can realistically use them in the parks. It's still difficult for people to get in and out of these devices, keeping them clean and operating and all that kind of stuff is very labour intensive. But the fact that they don't cost $\$ 30,000$ a pop anymore certainly makes it more economically viable. But we have to do a lot of modification to these devices to make them robust and useful in theme park settings" - A9

- "You have a sensor which is a very sensitive inertial measurement unit. That sensor would be able to do positional tracking. That sensor could either be mounted on the person's body, if that person's body was in a fixed position, which it often is in a roller coaster or it could be mounted on the craft itself. As the sensor follows the track, what its doing is it's always following the same pattern. So as the coaster moves, it is always giving the same set of readings. What it allows us to do is to identify different stages along the path with different spikes in data that allow us to process the data in real time and compare it to a recorded version that we've filtered and smoothed out. So by comparing the master guide path to the real time readings of the sensor, we can know we're in a particular position on the track." A6

- 'In September 2014, Gear VR was announced and that's when we started to develop [VR Coaster Management System]. We were testing by Christmas 2015 at [Leading European Theme Park]. In March 2015 we did a demonstration day and the client, the CEO of [Leading Theme Park Operator] got off and said, "That's the future." So we were immediately commissioned to start the project" -A6

- "It doesn't have to be a roller coaster, it could be a roller coaster, a pirate ship, an AGV (preprogrammed), simulator or entertainment robot. In that range there, you're looking at the majority of Theme Park attractions" - A6 
- The question isn't whether putting VR on coasters is a good idea or not. It seems it's probably not the world's greatest idea. If the roller coaster is so intense, then why aren't you just leaving the experience to be without VR? We kind of agree with that, to tell you the truth. Keep your sensational thrill rides clean, don't bother with adding VR. The ones that aren't drawing big numbers. This refreshes and reboots a very expensive capital expenditure of a roller coaster" - A5

- "Currently of course there's hype because these devices are all coming to the consumer market. Everyone in the Attraction business are looking to integrate these things. You can achieve an immersive experience deeper than with a typical photo-oriented cinema display. Integrating these into an Attraction is not really practical. I think we need to continue to monitor this" -A7

- "Within certain types of attractions, VR HMDs are not only great but also economical. But if you try to do other types of attractions, VR HMD is kind of the most expensive, worst thing you can possibly do. So the answer is, it depends. In general, the current VR HMD is somewhat of a passing fad. In order to do anything cool with it, it requires a very expensive software backend and optical tracking system." - A4

- "We've got other things that are being looked at but VR hardware is still not well hardened for Theme Parks. For instance, I've already talked to a few people about how buggy the [Leading Location Based Entertainment] experience was the first week or two. They had times when they were just doing two people an hour. The equipment was overheating and you have problems. That's not to say anything against [Leading Location Based Entertainment Operator], whoever's equipment it was and the guys putting it together. It's just the nature of the state of the technology right now. Its still pretty challenging to get it hardened. Its not like a 3D movie in a RealD theater or IMAX theater, which is a very repeatable and solid experience." - A10

- "I think VR is a migration step. In one sense it will always exist because there is a reason creatively if your trying to create an experience or tell a story within an experience and you want the person to be isolated from their physical world, then you need VR. It's a step towards a bigger mass market thing which is Augmented Reality" - A10

- "One thing that I think is going to work is mixing VR and a performance model because it can be fun to watch people in VR. Say your going to have a thing where you put ten people 
in VR, watch them do some crazy experience and everyone in the audience gets to vote on what happens. For example, activating the monsters. Then you get this combination show and interactive experience that actually works pretty well in terms of throughput and also handles the fact that in the particular family, some will have particular interest in VR while others might have none at all. I think that is going to have success somewhere but it's not intuitive to most people" -B1

- "AR is eventually going to be massive in the Theme Park. I think you can do things that the [VR Coaster Companies] are doing but I think they're more looking at interactive elements in general and AR is probably a better longer term solution for them." - C4

- "We like them; they have a way to go in terms of being commercially viable. There's hygiene, throughput, making sure they're strong enough to put hundreds of thousands of people though an hour. Then there's the throughput expectations of an attraction and making sure that the business and economics work as well." -A12

\subsubsection{New Mechanics for VR}

Many respondents alluded to the possibility for VR to introduce mechanics which will increase fun and excitement within Media Based Attractions. As increasing amounts of creators experiment with consumer based VR experiences, new innovative mechanics will evolve in that medium which the Theme Park industry will likely be able to leverage. While some respondents expressed concern for VR as a good storytelling medium, many Theme Park attraction designers were positive that there will be a lot of opportunities to get innovative regarding their approach to mechanics of ride experiences leveraging VR.

- "I definitely think there will be new mechanics, new ways of story telling and new forms of interactivity. That is one of the big differences I see between this round of VR roller coasters versus the one in the 90s. Because the devices are so cheap and ubiquitous, so many more people can experiment with this technology. There are so many people sitting in their basements, garage, their dorm rooms who are playing with this technology, coming up with new games and experiences. I think there is going to be all kinds of exciting new stuff coming out." - A9

- "I think the ones that get it right, find the core mechanic that's really fun and run with it will make a name for themselves. You know, if you look at every major platform, King (leading 
mobile game developer) didn't exist before mobile, Zynga didn't exist before the iPhone. There is going to be a new game developer class that's going figure out what the core mechanics and just nail it." - A3

- 'The biggest thing we've learned I've noticed that people love is there's no learning curve to the Void, you just put on the equipment and do what you normally do so we capture a really wide demographic. We had some women go through who aren't gamers who said they would do it every day because it's just like looking at things and exploring these worlds that don't exist. It's cool to see peoples' eyes when they come out after realizing they were in a warehouse a second ago and now their in this new place where their walking around and finding stuff." - A2

- "What's not clear is whether or not VR is a great medium for telling stories. In other words, is it just TV on your face or does it really enhance the nature of storytelling? I don't think anyone has proven that they can make a really compelling narrative. We want that to be true and we're testing it but it's not clear to me that any one has really proven that out." - A10

- "It's a pleasing approach (in reference to some of the top Cinematic VR Experiences). The question is, are those standalone stories? At the end of the day, none of us compare that to The Hobbit or to Harry Potter or to Star Wars because there's so much more complexity and duration of time in those stories as compared to Henry, Allumette and Invasion. It's debatable as to whether some of these things are standalone stories or just experiences." A10

- "What the bottom line is you're adopting the imagination of the director. If you see the film first and then read the book, you'll be trapped in the view of the world that the director created and you may never be able to develop your own view. Where as if you read a book first, you have your own original view which is of course based on all your life experiences and visual experiences.” A10

- 'I think most of the theme park designers actually need to go and try VR, because there's a surprising amount of people who haven't even tried it yet. Certainly a lot of the Theme Park designers we know have not done a lot of VR themselves. So I think a lot of them need to start by learning about the medium and what works and what doesn't. I think that would be a good place for a lot of them to start." A12 
- "I think there are new genres that will evolve in VR and then other genres will pull over from film, from games. As an example, if you think about YouTube and the genres that came over from television you have TV shows, news, movies those all work well on YouTube and Netflix but new genres came into play that weren't possible before. One easy line to draw is that whenever there's motion in a VR experience, whether you're flying a spaceship or flying on the back of a dragon or driving a car, those are opportunities for arcades and theme parks to actually do it better than what you can do at home. I think those genres might migrate towards parks because for the physiological effects. The VR coaster could be something that could become more interactive. You know maybe I'm flying an X-Wing or a stunt pilot flying an airplane, whatever it might be.” A12

\subsubsection{Combining Mature Technologies for Attraction Success}

- "What we do in Theme Parks is we generally take all these things that we know work, and we kind of shuffle or restack them up. So where [Interactive Theater Based Experience] was a big hit for us this year and won for both the technology and the attraction at the THEAs, we were able to take so many different things that everyone likes like a 4D theater, an interactive character all these things that other people have been playing around with and shuffling them all together - creating a new attraction based on things that we already know we can do" - A1

\subsubsection{Augmented Reality is the Ultimate Goal for Theme Parks}

A continual theme that emerged from the interviews was that people were more excited about leveraging AR than VR. Participants alluded to concerns that it may be a while until the technology matures to a point where it can be used within Parks. The current generation of AR headmounts are widely seen as too large, complicated and not high quality enough to be used in Theme Parks today. As issues such as the narrow field of view, size and weight get worked on and fixed, AR headmounts will eventually be reconsidered for being used within Theme Parks. With so much creative potential within the AR medium, people were very excited to, one day, leverage the technology to transform attractions in the future.

- "Augmented reality has even bigger potential in the long run, but also in theme parks. There's a lot of things you do like augmenting rides or augmenting the whole park." - B4 
- “There's a lot of emperor's new clothes going on at the moment. Magic Leap has fantastic technology but it's 10-15 years away. And they’ve been telling everyone that it is going to be available next year. So we're going to have a situation exactly like Oculus where people promise big and deliver small. There is still a lot of snake oil going in in the VR/AR sector." $-\mathrm{C} 2$

- "Augmented Reality is not ready yet but it certainly offers some of the greatest potential for attractions going forward because there's just so many things you can do with AR that's difficult to do with VR." - A9

- "We're very, very excited about AR, I think it has the ultimate potential. At least AR that can quickly be converted to VR. So you want a headset that does both. There are some things that are coming online now that show potential but it's still a ways out. There's certainly a lot of challenges before we get there. There's optical challenges and fundamental optical laws and stuff like that, that will make it difficult to get something the size of a pair of glasses, in terms of something you can put in front of your eye that completely fills your field of view, that is not so restrictive in terms of where it sits relative to your eye. There's fundamental optical design challenges that make that difficult." - A9

- "In time, AR will be what they switch focus to. Theme parks are desperate for AR because it's a shared experience, more social; you can see your family around you having fun. Very few of them realize how far off it is. I think for a theme park, it's probably 10 years off." A6

- "I think Augmented Reality is really where the industry is headed. Virtual Reality is really a stepping stone. Augmented reality on a coaster will be really cool because you could have digitally overlaid things like a giant, ripping out the track from in front of you but still get all the great natural sensations that a roller coaster provides - like anticipation before a big drop." - A1

- “AR as a technology for me, I'm not sold on yet. Not meaning that it won't get there. I really think that it's got amazing potential and in the end VR will look more like AR than it does today. Today I feel like AR is too rudimentary a technology to be useful in a lot of ways." - A3 


\subsubsection{AR Field of View Concerns}

Though many respondents alluded to AR being a good fit for pairing with Theme Park attractions, the technology was widely believed to be immature currently. Based on experts' speculation, they believe AR Headsets may be available for pairing with attractions, however it's a ways off. Many respondents estimated it could be up to a decade or more before Theme Parks start introducing AR Rides.

- "While I am impressed with the tracking that our friends at Microsoft have achieved with the Hololens, the field of view, it's appalling. They got caught promising that you've got this vista view and you've got half of a postage stamp in front of you. You've got to constantly keep moving your head to see the rest of it." -C2

- "Until they figure that out, it's not going to really be worth anything to us." - A1

- "The problem with most of the devices out there is that field of view is still very small. So it's difficult to do an immersive experience when you have such a small field of view. You can't see all of the virtual character, you can't see all of the environment. You have to scan your head around to see the entire space. There's some systems that are video pass through HMDs that actually look very promising because they have a much wider field of view; 120degree field of view. The challenge with those systems is you have to deal with latency between the time the image is taken and the time it is displayed on the display." - A9

\subsubsection{Growth of 3D Projection Mapping}

Through most of the interviews, many respondents pointed to 3D projection mapped environments as a good solution within Theme Parks. Projection mapped environments provided a good solution which falls on the Virtual Reality spectrum but doesn't deal with the limiting issues associated with HMDs (such as problems with throughput, durability, cleanliness and safety).

- "I think 3D Projection Mapping is one of the coolest new innovations for Theme Parks.

Dropping people directly into a digital world without having to put on a headset, without having to get too wrapped up in the technology. That's the whole point of our sector, we try to hide the technology. We do anything we can do to increase the magic, and 3D projection mapping is pure magic." - $\mathrm{C} 2$ 
- "If we don't restrict ourselves to head-mounts, you will see that there is a lot of VR already happening like CAVEs and 4D style experiences. That's a form of virtual reality, it's not what people think of but it really is virtual reality. You take computer generated images, you're blending them with the real world. We can call that mixed reality. That stuff I think we're going to see a lot more of because the computing capabilities have gotten a lot better, projectors have gotten a lot better and all of that." - B4.

- "There are attractions that can provide similar vision to looking through a 360-degree device. For example, domes and flying theaters. This is a totally immersive display that is high resolution but you experience it within a group, not just as a single user which happens when you are using a headset." - A7

\subsubsection{Growth of Free Roam VR Experiences}

- "We have two major product offerings: the arcade product and the arena product. The arcade product uses a wireless PC streaming head-mounted display that we make ourselves. So it streams the video from a high powered PC straight to the user's head. Best tracking money can buy, 360 times a second, we track anything with passive markers on it. So you could put stickers on a basketball and track it, you could put them on your hands and track them. Or you can do what we do and put the marker balls on a head mounted display and a prop like a gun or a magic wand or something. From the ground up, it's a wireless experience. The arcade experience is two users at once and the arena system is scalable to up to twelve users at once. The arcade experience is $10 \mathrm{ft}$. by $10 \mathrm{ft}$. while the arena experience is $100 \mathrm{ft}$. by 100 ft." $-\mathrm{A} 3$

\subsubsection{Importance of Physicality for Enhancing Presence}

- "We augment the virtual with physical. Where augmented reality augments the physical world with virtual items we flop that. What's interesting is how that affects people in the environment. Depending on how long you are in the experience, you eventually forget that what you're seeing is actually not real." - A2

- "The important thing for us is to differentiate our theme park experience from what you can get in the home. People are going to get amazing experiences in their living room in virtual environments. How do we make the experience better in a theme park to make it worth 
people driving to theme parks? This will be doing what we're doing well, for example our strength in creating physical spaces. I think physical spaces augmented with virtual reality content is certainly a very exciting opportunity. Virtual worlds are paradoxically much more powerful, the more physical they are. So if you can reach out and touch a virtual object, then it becomes much more real, immersive and compelling." - A9

\subsubsection{Provide an Experience that can't be Achieved at Home}

Among respondents, a common mantra was continually referred to which governs strategic decision making within Theme Park development and location based entertainment communities, to provide an experience that cannot be achieved in the home.

- "The most important thing to remember with location based entertainment is the number one rule of location based entertainment; you've got to give people something that they can't get at home. Then you've got the question of, OK, people are going to have affordable high quality VR in their homes, what are we doing at the Theme Parks that is going to be different?" - B1

- "I think everyone we've talked to, especially on the theme park side, less on the arcade side. They understand how to stay ahead, how to differentiate themselves from anything you're ever going to get at home. That's their job. That's why they still exist. Theme Parks thrive because you're not going to have a roller coaster in your living room. Every theme park company interested in VR knows that they want to do something that's just 1000 square feet, they want to do the arena. They want to run around a space that you're not going to have in you're living room." - A3

- "Our biggest risk is that it's going to be stale in three weeks and somebody's going to have it in their living room in six months. Now you've spent \$200 million dollars on something that's not worth $\$ 20$. It may be state of the art when you put pencil to paper but three years later when you have finished development, it's already been surpassed. Instant and unplannable obsolescence is our biggest risk" -A11

- "The moment you say you are doing AR and start planning for space and capacity, sterilization of the machine, setting up the system and network so my monster pops out at this place. It takes us three years to build one of these attractions. In three years, that stuff is 
going to be totally changed. So we haven't even opened and we're going to be obsolete." A11

- "With our Theme Park partners, they have a range of experiences. Each experience or attraction may require completely different hardware. So we're not limiting ourselves to a single piece of hardware or any single type of attraction. What we're really trying to do is to figure out what's the best thing we can do with hardware that exists today? What would that experience look like a year from now with new hardware that's coming down the pipeline? We work with our partners to develop that roadmap of what's realistic today versus what should we build for a few years out. So we try to bring a strategy to the roadmap. Without that, you could spend a lot of money and time on something that just won't work. Something that's early or that won't meet the business requirements." $-\mathrm{A} 12$

- "One part is for location based entertainment, it's got to be something they can't get at home. Or something you won't be able to do at home a few years out. We have very good relationships with the hardware manufacturers, we've been working with them for 3-4 years now, closely, on their roadmap. So you need to make sure that what's coming down the pipe, won't remove the need to go on a park ride. Will people have motion systems in their home? Probably not. What are things you can do that are future proof? The second thing is that we also try to design rides and attractions and the tools and technology build towards a future hardware target date. The great thing about VR, is that its' the first time your going to be applying a software real time game engine to location based attractions." - A12

\subsubsection{Enhancing Experiences in Lines}

- "We're already seeing 3D projection mapping and gesture recognition being used in queue lines. I was at one line at a large theme park prototyping a game that's played in the cue line. They project onto the wall and you take part in a game. There were people staying in the cue line longer than to go into the attraction just so they could play the game. The interactive queue line is something you're going to see at every park." - C2

- The way virtual queuing works is, “you'll have a mobile phone app and say, I want to go on Big Thunder Mountain, it says the cue is 50 minutes, you go right, tell me when my virtual space in the queue has arrived. In a few minutes' time, you walk up to the queue line, you 
zap yourself in and you get straight on the ride. It kind of works like a buzzer at a restaurant." - $\mathrm{C} 2$

\subsubsection{Importance of Social}

The interviews backed up the assertion gathered from the literature review pointing to the importance of social elements for attractions and interactive rides. Though traditionally, roller coasters are not seen as social activities as the attraction is occurring, going forward, many respondents acknowledged the ability to leverage the social nature of VR to enhance and enable social interactions among groups.

- "If you're on a "hang on for your life" type ride, you're not focused on anyone else. It doesn't make it bad that it's not a shared experience because it will be shared as soon as you get off." - A1

- "From a technological perspective there's a lot of networking that needs to happen to be in a physical space with your three buddies and physically make it all work. So that when I reach out and touch you, I'm actually touching you. I think there's a lot of work to be done there. From a creative perspective we've got to figure that out. Because at theme parks today you're locked in a ride vehicle, you're not interacting with anybody. The question then becomes with VR, are there creative experiences that you can make to allow interactions in a group?"-A4

- "That's what we're focusing on in terms of how to make it a social experience. Because you want to be there with your friends and family. So we're looking at ways to bring in the people you're with into your virtual experience." - A9

- "At the time (mid 1990s), I was focused on multi-player networking and how do we manage networks to keep bandwidth down because those things were all a concern for large scale multi-user environments then. I think a lot of those problems fortunately have been worked on since then in things like, World of Warcraft and a lot of online games have been dealing with having chat, having latency and having people in shared spaces and all that kind of stuff. So we can leverage all that which is great." - B4

- "[Leading Free Roam VR Experience] is a social experience. Right from the very start, you go in so you experience the world together. You're dividing and conquering the world together. Each of the people are part of the story. We want people to be in this together. We 
saw a huge difference between solitary experiences and then when we started putting people together we've always wanted to be that way. Eventually we want our stages to be networked to each other so you can actually have ten people on a dimension stage and then ten over there and we can merge their gameplay. They can either be fighting each other or co-op playing something. Once we get the stages networked together, which we're closing in on, then we want to network our centers together. So we can have teams here playing teams in China just like video games now." - A2

- "We actually pioneered in the early days of VR at [Leading Global Entertainment Company] a patented networked, multi-rider VR experience. So from the get go, our work has always been very social in VR. So when we hear about VR being isolating, we have the opposite opinion in terms of the things we've built. They are very memorable experiences. Most of what we've seen out there is very single player based and I think that's where people pick up on the fact that VR is isolating. But in fact, we've found the opposite." -A12

\subsubsection{Managing Throughput}

A clear issue that was continually referred to when discussing VR HMD based rides was the issue that they limit the throughput that an attraction requires. While different attractions have different targets for throughput, in general, theme park attractions need to be able to get large amounts of people through the attraction per hour. HMDs were widely seen to disrupt this process. In order for HMDs to be successfully integrated into attractions, considerable efforts were required to make the process of getting through the attraction streamlined from an operational perspective. Some of the strategies different experience providers had for managing throughput are described below.

- $\quad$ "One of the troubles with VR and theme parks still, even though technological advances have made, is it needs to be more practical. For example, tracking systems work better, they're lighter, more comfortable, cheaper. From a price point, it can make sense, there is still a throughput issue with virtual reality experiences in theme parks. It is going to be limiting. If we don't restrict ourselves to head-mounts, you will see that there is a lot of VR already happening;. CAVEs, 4D style experiences." - B4

- "We were given a target of hitting a throughput of 900 an hour. That was a reduction of 200 an hour from what the coaster was doing before. So, it was doing about 1,100 an hour and 
they said we know it's going to be slower with headsets on. There's obviously more to do with loading and unloading. So they said they would accept a drop of 200. We achieved that. I think their best, at peak times has been about 950. It really depends a lot on the staffing they've got, how well they've got their operations managed." -A6

- "The key to what makes an attraction good and economic is high throughput. Getting as many people through the attraction in the shortest time. The VR headset disturbs that process totally." - A7

- "The thing we are looking at specifically here is how do we take VR technology and apply it to the business case of theme parks? For example, things like throughput. All the existing arena style experiences do not get throughput of attraction that we need. Typically, you're aiming for about 700 THrC." - A4

- "We have a couple different stage designs; one is called the [Name of VR Stage Design 1] which is larger. The one that we created for standalone experiences like [Leading Location Based VR Experience] is called [Name of VR Stage Design 2]. They actually have a looping method that we are trying to patent. Where the game actually controls groups of people, in [Leading Location Based VR Experience], we can have five groups of four in the system and basically the first group will move to the second position and put in another group. The game engine controls their position throughout the game. We know how long methodically people will spend in a certain area which totals about 10 minutes" - A2

- As a hypothetical example, when looking at a free roaming experience, the amount of hardware that is required to get that is unbelievable. You're normally trying to carry twice THrC, that means if you've got a 700 THrC, all of the sudden, you've got 1,400 minimum devices (Back-mounted PC, HMD etc.). You have a lot of money invested in that hardware. It's very easy to quickly get into a very, very expensive proposition. The second thing is VR head-mounted displays aren't available today, but tomorrow they will be! So you have to ask yourself, what are you delivering that is different from what an average consumer is able to get at home, because that will become a reality very soon." -A4

\subsubsection{Leveraging Haptic Technologies}

Several interviewees spoke about the importance of haptic feedback to increase the sense of presence in virtual environments. Though this has been used by Theme Parks for many years in 
things like 4D attractions and dark rides, as VR proliferates through Theme Parks, people believe that new haptic technologies will be able to be leveraged to impact the guest with all of their senses.

- 'In VR, its so much more immersive. If you suddenly turn a corner and there's a flaming lava stream and you get belted by a wave of heat, it's extraordinarily effective." - A5

- "The visual part of what we do is VR and everything else is hyper reality. [Name of Attraction Designer] is an illusionist and we actually have a version of [our experience] that we create for the blind. So we basically create a virtual experience for a blind person inside the [Leading Location Based Entertainment Experience]. That's how much the visuals actually play a part in the whole thing." - A2

- "The backpack computer is actually tied to our haptic vest, which has 22 points of feedback that are throughout the whole vest. There's five different types of vibration motors and transducers that actually create different kinds of effects. For the first time in Ghostbusters, it's completely directional. We programmed it so that when objects fly at you, they hit you in the appropriate place. If something explodes and your back is turned towards it, it explodes on the back. It's all dynamic. Our gun was built for VR specifically. It's wireless, has three different types of haptic feedback - force kickback and two other vibrational motors. So the gun can represent any weapon in the virtual space." - A2

\subsubsection{Safety}

- "Our HMD is designed as a helmet actually like a bike helmet. So if you take a hit or you bump into something, it doesn't smash into your face. So people sometimes look at our helmet and say that's kind of bulky, and it is compared to home VR but home VR (with a block that you strap to your face) has no safety considerations like that at all. If you walk into a wall, that thing will smash into your face." - A2

- 'Some people are still a bit uncomfortable being put in a virtual environment. So that's one issue. There's also the problem of cables. If you are talking about backpack or tethered cables, you've got to have an attendant there to make sure that they don't fall over. Because they can sue the living hell out of you if you break your nose or worse. Then you look at the hygiene issues. How do you clean this effectively? You want to avoid pink eye. If it's got slow latency, its going to make people sick or uncomfortable." - C2 


\subsubsection{Quality}

- "In VR a challenge is getting high quality. Finding solutions at the moment to getting the quality as high as it can be in the headsets." - A5

- 'It has to be good, simple as that. It can't be mediocre. That's an obvious statement I know, but you'd be surprised how many companies are just using the technology just for the sake of the technology rather than the experience. " $-\mathrm{C} 2$

\subsubsection{Sanitation}

Nearly all respondents acknowledged that sanitation needs to be managed when using head mounted displays in Theme Park attractions. With thousands of guests sharing headsets, transmittable diseases such as pink eye can quickly become a big issue if headsets are not properly cleaned. Cleaning the headsets is typically seen by respondents to be a labor intensive process which is in need of a streamlined solution if HMDs are to work within Theme Park attractions.

- "We custom designed a wipe-able head-mount for proper sanitation." -A6

- 'Designers need to think about hygiene, so the head-mount's don't get corroded and yucky and filled with bacteria. Having disposable things and cleanable things is great. If you have a cloth like thing that you wipe anywhere where a person is going to be touching the device. It needs to be streamlined." -B4

- "Since we make the hardware that the user actually wears and holds, we just make every component with hygiene in mind. We use closed foam. Consumer HMDs have a nice cushioned foam, that feels really nice but would absorb sweat into it. We make the headset with a closed foam so sweat will just bead off of it. Then it can be wiped off with alcohol between each user." - A3

- 'If an influential member of a party says I don't want to put that on my face, I don't want to get pink eye. And then all of a sudden you've got three or four people saying me too. That's a concern because if you have a theme park you don't want to have ten people walk in and only six people do the experience. You'll lose revenue." - A10 


\subsubsection{Robustness}

A key issue in allowing HMDs to be viable within attractions is making them very robust. Respondents spoke of the fact that Theme Parks are quite harsh environments. Head Mounted Displays, the tracking marker and props such as guns and wands can sometimes be quite delicate. Designers spoke of the critical importance of building things to be robust so that if they are dropped or bumped into a wall, they will still work. Additionally, designers pointed to the fact that HMDs needed to have modular components that could be swapped out if one component stopped working.

- "You've got to think about things like wear on the devices. It puts a lot of strain on the devices to take them on and off and that's not something you would do hundreds of times a day as with a home device. You've got to think about the toughness of the equipment" - B4

- “There's the maintenance reliability issues. Making sure the thing is actually working. If somebody puts it on and it's not obvious right away that the signal is coming through properly, that the image isn't messed up somehow or that it's even turned on. We've had people come for demonstrationss and one eye isn't working. People sometimes don't understand that it's not working properly, don't know how to articulate it or they're embarrassed to say something. And just how reliable these things are going to be in the parks because it's a pretty harsh environment. A lot of the time, they've got fragile tracking markers that could very easily be broken off, the second a six-year-old kid drops the head mount on the floor." - A9

- "We're getting up to 10,000 people a day through this so it needs to be pretty robust." -A6

- "We designed it to be waterproof, because at [Leading European Theme Park with a VR Coaster] they have a lot of rain. So this has to work in the rain a lot. So it's waterproof, its breathable, and all of the interior elements are wipe-able." - A6

- "Hardware designed for durability and throughput, these things that are on thousands of users' heads. Making sure they are clean and if they get dropped or mistreated, that they will still perform accurately. Trying to use really durable materials, trying to pad the important components. The electronics component of the Head Mount is by far the most protected by padding, so keeping that in mind as you design the hardware. Is this going to break if it drops? And then actually testing and doing actual drop tests is something we do. Asking, 
will this break? Which part will break? Which part do we need to pad more? Really thinking about it from the design stage from the ground up." - A3

- "The key thing is that we've built the cases that everything needs to be waterproof and as durable as possible. We're very careful to make sure that everything's got the right fixings and right amount of padding in it." - A6

\subsubsection{Personalization}

Several interviewees mentioned the potential for increased personalization, especially as attraction worlds become increasingly virtual. Some interviewees expressed that the effort is not currently worth it to personalize attractions. However, as technologies such as 3D scanning of people and personalized avatars mature, they may be able to be integrated into attractions in the future. People could be represented by a real scan of themselves or a modified character version of them that they have personally made and customized.

- "It makes a load of sense for them to do a custom version (for things like corporate events). I think what people miss is that to make the content personalized, depends how you're going to do it but if you want to give people a different experience. There's a load of content to do and that comes exponentially more expensive. It better be a pretty valuable person that you're doing that for." - A6

- "There are issues of avatar design, the kind of representation you want for yourself and your guest. There are some techniques where you're looking at green screen compositing sort of like a 2D video composite image of the people you're with in the virtual world. There's also volumetric capture which is about scanning a 3D model of the person in real time so that as they move around, you see a $3 \mathrm{D}$ representation of that person moving around in the virtual world. Microsoft Research has done this thing called Holo-portation which does some of those elements." - A9

- "Their called Theme Parks because of the concept of Theming. There will be places where it is totally customized, but when you've got a big ride like this you want people to think that the whole experience is themed so you get immersed in the environment. When looking at theme parks you're not going to be chopping and changing, you might develop a new version of the animation that's going through the planet and the stars, but everything else is in place, because it's quite costly." -A5 
- 'I think you're going to start seeing a little bit more of that. Every movie you see about VR, that's the first scene, the person's getting scanned in. I think it's going to be necessary. Eventually I'd love to be able to use actual scans of peoples faces and either show an avatar or their face" - A4

\subsubsection{Locomotion}

Several interviewees alluded to the fact that virtual based rides are typically significantly enhanced by motion. The key in successfully integrating motion is ensuring that motion doesn't give people simulation sickness. Some companies were most excited of the concept (brought up first in the literature review) of Composite Attractions within VR Attraction worlds. This would allow attractions to blend walk-throughs with sections where you also get on a motion vehicle. This would greatly enhance the feeling that someone is actually in a world, as they can achieve multiple types of motion in one attraction bolstering the sense of immersion into a world.

- 'Right now we say physical locomotion is best, that's why we're pushing towards the arena system and having users physically move around. I'm really wary of moving users without having them physically move because that's how you make people sick. If you have some sort of joystick navigation system, or a fly through, anything outside of their control, scientifically speaking, will make them sick." - A3

- "Ultimately you want to let people just walk around but if you're doing something for six hours straight you don't want to walk around all the time, you want to be able to fly, teleport." - A9

- "In [Out of Home VR Experience 1], we have a drop floor where we drop you about 6 inches but in Virtual Reality we drop you about $15 \mathrm{ft}$. and the one to one match is just good enough to make it feel as if you've just fell. So we're implementing all kinds of stuff like that on our stages. Also we have a track on [our experience] to build these self-controlled simulators that are not on rails. So you could be any type of vehicle and then those would merge with our walking around experiences. So we'll have these motion controlled simulators eventually, they'll merge together to where you're on a ground simulation and you'll be walking around and you'll be able to go to some helicopter thing and you'll be able to walk into a simulator and fly into a different planet and then hop out of the simulator and you'll be 
on a different planet. These transport methods are very important for us to make the worlds feel bigger than they are." - A2

- 'Our infinite hallway IP that we've patented is very important to our experience. It's a unique version of redirected walking because we use stage effects and physical walls that map one to one with the redirected walking. So on our full stage it has a full infinite circle that goes all the way around and you have rooms and a hall system inside the circle. So basically you can go down a straight street, into a building through the whole building and out the back door, down another straight street into a new building, out the side door, down another straight street. You could rebuild New York City inside of a $60 \mathrm{ft}$. area or any scaled place. You could walk forever in a straight line for days if you wanted to. " - A2

- "As the technology improves, screen technology, chips whatever else. This could be rerendered at a higher quality when the systems can achieve it. We're not stuck, we think we'll be able to move along quicker than the real time people as we go forward. That solution isn't just better now, but better going forward." -A5

- 'We've tried pretty much every tracking system that you can imagine, with the two big things that we're looking for being: accuracy and speed. There's really no compromise for that. Cost-wise, we were going after the best system money could buy. We wanted the most accurate system for tracking multiple users in a large space and the fastest way we could compute where that user is and transmit it into that user's head. That's the key, limiting that latency completely eliminates motion sickness. If your tracking the user accurately in the space and the content is designed in a way that you're never high-jacking the user's view, it's always their movement one to one that's being represented in their headset, you will not get sick." - A3

\subsubsection{Complexity of Development}

- "The tricky thing here is that you're developing something that is very, very complicated. So you have 150 heavyweight PCs running this thing, on a motion base. It's a complex thing to do and complex to have all of these people having exactly the same experience at exactly the same point in time, without the gear breaking down. Its beyond complicated at so many levels. You can only finally develop it once all the motion has been sorted out, once the engineering is in place. It is a very brave undertaking." -A5 
- 'The biggest hurdles have been in the hardware technology. Creating commercially viable hardware. Dealing with hardware and creating the best visual experience. That combination is really tough. But we've conquered it now. It's all about refining and getting our equipment online so we can drop the price." - A2

\subsubsection{Complexity of Operation}

- "With any VR system, there has to be a higher reliance on personnel. Park staff have to get involved because you can't just leave these things to run themselves. If you've got the right number of staff, they're well trained, then you'll have a better result. But it also needs to be the right system." - A6

- "We developed a touch screen that has every seat on the craft and it's telling you information on battery life, if something needs to be re-oriented, how many milliamps have been drained from each battery from each phone, temperature of the phone." - A6

- "Making sure that they're easy to operate and easy to fix when something goes wrong. Easy to swap out components when certain ones break. After a certain amount of time, some cable may break and we have to be able to identify which one broke." - A3.

\subsubsection{Enhancing the Design Process with VR Pre-Visualization}

Though the interview format didn't specifically have a question for this, people often felt compelled to bring up the massively transformative impact that VR has in terms of its use as a design tool. By providing the ability to pre-visualize attractions, VR is very useful in making the design and development stages of a project more efficient and allowing for more experimentation and overall better final products. By enabling better communications between project teams, enabling faster delivery and cutting project costs, VR has compelling reasons to be leveraged during the design stage to enable better and more efficient working teams. As a result, respondents expressed excitement to continue using VR technologies to enhance their designs and improve the overall future projects that they work on.

- "It was the first ride fully designed in the Oculus. It sped our development timeline up from something that would have taken a year to about six months. It allows you to have your client see the ride from the ride view the entire time, where they couldn't do that before. You need to wait for a full-scale mockup or for it to be built. Only then, the client could say, "Ok, I 
like it, or can we change this?" The way we were doing this was we would send the Oculus to the client, we would be on our side, they would be on their side. We would both ride the ride on the Oculus simultaneously and be able to make notes. So we began to add all sorts of tools into that like laser pointers, controls for screen capture, all the show control, all of that we added into our custom Oculus pre-visualization App." - A1

- "As a tool, its great and fantastic for our business. It's going to revolutionize what we do and how we communicate our ideas to our clients and other people on the globally distributed, delivery team. Also, instead of waiting until the end and saying, oh boy I wish we did this, and undergoing really expensive changes, we're able to make changes on the fly."- A1

- "We still think CAVEs are very effective from an internal design perspective. The fact that multiple people can share the space, you can see each other, you can make eye contact, all of those things are very important for a designer. You can see what someone's looking at, you can see how they're reacting to it. The problem is, they're still really single person environments, they're very expensive, you need all the room, high quality projection systems and all that kind of stuff. You can give everyone a much more correct perspective much more affordably in a HMD than you can with a CAVE." - A9

\subsubsection{VR Game Design}

Respondents referred to the need for testing when creating future experiences in the VR medium. With such a new storytelling medium, concepts and experiences need to be prototyped and ran through user tests constantly in the design process to ensure they will work. Additionally many respondents stated the importance of having people with direct experience of working with VR to add to the project team. As there are so many lessons to be learned during design of VR experiences, having someone who has been through it before, is invaluable.

- "You've got to prototype everything because a lot of the things you think are going to work aren't." -B4

- "Since VR development is so challenging and so expensive in terms of trial and error. There's just so much error. Having someone on your team that has at least one VR title under their belt is probably crazy important because you'll avoid so many mistakes that they've already made. There are so many things that I wish I knew." -B3 
- "The most compelling thing I've found is that the company needs to have a background in gaming and have technical people there. To have someone who's working on hardware and someone who's great at storytelling. The things that I have enjoyed most are games period." $-\mathrm{C} 4$

- "I think a really big thing is, scale back your ambition. As a developer, you're going to want to do all this crazy stuff. Especially if you're working with partners like Theme Park owners or marketing people, they're going to have a lot of ideas. I think in VR, it's really sobering, that if you try to do something crazy and new, the user's just not going to get it. You're going to have to pick one thing and make it really good and make everything else really familiar because people are going to have a hell of a time figuring it out." $-\mathrm{B} 3$

\subsection{Content}

\subsubsection{Understandability}

The overriding need for understandability in VR/AR/MR attractions which was discovered initially through the literature reviewed was continually echoed in several interviews. It is very important in both interactive and passive experiences for narratives to be clear. Respondents stated that since the attractions are so immersive and overwhelming, guests are not able to digest complicated narrative. Additionally, if it is an interactive attraction, several designers referred to the fact that there isn't much of an opportunity for training or for people to figure out complicated interactions (such as puzzles). Interactive attractions need to be immediately understandable so people get in the attraction and get started with the fun.

- "One of the key things in a Theme Park experience is that it needs to be SUPER simple and clear. Don't try to overcomplicate things. The experience itself has to be easily understood because it's so overwhelming. In many cases you're on a motion platform that's shaking around and your trying hold yourself steady and make sure you don't bump into the people next to you. You've got a lot going on, so to expect people to be able to absorb a lot of complex story or dialogue is asking too much." -B4.

- "The games have to be incredibly intuitive, that's one of the biggest design constraints around designing for VR and especially out of home VR. Because of the high throughput, quick playtime of a three to five minute experience or even if it's ten to fifteen minutes, users have to be up and running with little tutorial playing the core game mechanic very quickly. 
Being able to design a very simple mechanic is important. You're not going to have a controller with twenty buttons on it, you're not going to have a complex situation and be able to teach users of varying demographics with a limited tutorial. Keeping them simple and nailing a simple mechanic is key. We have a lot of shooters now because everyone knows how to shoot a zombie. If you look at Wii Sports, the Kinect, PlayStation Move; some of the very simple games there were some of the most successful. I think that's what a lot of out of home VR is going to go after, at least in the beginning." - A3

- "Every time I think that something in VR is going to be intuitive to someone, it's just not. For example, in [Leading Consumer Based VR Game], you have to find a key and put the key in the gate. On a PC, that would be such a basic mundane mechanic. Like this doesn't take any brain energy. But it's really hard for people in VR because many of them it's their first time in VR, so they're already overwhelmed. So they're looking all around, feel like their potential is endless. When you give people a linear narrative and tell them where to go, people just follow along but VR inherently is non-linear. So it's very important to make it basic. It can't be basic enough." - B3

- "Once people start shooting at a screen, people do not remember. They go through the Justice League attraction and they don't remember what happened. Who were the main characters? They don't remember any of that because they narrowly focused in on the fact that they've got to shoot this stuff. That's not a theme park ride. You're kind of missing the story points." - A4

\subsubsection{Attractions need to be Repeatable}

- There should be richness throughout the environment. Don't cut out the details. This is what makes it revisit able, and exciting again and again." - B4

\subsubsection{Pre-Rendered vs. Interactive Experiences}

A significant area where many companies seemed to be investing time and energy was the push to real time interactive media. Though people had different opinions on how to do this best, a lot of companies have recently been focused on offering shooting games. As more experimentation happens, new genres and concepts may emerge. With new innovations and better real time game engines being used to support VR/AR/MR rides, interactivity will be more 
possible than in the past. Attraction designers will need to leverage their creativity to push interactivity past shooting games. With access to real time media and real time motion, there will likely be a surge of new interactive rides being introduced in the coming years leveraging new innovations such as branched content. This will allow people to have more agency within theme parks meaning their actions will be able to affect outcomes within the digital/physical world.

- "To me, putting a 360 video in VR is like putting a picture on a TV. You can do that, but you're not taking full advantage of the medium. If I can't see things, if I can't move around, I don't feel like I'm in VR. There will be people that want those passive, film-like experiences and there will be emotional things where you can be there and you can be lazy. There's always going to be a market for that kind of thing. There's also going to be a market for full body, immersive, engaged experience." -B4

- "For many years, the theme park industry had never really been a big fan of interactivity. There are various reasons including; difficulty to execute, expensive, not proven and it's too much like video game." -C2

- "We think it's important and one of our goals is to give our guests more sense of agency, ability to control and interact with their world and have that world respond to them and focus on them and give them individualized experience. They don't want to just be pulled along on an experience. They want to change the experience. That of course is very difficult but still something we think that is important." - A9

- "Our focus is shifting to interactive and real time media. There has been a big push in the industry going away from pre-rendered media (i.e. pre-rendered simulations) towards real time media. If you are talking about a true VR experience, not one where you're locked into the experience, but where you are giving the guest some level of control and agency in the VR world, you have to switch away from pre-rendered to real time. That is the bet that we have made on the industry. It's actually a very good example of what our company does that makes us very different from the rest of the industry." - A4

- "We are looking at branched content. So you can manipulate how the story unfolds. A big interest area for me is not just real time graphics but real time motion. Not only does your action have effects on your ride vehicle but you can affect ride vehicles. We're talking to a ride manufacturer right now who has real time motion." -A4 
- "The reason why you do digital media; one its changeable and two, its manipulable.

Changeable means I can do tweaks, for example a PG version of an attraction during the day, then a more adult version that can play as it gets later at night. About five years ago, the industry said, "Kids love video games, so we should do interactive in the industry." However, they completely missed the point of why video games are popular. Video games are not popular because you can shoot at a screen. There's a lot of AGV vehicle rides with shooting involved with them now where you do it once, do it twice and then ask why am I shooting at stuff? It's because they missed the point. Videogames are not popular because their interactive, they're popular because of the concept of player agency. You as the player can have actions that affect the digital world. That's what makes it fun" -A4

- "Everyone always wants rides with multiple paths in one attraction and it always gets cut. It's usually a budgetary concern. So I think we need to always push for that and hope that little bits get through. The problem is that it's simply a cost issue. Every additional path you make costs money to build. I think we will see more of it as the cost to produce these things comes down. Especially the more virtual it is, the easier it is to develop that." - B4

- "Genre-wise, I think we're trying to hit across the board. That we're trying to be accessible by a wide variety of demographics, we want to have a rich content library that different arcades and theme parks can choose between so that it's not all little kid games, not all horror games, not all for core gamers that want to be maximizing their score." - A3

- "I think good shooting games are kind of a natural slam dunk because you don't have to move around much. So I would think we're going to see a lot of turret based shooters particularly with theme parks. Because I don't need to explain a bunch to you to get you into a shooter, it's just point and shoot. Puzzles don't work in a theme park, anything with puzzle solving is probably right out. Flying around and navigation isn't a very good idea, people will try it but it will be a bad idea. We'll see some of that but it will be short lived because generally it'll make people kind of sick. I think horror and games with jump scares will be popular in theme parks. I also think 4D films will be popular because you'll be able to supplement them with all kinds of things, to make it a more interesting experience. And because so many theme parks make a big deal about their Halloween experience. Someone will probably make a bunch of money out of some kind of 4D, jump, scare, VR experience 
that can go into a theme park that can be there for a couple months then pop out again. Trailer oriented, with throughput in mind." -B1

- "Traditionally one of the reasons that most theme park rides have not been interactive has been practicality and technology limitations. What we're seeing right now is that more and more new generation Dark Rides are interactive from the beginning. Nothing to do with VR but just due to changing consumer habits that they're more leaning on being an interactive component because guests are demanding it. I don't see that trend slowing down. I don't think you will see a "choose your own adventure" on a rollercoaster. When you're hurling someone around at 60 miles an hour, they're ability to make rational choices is impaired. Trying to force them to make actual analytical decisions while you're hurling them down a track at that kind of speed, I have yet to see that to be fun. Like we've seen VR coasters where you shoot at targets and stuff, that's fine, that's fun, but trying to make a decision about what a character's saying if you have like four seconds before the track moves again, it's going to be a while until somebody cracks that." A13

- "When you build an experience or an attraction and you try to decide whether it should be interactive or non-interactive, you really have got to design it so that the visitor understands what's expected of them. If its unclear, we've learned through a lot of trial and error that it needs to be clear what the ride is going to be interactive or what the expectations are so that people aren't disappointed when they try to interact in a non-interactive ride. Or say they want a passive experience, they want to sit and chill and now they're being asked to interact. You have to make sure that you align the expectations before somebody gets into the experience." $-\mathrm{A} 12$

\subsubsection{Requirement for Good Storytelling in VR/AR/MR Attractions}

- "A good attraction is based on a good story. You can have the best technology, but if the story is bad it won't work. So story telling is the key point. When this is done well, the technology supports it and makes it more unique." -A7

- 'It's story telling, but storytelling in a very constrained environment as to what can and can't be said. Theme Parks have to do something that is not achievable at home or in the smaller centers. It's absolutely the first things they must do. How can you use VR in such a way that 
it is such a sensational experience, and it could not be experienced at home, in an FEC or an Arcade?" - A5

- "The challenge of meshing CG worlds and synthesized characters, making them sit nicely together and be credible enough for dramatic narrative in VR is where we are. Storytelling works on shots and cuts. The cut being the most powerful storytelling device in the world in my view. Cutting is an enormously powerful device for storytelling and VR doesn't really have that. So what can you do that is going to be powerful in VR? I think people are still looking to tell you the truth." - A5

\subsubsection{Branded Content vs. Custom Content}

While most respondents acknowledged the business benefits of using branded content, respondents also stated that custom designed attractions can be just as impactful. Benefits of using branded content which were mentioned include: ability to draw crowds, ability to leverage previously spent marketing funds, increased ability to sell merchandise and less need to provide context. While most respondents indicated they were excited to continue working with big brands in Theme Parks to create blockbuster attractions, most also enjoyed the possibility to create attractions using custom designed content. With custom designed content, it can be just as "magical" if the designer ensures they are providing the right amount of background and context to ensure the storytelling narrative is clear and impactful.

- "Branded is king at the moment. You benefit from all of all the money invested in the IP already. The problem is that you can be lazy and come up with formulaic approaches to the rides. For non-branded rides, the jury is still out because we don't have a lot of Interactive Dark Rides out there." -C2

- "I think the new experience that I don't know, something that I'm discovering and have never seen before. I think it can be something that is really magical. You can have just as great experience in an unbranded experience like The Haunted Mansion that was just created out of thin air as a new experience. I think people may get burnt out on a collection of brands. For example, if I'm at a theme park and I'm going to X, Y, Z branded ride, ride, ride, as a collection of brands, you kind of want to go to a theme park to experience something new. Plus, you have to worry about shelf life with branded content." - A1 
- "What makes unbranded content rides difficult is that you have to learn the entire story before the ride. Where am I? Who am I? What am I doing here? You've got to tell a lot of story." - A1

- "When looking at branded content against unbranded content, the pendulum swings all the time. There's a race to get all branded content, because its easier to market, people know the characters and you come in and knowing the story so you don't have to learn that." - A1

- About Harry Potter World, "Rowling wanted it to really reflect the films, so she demanded that the art team who worked on the films stayed and did the Theme Parks. It was a game changer for big parks. It increased the level of quality you need to achieve to draw people." - A5

- "Partnering with the right content developers for example triple A studios making well known branded games, making really high polished theme park experiences, pioneering some of the stuff. We are very interested in Branded IP; Hollywood is getting very interested in VR. All of the major movie franchises want a VR experience. Any sci-fi movie or show you can think of, there's somebody figuring out how to do it in VR." - A3

- "I think branded content's going to be huge. I'm starting to work with a couple of IP's. After reaching out to some companies, I am seeing a really favorable response to VR. I can't believe how much everyone wants their brand in a VR experience. I haven't talked to anyone who said they're going to wait until they see if VR is going to be successful or not." B3

- "We really want to capture some amazing IP from the studios that are out there willing to work with us. They are super excited to bring those worlds to the general population. To actually go inside those worlds. Watching [Leading Movie with Out of Home VR Experience] then going across the street and being a [Character from the Movie] across the street is pretty epic. When we create our own IP, we'll be creating worlds that are specific to our environment so we think our IP will be really impactful. So we'll get people in the door with recognizable IP and then when they ask what else they can do, things like [Custom Out of Home VR Experience 1] and [Custom Out of Home VR Experience 1] and they'll get to try that too." - A2

- "The VR Experience, based off a movie scene; is that something we can monetize? We don't know. Is it so compelling that people would pay to have this experience or does it 
because something like bonus content. Stuff that you put on a disc when you sell a blue ray and the consumer largely expects it to be there and to be free. No one thinks they should need to pay for it." - A10

- "At the end of the day, the consumer is saying, why should I take this headset put it on and do VR? There's got to be some compelling reason that makes it right and only able to be done in VR. If I get the same story experience watching a TV or on my phone or iPad, then why would I put on a VR headset? Not just that it's better in VR. It has to be that it needs to live in VR." - A10

- "Branded Content will help VR break into the mainstream. What will happen will be the same thing that always happens, just like how we just saw with Pokemon Go. Pokemon Go came out and people suddenly thought it was such a great idea for a game. People have been playing these games for ten years, but finally,ff the games have gotten kind of mature and someone put branded content on one of the mature game structures and now it's in the mass market. We'll see the same thing, very little branded content to start, then once some of it gets more successful, someone will take a gamble with their brand. I suspect by Christmas 2017, to see a significant amount of Branded Content begin to appear for VR" - B1

- "We love branded content; we love making custom content. We have a history of working with branded content with some of the biggest properties from Hollywood. We have an appreciation for how that helps the business side. Also on competing in the marketplace. The right brand can make a big difference. We also have an appreciation for building new content. Especially when you come to new mediums. There's an opportunity to establish new brands with new technology in a way that is harder once the market matures more. The nice thing is that we have a range of experience doing branded to non-branded content. Most of our customers have huge branded IP that we're working with. They have their challenges and they have their benefits." $-\mathrm{A} 12$

\subsubsection{VR Show Experiences}

- "For example, put people in VR on a stage, watch them do some crazy experience and everyone in the audience gets to vote on what happens, for example, activating the monsters. Then you get this combination show and interactive experience that actually works pretty well in terms of throughput and also handles the fact that in the particular family, some will 
have particular interest in VR while others might have none at all. I think that is going to have success somewhere but it's not intuitive to most people" (Schell, Personal communication, 2016).

- "We are excited about enhancing the spectator experience. Its really fun to watch someone play our games when your standing in front of them and see them flail in front of a zombie that's trying to claw them to death, cast magic spells. You can look silly, but its fun to watch the side by side and see what the user is doing. Taking that beyond the onsite activity. For example, spectating at home, spectating on Twitch, spectating on mobile, in VR on the consumer platforms. That's something we are looking to push forward and pioneer. But also maybe you design your character, or maybe you design mini-games. A completely different experience but you're earning credits towards the next time you come to the arcade. For example, you've unlocked the new shotgun or added a power up to your assault rifle, your character maybe has a special hat. We want to be able to drive people into the arcade at home." - A3

\subsubsection{Transmedia Experiences}

Respondents were excited to extend the Theme Park experience outside the park by using cross platform content to interact with guests where ever they are. By taking advantage of the fact that consumers are now more mobile and connected, some attraction designers expressed the importance for engagement of audiences before, during and after their park experience. By using concepts from video gaming such as customizing characters and experiences, attraction designers though there would be some convergence of online processes such as gaming and offline experiences such as riding an attraction.

- "We are driven by the audience. Most kids now have access to at least 4 or 5 screens. When they watch television, they've got a mobile phone or a laptop and they're doing stuff while they're watching TV. So we have to give them that level of engagement when they come to our facilities. So that means agency, repeat visitation and cross platform content. You start at home playing the game, you then take your high score and your ranking to the theme park. You rank up even more while you're at the park, you go home and you carry on when you've left off and you come back again when you've accrued. A lot of companies are frightened by 
that. That's one of the reasons Electronic Arts and Nintendo are joining the theme Park industry." $-\mathrm{C} 2$

- 'Our business model is really unique and there's not many people in the market like us. We want to create VR Experience Centers in locations all across the world. And those locations will all connect to each other. If you parallel a movie theater model, we're basically doing the exact same thing. We want to create the new IMAX experience for Virtual Reality. So you can have your at home VR, in fact we want to support at home VR because a lot of our experiences will kind of move into the home VR area too. So you can actually go to [Leading Out of Home VR Experience Center], go home and play and then come back to [the center] with new items. We want to provide the best Hyper Reality experience possible while lowering the upfront cost for the consumer." - A2

- "Before you actually go to a [Out of Home VR] experience, you can download our app. At [Leading Out of Home VR Experience] I can actually click on my ticket and customize my character. Our app is a lot like a travel app, so it's a lot like getting on an airplane. You have a boarding pass and then you can adjust your avatar that you will enter the world as. You can be a male or female. You're a dimensional traveler and as that you can earn XP and credits when you go to these load outs you have options for your character. In the future I'll be able to buy different types of suits or hats inside the app. Or I can play mini-games to get those items." - A2

- "I think VSports are possible. For video games to turn into sports takes a long, long time. Think about how long it was in between the development of Warcraft and Warcraft becoming an eSport. It's kind of a long, slow path and one of the problems with it happening in VR is because it's so physical, there are ways you can cheat it with the controllers right now. If you've ever watched anyone playing Wii, people are using the controllers in ways that the designer didn't intend. I think we're going to need to wait for these things to mature a bit before we see any kind of eSports anybody cares about. I don't know how long that will take, because I'm having a hard time figuring out how stable VR will need to be before a real sport shows up. My guess is that it's at least five years away, maybe more." - B1 


\subsubsection{Transferable Innovation in Military VR/AR Technology}

- "There is some of the good AR stuff that we are seeing in the military simulation industry that I am expecting to see in the Theme Park sector. Especially the single field of view units, the ones that sit over one eye and allow you to see the rest of the world and receive telemetry information. A bit like terminator. I think you're going to be seeing that in Laser Tag very soon." - C2

\subsection{Economics}

\subsubsection{Cost of Personnel}

Some respondents warned of a sometimes overlooked cost item which is of critical importance when designing a Theme Park attraction - cost of personel. When considering an attraction that requires Head Mounted Displays and a lot of complicated networked hardware and software, there is a higher requirement for ongoing maintenance and management to ensure smooth running operations. As a result of this increased need for personel, the profitability of the attraction goes down. Developers stressed that it can still work, however it is better to strategize how to set up the systems in place which require the need for many attendants. Where possible, streamlining of operational processes is imperative to cut the labour costs associated with a VR/AR/MR attraction.

- "One of the things that was a little unexpected to us was how much the parks judge the viability of a project based on the ongoing cost of personnel. It sounds kind of obvious when you say it but it's a really big deal. For instance, we originally designed the system to have batteries that would be taken off the ride and charged up. The process of taking 84 headsets off the ride and putting them in a charger overnight was completely unacceptable to them because it would take too many people, too much time and that time isn't time that customers are paying for. So that wasn't an option. We actually worked with the engineering team there to create a custom charging system so that at night they would hit one button and the whole thing goes on charge. In the morning they hit another button and it goes off charge. That's it. So from their perspective, they would rather put the money into getting that charging system built in the beginning, rather than have someone go around every night and do that work." - A6 
- "You need more operators ensuring that people are using the display correctly. Especially when it's tethered it's much more complicated." - A7

- "The new content has to be coming out every year and big changes to the technology needs to happen every three years" - A5

- "We will adapt to anything, whatever we can get our hands on, whatever we can create for our JV partners. We want to update the equipment on an 18-month cycle at the least. So you'll always have the best and latest technology available at our centers." - A2

\subsubsection{Development Cost}

While some respondents were positive about the fact that costs have dropped for head mounted displays since the nineteen nineties, other respondents mentioned when you factor in the total cost of peripheral gear required to create a VR attraction, it adds up quickly to an "expensive proposition."

- "As long as it's justified, the checkbook has to remain open on the client side. As long as they understand the complexity of the project they're going for. You give what you think is the price to do it, but there are so many variables, in terms of the fact that the technology's never been used in this way before, issues dealing with other vendors and scheduling issues. The client has to have contingency going into something that is a handmade, one off, never done before project. If the brief changes, inevitably so does the price." - A5

- "If they want a project that they can claim on television is the newest, the best, never been done before; it better be true, and if that is the case, it comes with a lot of challenges. If you have a change of brief, there's no way you can do it for the same price. It's not possible."A5

- 'It doesn't matter if they've taken a guess that this thing will cost X million dollars but it doesn't matter if its $\$ 23$ million dollars. It matters to them because they'll have to fiddle with their books and change what their plans for a strategy are. But it doesn't matter if actually, it's massively successful. If you bring it in perfectly on budget but it's crap, no one cares and it'll lose money." - A5

- "I know they (Major Theme Park) signed an open ended cheque. Then Lehman Brothers went bust. I speculate they probably wouldn't have gone ahead if they knew that was coming. They thought people were going to stop travelling to theme parks on aircrafts. They 
thought with everything going bust, people were only going to be able to afford food and toilet paper. However, they ended having eleven and a half hour queues first day and it's gone on and on and on. Now they've built a second park, same thing." -A5

- "Our core technology platform is the tracking system, a high powered gaming PC with our content, the wireless HMD and a simple prop. That core system, is far, far better than anything else out there. Compared to any experience you can get at home, compared to any VR system I've tried, we can do more right there in the "out of home" space with that core system. It's not cheap, the tracking system being the costly component because of its speed and accuracy, but right there, being able to build out a content library, I think is going to get us really far. We're not going to stop there, we're experimenting with environmental effects, custom content, hardware integrated, rumbling floors, if customers want that, its stuff we are looking to be able to support." - A3

- "I bought the add on ticket in advance. So when I got there, I knew I wanted to do it and I already had my ticket. The norm is that you are supposed to pay additional money on top of the overall park experience for this specific experience. That kind of an up-sell model is a hard sell if it's mom and dad and two kids and they start thinking about how much more do we have to pay to have this ten to fifteen minute experience? Without a good idea of what they're getting, they may shy away from it. The technology is interesting. There's definitely a novelty effect to it. Early days, but it's interesting." - A10

\subsubsection{Location Based Entertainment Growth}

With the growth of the overall VR industry, Location Based Entertainment has become a significant area of investment for several companies. Based on the state of new consumer VR headsets and the ability to provide an experience for people to experience quality VR, on a rental basis, "out of home" is increasingly seeming like a good value proposition. As more Location Based Entertainment venues open around the world in places like Theme Parks, theater complexes, Arcades, FECs and dedicated locations, partnerships were referred to as an accelerator to growth for companies operating in this space.

- "Location Based Entertainment is one of the fastest growing sectors in the VR space."-C5

- "We're not selling our systems directly to most of the arcades and theme parks, we're selling through distributors that have established relationships with FECs and Theme Parks." -A3 
- "The way our business model works is that we have joint venture partners that actually have the locations. We're going to build a few locations ourselves but for the most part, these next couple of years, we're going to be working with joint venture partners, theme parks, theater chains, people that own big retail facilities, for example malls that have lost their anchors. Those are the types of places we would go in and retrofit our system. The Void's business model is to create the technology and then lease the equipment and provide the experiences to the JV partner that runs the actual location." - A2

\subsubsection{Location Based Entertainment Barriers}

While more and more Location Based Entertainment open up, significant challenges need to be overcome in order to make it a sustainable business model. Some examples of the challenges that were referred to include: need for throughput, high development costs, high staffing costs and obsolescence risk.

- "The main thing they can offer is touchable environments and tactile experiences. The problem of things like [Leading Out of Home VR Experience Provider] is whether they're actually feasible from a business perspective. One of the things theme parks care about the most is the ratio between number of guests per hour and square footage of an attraction. How many guests can I push through per hour, per square foot. Ultimately what they really care about is, how financially feasible is this thing? The problem of putting a VR attraction into a theme park is it's very expensive upfront costs. Usually one of the costs that people don't think about is the number of park attendants that it takes the attraction per guest. With the ratio of attendants to guests goes up. Staffing costs go up dramatically, development costs go up dramatically and in terms of square footage, to make it interesting, you need a lot of square footage. It takes a lot of time for people to get in and get comfortable. The finances often start to not line up. Also, what's new and cool now, three years from now will be stale and old. If you're not careful, you fall into that area. There will be a lot of short term Theme Park pop-ups where people can spend five bucks to try it. But that's a very short lived business model." -B1

- "I think the original plan with Disney Quest, was to roll them out all around the world in every major city. It was a similar story to what [Leading Out of Home VR Experience Provider] is thinking about now. After I worked at Disney, I worked at Sony Development 
and Metreon was our first big project. After that, we did Mediage in Tokyo. There was a big push towards Location Based Entertainment with companies like Disney and Sony doing it. But then that whole market crashed because the economy was having trouble when the Dot Com bust happened. Spending was dropping all over the place. The real estate market was troubled so it caused a real problem for these kind of Location Based things. Also, this was also based on Silicon Graphics so it was very expensive. There had to be a lot of people with disposable income willing to spend money to be able to justify the business case. So they cancelled the plans to roll that out worldwide." - B4

\subsubsection{Growth in Asia}

Many interview participants pointed to their growth objectives within the Asian Market. With so many Theme Parks currently being developed there in response to the growing middle class and massive population, there seemed to be huge opportunity within the Asian market. Many respondents stated that the Chinese market is very attracted to new technology and entertainment experiences. In response to this growing demand, several companies mentioned the fact that they are focusing a large portion of their resources to satisfy that need.

- "The Asian Market is massive but can be tricky. We are looking with different people there to partner with for content development and hardware solutions." - A5

- 'I think there's tremendous opportunity, if you look worldwide, there's a lot more theme parks being built in China, their building theme parks in almost every major city." - B4

- "Well China is shaping up to be a major leader with their technology. America is going to play catch up and then Europe is going to play catch up. UAE is a very big player because they've got so many big Theme Park projects and they have a highly sophisticated audience and they need to have the best." -C2

- "Chinas a major growth market for us especially over the next six months" $-\mathrm{A} 3$

- "Where we're seeing people being a little bit less risk averse is in new markets like China and the Middle East. Also, the mid market; for example, interactive FECs which are not expensive, so there's not that much of a financial risk, there's a lot of new technology going into those because people are much more willing to experiment." -A4

- "So far, I think the Chinese market is the most important VR market in the world. Based on analysis, China shows much more attraction to VR, much more than other countries. So far, 
[Leading HMD Manufacturer] only has two headquarters, one is in China, the other is called Global. So you see, China is very important. Young people in China are attracted to new technology. Most importantly, they want to buy." - A8

- "Do you know how many companies we have in China? Hardware? Content? There's thousands. When looking at headset manufacturers in China, there's over 100. So big market, big competition." - A8

- "The new Theme Park markets like China and the Middle East are far more willing to experiment with new technologies and concepts." - A4

- "With our theme Park partner in China, there's 23 million people we're going to bring VR to. We're excited about that and to learn from that. So I think what we're most excited about is giving people their first introduction to VR in a really fun and friendly way." A12

\subsubsection{Talent Shortage}

- "We could scale up to take on almost any new opportunity but not immediately. So if you look at a two to three year timeline, which is the type of timeline for one of these companies to put it into their CAPEX budgets, we could be handling anything that people give us, but building teams up that can do this efficiently and scaling up is the hardest thing of all because, they're not out there. We have to find them, put them together and motivate them. Some of this stuff is hard to do, you have to work nights when the coaster isn't working. Building those teams is one of the greatest challenges." - A5

\subsubsection{VR Industry Growth Drivers and Barriers}

Nearly all interviews touched on the growing VR market in general. When asked what people made of the media buzz, most respondents stated they agreed that eventually the market will grow as big as analysts believe but it will take time. Nearly all interviewees saw big potential in leveraging virtual technologies to improve experiences within Theme Parks. Due to all the large technology companies investing in the space, people were open to incorporating VR technologies into Theme Parks and excited about future innovation for the overall industry.

- "I think it's important to note that while we think the VR industry is going to be sizeable by 2020 , it's not going to be massive. So if you combine the gaming, video, TV markets 
together, in terms of the overall entertainment market, VR will be $2 \%$ of that by 2020 . So sizeable in monetary terms, but in the wider picture, it's still going to be very niche." $-\mathrm{C} 1$

- "Adoption of Virtual Reality will be fairly revolutionary, but that's the problem; it's revolutionary. It requires a change in mindset, it requires a real change in how thought processes and decisions are made in order to fully adopt it and make the most of it." -C1

- 'It's clear that the consumer price points are there, even if its not 2016 mass adoption, it's coming soon, and for Location Based Entertainment kinds of applications, it's now. The price points are a lot more reasonable than they were when we were trying to do Disney Quest and Metreon. It's clear that there are big opportunities to do cool stuff now."-B4

- "In my opinion Theme Parks need to think big. With technology changing so quickly, Theme Parks have to face up to that." - A5

- "When looking at which technology companies have the most Head Mounted Display Patents it is Apple closely followed by, Google, closely followed by Microsoft." -C2

- "Will VR replace theme parks? My answer to that is I hope not. Why would I want to go to a theme park and just have a VR headset on all day? To me, even as a VR evangelist, I don't want to go to a theme park that's just VR. I want to go to a theme park that might have some VR that's used in a really clever way, that I couldn't experience at home, because I want to see that, but then I want to get on the scariest coasters, go through unique experiences and see beautiful, unique theming that makes me feel like I'm on a movie set. I want to experience things I can't do at home and VR could be a really brilliant addition to the toolbox of tricks." - A6

- "I think it could be the ultimate entertainment experience in terms of unlocking untold numbers of fantastic worlds that we can immerse our guests in and our company is lucky because we have some of the world's best IP to play with in terms characters and worlds. We have so much to play with and the worlds that people want to go and visit. I think the world will be totally changed much faster than we can believe because I think there is so much opportunity here."- A9

- "Two years ago, IAAPA (International Association of Amusement Parks and Attractions) only had four Virtual Reality attractions. Last year they had about fifteen, this year they're going to have about fifty." - $\mathrm{C} 1$ 
- 'It's a multi-year road map. So if you're planning for three years from now, you can imagine based on the last year's evolution of the hardware, it's progressed pretty dramatically, so I think it's only going to get better. If Oculus was the only player in the market today and no one else entered the market, then I would be pretty worried, but because Sony, HTC, Apple, Microsoft, Google, Magic Leap, ODG we could go on and on, there's a ton of money pouring into the hardware side of things. So the real question is not if, but when, and I think when could be a couple years, could be five, who knows. So I think it's a good sign that the headset will become commercially viable sooner than later."-A12

- "Some parks have very much been seeing VR/MR as the future. It's easy to bring VR into rides, tomorrow with MR and VR, the world might become a Theme Park. I think Them Park operators need to embrace the fact that this technology is going to change the way we experience our real world and they need to stay one step ahead of that. So we have found some partners embracing that, like our Chinese partnership with Songcheng. We need to invest so that we don't find ourselves a few years from now where people stop coming to Them Parks, because the in home experience is that much more amazing." - A12

The following table illustrates and organizes all of interview responses related to drivers and barriers to the growth of the VR industry. This is important to consider because economic success of the industry will help to dictate how quickly innovation will occur within the VR industry. This will affect the Theme Park industry in terms of the types of products and components that they can leverage within their Attractions. 
Table 11 -Drivers and Barriers for the VR Industry

\begin{tabular}{|c|c|}
\hline Drivers & Barriers \\
\hline $\begin{array}{l}\text { - The Consumer Experience particularly at } \\
\text { the high end. As more people physically } \\
\text { try a cool experience, they will become } \\
\text { more likely to want to buy it and join and } \\
\text { support the ecosystem } \\
\text { - Companies want new revenue streams as } \\
\text { - } \text { Borld becomes more competitive } \\
\text { Big entertainment companies Licensing } \\
\text { their IP } \\
\text { - Big technology companies investing in the } \\
\text { space } \\
\text { Venture Capital investing money into the } \\
\text { space }\end{array}$ & 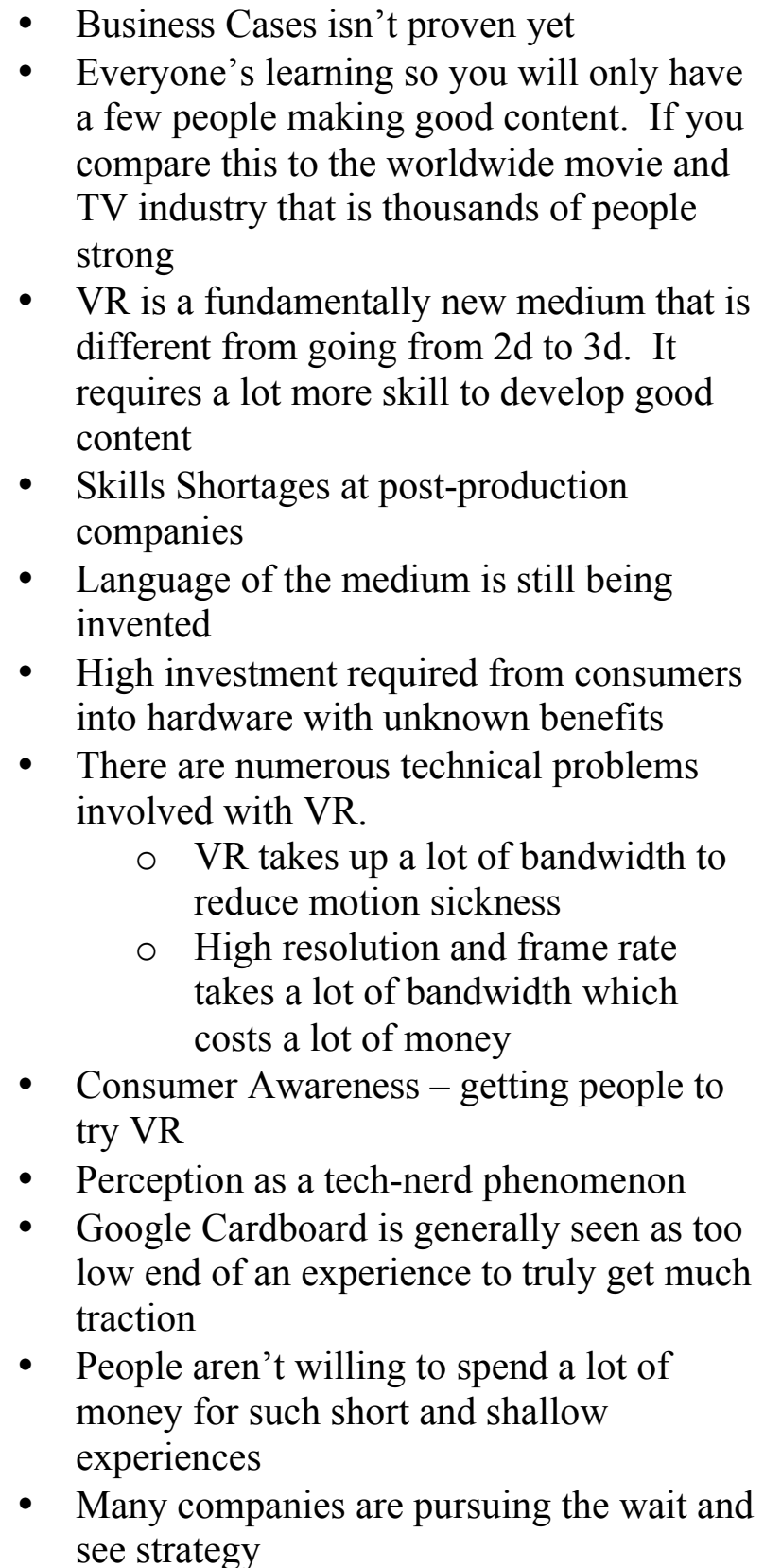 \\
\hline
\end{tabular}




\section{Discussion}

Theme Parks are constantly looking for ways to ensure they are providing their guests the best experience possible. A big part of this is giving customers something they can't get at home. That is especially important to remember when considering implementing a VR/AR/MR Theme Park attractions. The interviews and research consistently pointed to a robust outlook for VR/AR/MR in Theme Parks. Based upon the dynamic cross section of VR/AR/MR experts interviewed, this technology is a platform worth extensive investigation for Theme Park operators. Theme Parks are pursuing innovative strategies with their attraction investments in VR. Within any Theme Park attraction mix, there are ample opportunities for VR/AR/MR technologies to transport guests to new worlds. Whether that is done physically, digitally or a mix depends on the creative intent of the new Attraction or Land. Every one of the Theme Park attraction providers interviewed is aggressively pursuing their own strategy for bringing these technologies to market and addressing this opportunity.

\subsection{Attraction Investment Methodology}

The Attraction Investment Methodology (AIM) will help Theme Park operators guide their investment decisions in relation to introducing virtual reality into their Theme Parks. AIM has three considerations that need to be effectively integrated; the mechanics of the attraction, the attraction's content and the overall attraction economics. When these three elements are effectively integrated, the guest experience is optimized and that is what the ultimate AIM is for any Theme Park operator.

When considering VR or attractions, content, mechanics and economics must all be considered concurrently for the ultimate success of a project. Missing just one circle could mean the failure of a project. For example, if only economics and mechanics are looked at, the attraction will lack marketability. Not involving a sound content strategy could detract from the pull factor required from an "out of home" VR/AR attraction. Not considering mechanics enough could lead to an undifferentiated experience that could easily be copied at other parks or in the home. Not creating a strong business case would likely result in a weak ROI on the project.

Due to the importance of content, I developed a new methodology for Theme Park operators to follow when creating their content strategies across the entire lifecycle of the guest 
experience. This methodology includes the following stages; Attraction, Engagement, Empowerment and Extension.

When analysing mechanics, current trends in the industry and to assess what we can expect in the future. If a VR based attraction can be copied at home, then it will likely not be able to differentiate itself from the rapidly innovating consumer market. As a result, it will fail to sustain people's attention and in the end will cut away at long term viability of the attraction. In this paper, the breadth of different attraction types is considered when providing specific predictions for the future along the various categories of different ride system types.

Within the Attraction budget analysis, economic considerations such as attraction feasibility, revenue sources for theme park operators, risks and revenue strategies were considered. As with any investment in a technologically intensive attraction, there are many risks that need to be assessed. Risks must be associated with a mitigation strategy especially when implementing a VR/AR/MR attraction.

Figure 10 - Attraction Investment Model (AIM)

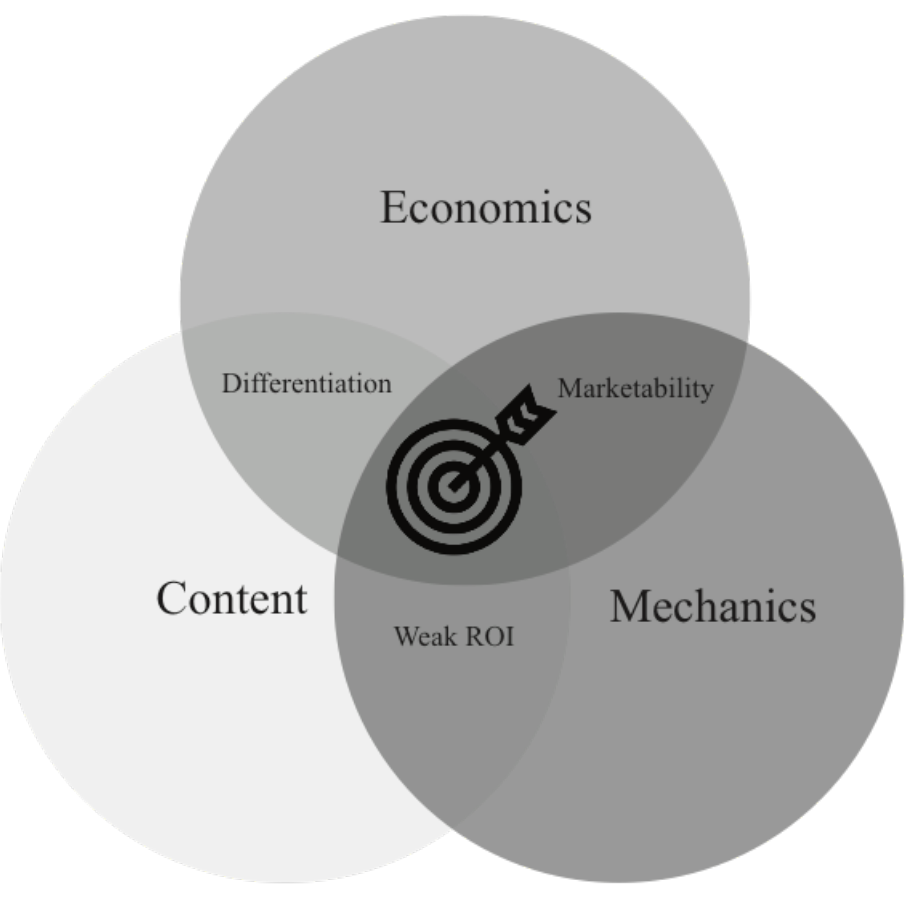




\subsection{Content}

Having high quality content is a critical element of a successful Media Based Attraction. As Theme Parks increasingly rely on incorporating story into their attractions, several elements need to be considered to optimize the guest experience across many points along the content lifecycle. This section shows how VR/AR Attraction content can be used to attract, engage, empower and extend the guest experience.

\subsubsection{Attract}

Theme Park's need to be able to draw people out of their homes into their parks. This comes down to having an incredibly fun and differentiated experience that cannot be achieved in the home. Due to the constantly plugged in nature of society through social web based technologies, a Theme Park's reputation is paramount. As a result, they need to always have a keen focus on key elements such as providing a safe, clean, high throughput and robust attraction that won't break down. Most importantly though, their reputation needs to be absolutely tied to fun.

Theme Parks should be leveraging the grassroots and trans-medial nature of the internet to ensure that people understand what they're known for, and that people know can't get that sort of experience anywhere else. A media conglomerate's properties often include video games, TV, movies, web, social, mobile and Theme Parks. It is important to ensure all of these mediums are telling an integrated story where people are actually being pulled to the Theme parks to continue to being a part of that story.

\subsubsection{Engage}

Once people are at the parks, they need to be part of a very engaging and fun experience. Through a variety of interesting theming and fun attractions (some passive, some interactive), a guest should always be satisfied and delighted by their decision to have come to the Theme Park.

Virtual, Augmented and Mixed Reality can be used as enabling technologies that bring interesting themes, stories, characters and worlds to life. When creating a VR/AR/MR attraction, it is critical that it is unique, fun and broad in it's appeal. Ensuring that there are lots of interesting details will add to a ride's repeatability, that should be a top goal for attraction designers. Another key is for attractions to have a good excitement curves which progressively peak more and more of the guest's interest but still have small opportunities for people to relax (Schell, 2014). 
Many new rides should offer guests agency to influence what the outcome of the experience is. In these cases, attraction designers will need to ensure that the narrative structures are very understandable and that there are clear expectations of what is expected from the guests. In conjunction with agency, increased personalization can add to a guest's enjoyment of an experience, if done tastefully. Though the jury is still out on what types of interactivity works within attractions, literature suggests that some key elements which lead to increased levels of fun include; making experiences social, immersive and involving meaningful challenges (Lazzaro, 2004).

Waiting in lines can be enhanced with technologies such as MR and AR. When many people think of Theme Parks, they think of lines. Creating games that people can play in lines help them to perceive the weight times to be shorter. If a guest is entertained the whole way through a line, this can greatly enhance the overall experience. Ways this can be done is through an interactive game, mobile game, illusion (AR, Holographs) then the going to the main experience. Though this can be an expensive proposition, it adds to the experience and can ensure increased customer satisfaction.

\subsubsection{Empower}

A content strategy will enable people to do things in the park that they can't do anywhere else in the world. Thanks to immersive technologies such as VR/AR/MR, people are now more able to achieve the impossible, fulfill their wildest dreams and become a part of a magical world. Good content will be able to do all these things.

By introducing "gamification" to the overall park experience in the form of things like scavenger hunts or AR mobile games, people can be empowered to feel like they're a bigger part of the overall story and experience at a Theme Park. Allowing people to level up throughout the day and attempt to hold peoples' interest in a fractal interest curve will ensure that people are progressively more and more interested in the next part of their theme park experience (Schell, 2014).

Immersing people in detail rich environments is key to making people feel like they are truly a part of a story world. Harry Potter changed the game from a content perspective within the themed entertainment industry. With characters that are such good role models, parents will invest in the quirky merchandise to aid in their children's wish fulfillment. By selling items such 
as interactive wands that can activate physical "magical" things around the park, it seems like a smart way of empowering people to participate in the story. Theme Park companies will be on the lookout for similar worlds to engage their people in and hopefully get them participating. As can be seen with Disney's investment in the Star Wars IP at their parks, the trend of empowering people to become part of story worlds seems to be continuing.

\subsubsection{Extend}

A refreshed marketing strategy for a Theme Park would need to take into account the changed communications landscape that society now operates within. While many Theme Parks operate extensive integrated marketing strategies, it is important to ensure that customers are engaged and empowered to join the conversation or be a part of the world.

Theme Parks need to leverage their media assets to get people online engaged before, during and after their Theme Park experiences. They should be leveraging more grassroots type communities to become a part of their brand story.

In the new world of cross platform content, world building presents a great opportunity. With audiences encountering new worlds, through movies, videogames and on the internet; VR and theme parks present an opportunity for people to visit and become a part of these worlds. That is why video game companies like Ubisoft and Nintendo are now getting increasingly involved in the world of Theme Parks by licensing their IP.

As can be seen in the success of Pokemon Go, people love being part of a conversation. People want to post things online, photoshop a joke or meme or even participate in large, shared cross platform experiences. These people should be leveraged as brand ambassadors or connectors that share the Theme Park's brand story. As long as something doesn't feel overly corporate but more like a grassroots viral movement, it can have huge impacts and mean financial success for a media franchise.

Theme Parks and media companies, to some extent, can try to control these conversations but in many ways, the people now have more power than they did in the mass media age. For example, currently, if someone has a bad experience at a park, they are now more than happy to tweet about it or share it with their Facebook friends, thereby influencing that group to think twice before coming to the park. On the other hand, if Theme Parks work to create stories, games or engage their people, they are now better able to connect to people than they ever have 
been in the past. That is why Theme Parks must now involve their customers in their stories and make them feel as if they are a part of it. This sense of agency will result in refreshed interest in people coming to parks and a more engaged audience base.

\subsection{Mechanics}

\subsubsection{Overview}

Mechanics are a critical point which Theme Parks need to consider carefully. As with any Location Based Entertainment, the golden rule is that you need to provide guests an experience they can't get at home today or even a few years from now. That means attraction designers designing VR/AR/MR attractions, need to ask themselves, is this attraction future proof? Based on the interviews, ways to differentiate from what can be achieved in the home include: combining physical spaces with digital elements, using motion bases but most importantly, focus on making the experience fun to ensure it's a sustainable attraction within the overall attraction mix. Attraction designers chasing the latest and greatest technology may be missing the point. Attraction design is about hiding the technology. As one interviewee mentioned, "it's about taking technology and finding some way to misuse it. Some areas where companies have seen the greatest success is by taking a bunch of mature technologies and stacking them up in an innovative way that they know will work.

Attractions need to meet lots of base level requirements just to be considered possible. For example, things such as safety, sanitation, throughput, durability, operational cost (of added employees), and latency must all be conquered in the quest to create a viable attraction. These sorts of operational challenges only compound the complexity of designing a good attraction when you consider that it also needs to be fun.

Though there is lots of opportunity for VR/AR/MR to transform the rides of the future, by no means is it a simple challenge to overcome. As questions such $\mathrm{s}$ what type of interactivity to offer, should the ride use Virtual, Augmented or Mixed Reality or none at all? The likelihood that Theme Parks will continue to experiment with these technologies (based on interview responses) is high. 


\subsubsection{Ride Types that could be Enhanced with $V R / A R / M R$}

Theme Park Attraction mechanics vary based on the type of attraction. Theme Parks strive for a balanced, variety of attractions in their total portfolio of attractions all making up the "attraction mix" (Younger, 2016). There is a wide variety of opportunities to leverage VR, AR or MR to enhance various Attractions in the future. The attraction categories that seem to have the most potential to leverage VR/AR/MR for overall success include: Dark Rides, Composite Attractions, Competition Rides, Excursion Rides, Thrill Rides and Transportation Attractions.

Dark Rides allow attraction designers to be very creative in terms of the experience they can give to guests. While trying to immerse guests within a "movie world", attraction designers have different motion bases, set scenic, lighting, special effects and audio at their disposal when designing these types of attractions. Going forward, Mixed Reality and Augmented Reality will be best suited to transform this type of attraction.

Like a Dark Ride on steroids, Composite Attractions are great because they are not constrained to one experience. Similar to Dark Rides, the best technology that is suited to this attraction is likely Mixed Reality technology, currently and augmented reality technology, once it is more mature. However, as you can have multiple experiences in one larger format attraction, this may be able to encompass something that feels more like a movie or a video game as they can offer a few different types of motion within one experience (for example, a car chase scene and a flying scene).

Competition rides are gaining in popularity after various successful installations around the world. The trend will likely continue as this ride has been seen by many to be a "slam dunk" attraction within Theme Parks. By mixing social, with immersion into a new world and involving interesting challenges these attractions can often be very fun and repeatable (Lazzaro, 2004). Currently, these are using a lot of mixed reality screens, motion bases and blending digital elements with physical elements for success.

Excursion Rides and Thrill Rides also have a potential to be transformed by VR/AR/MR. These types of technologies would most likely need to be done within an indoor or darker attraction to work however, these sorts of technology would be cool to add a potential illusion layer overtop of a physical space. Media content (whether it is in a VR headset, mix of 3D projection mapped screens or AR headset in the future) can add a whole new layer of excitement to a story that can be manipulable and changeable over the lifespan of the attraction. Similarly, 
thrill rides can use media content to provide physical or psychological effects over top of an attraction experience.

\subsubsection{Ride Systems Most Likely to be matched VR/AR/MR Technologies}

Among the different attraction systems including; Roller Coasters, Tracked Rides, Trackless Rides, Show Attractions, Alternative Attractions, Flat Rides, and Water Attractions, it is clear that various immersive technologies can enhance the various types of attractions.

Many parks have been piloting the concept of VR Coasters. While certain aging and more gentle roller coasters have been successfully fitted with current generation VR technology. It will be interesting to see what the future will bring in terms of adding improved VR technology or AR technology to rides.

Tracked Rides (indoor or outdoor) may see an increase in VR/AR/MR influence as people increasingly enjoy being immersed story worlds. Based on many interviews, Virtual and Mixed Reality can currently be paired with these types of rides successfully but Augmented Reality headsets are not at a level of maturity to be implemented at present. Many interviewees were most excited about mixed reality due to it's ability to blend $3 \mathrm{D}$ projection mapped screens with physically built worlds.

Accompanying the shift from pre-rendered to real-time media, Automated Guided Vehicles are helping to support a more interactive experience in Theme Park rides. Ultimately AGVs will help enable true interactivity in Theme Park attractions as they finally enable nonlinear experiences that can be altered by the inputs provided by guests. Motion, Haptic, Audio and Visual feedback will eventually all be operating in a real time manner, synchronously outputting information dynamically as the attraction is operated. This may take the form of either Virtual, Augmented or Mixed Reality.

Production Attractions can leverage HMD's and green screen technology to create new live interactive experiences. This type of situation could incorporate real time green screen technology with motion capture technology. For example, if a person uses VR in a green screen environment, they can experience the experience through a headset, while the audience could experience, or view it on an adjacent screen and vote on what happens to the participants. HTC Vive has been demonstrating some of these sorts of use cases online but it would be cool to bring it to a live audience through a Theme Park (Engadget, 2016a). 
With the novelty of VR and all the hype surrounding it, Alternative Attractions will likely be a big trend going forward. Augmented Reality Games and Pop-Up VR experiences will likely continue to come to Theme Parks over the next few years. Regarding AR games, there have already been quite a few successful games launched to the market typically in the form of Scavenger Hunts. In one example, people can hold up RFID cards that show something on a screen and directs the people to the next stop. Another example is a game where guests can purchase a Wand that can trigger different things to happen around a park when they push a button on the device (i.e. a golf ball appearing that they need to take somewhere, or a volcano exploding, or something cool that could happen on a screen) (Younger, 2016).

Based on the fact that so few people have actually tried VR currently, it is likely that within the next couple of years, we may see VR companies demonstrating their technology at Theme Parks to expose people to some of the experiences they have been creating. Though these may not be long-standing attractions, it is likely that they will still get attention and interest from guests.

Though uncommon, some flat rides attempt to tie in elements of story. In some cases, flat rides are even put inside, with its machinery disguised. This creates opportunities to use mixed reality technology to tie the kinetic motion to some kind of narrative. Much like Dark Rides, Water Attractions often move through indoor sets and can be augmented with Mixed Reality Screens. Additionally, they could leverage AR technology or VR technology though VR technology. An interesting use of VR technology is the Finding Nemo Submarine Voyage where guests see a virtual underwater scene through a circular LCD screen simulating a circular window on a submarine.

Some attractions categories might not experience as much impact from new AR and VR technology. By adding VR or AR elements to these, you would take away the best parts of being on these rides in the first place (i.e. ability to look around at your surroundings, seeing the reactions of the people you came with and enjoying the visceral sensation of the motion in combination with looking around the natural surroundings). The specific amount of virtual or augmented content that a ride may warrant would vary on a case by case basis depending on things such as the designer's creative intent and overall budget. With that being said, as the technology improves and things like Augmented Reality blur the line between physical and 
virtual, it is hard to rule out any category of Attraction Type altogether from being influenced by AR or VR technologies in the future.

\subsection{Economics}

\subsubsection{Theme Park Economics}

Theme Parks need to be profitable to be sustainable. Theme parks need to ensure high levels of per capita spending to ensure a successful business. Attractions can help bring new revenue to the park by increasing admissions, amount spent on retail, food and beverage and through sponsorships (Younger, 2016).

"A popular new theme can increase per capita spending, as in the case of The Wizarding

World of Harry Potter - Hogsmeade, where its major success was not only the creative excellence of the design, but that it increased per capita spending enormously as people desired to purchase butter beer, wands, cloaks, house scarves, chocolate frogs, and numerous other merchandise unique to the park combined with the unique experience of shopping in the Hogsmeade stores. Some estimates put the spending at over $\$ 100$ per person; a rise of somewhere around 200\%" (Younger, 2016).

Net new attractions of any kind (VR/AR/MR or other) should be tied to a revenue strategy including: increasing number of visitors, increasing per capita spending, increasing the length of peoples' visit, increasing their frequency of visitation and through cannibalization (Younger, 2016).

Designing technologically enabled attractions is an inherently risky process. The main risks to consider and map out mitigation strategies against include: strategic risk, compliance risk, operational risk, financial risk, reputational risk and obsolescence risk. With so many risks to consider, clear plans must be made to ensure that any new undertaking has been looked at from many internal and external angles. The risk of doing nothing may in fact be the risk of all because in that case, a park will undoubtedly be come stale. Ultimately facing negative word-ofmouth, switching, loss of sales, declining market share and potential bankruptcy (Boshoff, 2006).

Location Based Entertainment has been growing considerably over the past year. With companies such as The Void, VRCade and Zero Latency projected to grow their businesses considerably over the next few years, it is likely that many people will finally get to experience high-end, Out of Home VR experiences. While it is very positive for the industry that more and 
more people will try VR in these high-end settings, the interviews pointed to several challenges that Location Based Entertainment operators will have to overcome. These include the ongoing cost of personnel to run the systems, the high development cost of the systems and the uneconomical ratio of number of guests per hour and the square footage of an attraction. Challenges like these will need to be addressed in order to experience the growth many are hoping for within these businesses.

The interviews continued to point to high expectations from the Chinese market. With a growing middle class and massive population, it seems likely that these markets will continue to grow, however, will the reality live up to people's expectations from businesses?

In conclusion, though there are increasing levels of hype surrounding the resurgence of consumer based VR, it is important for Theme Parks to not get caught up in that hype. With large companies such as Sony, HTC, Microsoft, Google, Magic Leap and Apple entering the VR/AR markets it seems likely that the industry will continue to experience growth. However, it is important that Theme Park owners and attraction designers to not base their decisions on that hype. Instead, their decisions should be based off of how they can develop the most interesting, fun and profitable attractions possible that have sustainable drawing power. 


\section{Conclusions and Recommendation}

The purpose of this thesis was to determine the global impact that Virtual and Augmented Reality will have on the Theme Park industry globally. To address this question, an extensive literature review was conducted as well as global interviews with industry leading experts from the Theme Park industry, Theme Park suppliers, consultants and industry analysts in Europe, North America and Asia Pacific, the three global markets that represent 90 percent of the industry (TEA \& Aecom, 2015).

Based on the common themes which became apparent during the literature review stage, the importance of attraction mechanics, content and economics became clear. As a result, the Attraction Investment Methodology (AIM) was developed to help Theme Park operators guide their investment decisions in relation to introducing virtual reality into their Theme Parks. The mechanics of the attraction, the attraction's content and the overall attraction economics are the three elements that must effectively be integrated, thereby optimizing the guest experience. That is what the ultimate AIM is for any Theme Park owner.

Through all the interviews and research, it became abundantly clear that "content is king" when it comes to successful application of VR/AR in Theme Park attractions. With many different options available for theming the critical area of importance in VR/AR attractions becomes the ability to conduct story telling which should ultimately bring characters and worlds to life. Attractions need clearly mapped out and upwards progressing Interest Curves. One theme that continuously emerged from the interviews was how important it is to make things understandable in VR/AR/MR attractions. Additionally, in order to unlock fun, four keys should be simultaneously focused on including; making attractions social, producing internal sensations of excitement and relief, creating meaningful challenges and immersing people into interesting worlds. Though the interviews both pointed to how powerful Branded IP can be from a business standpoint, many respondents felt that an equally compelling attraction can be delivered using custom content. Many respondents businesses were leveraging the fact that the customers' interactions can always be on whether they're at a Theme Park or not. As a result, content needs to be integrated and connected across the various available channels including mobile, web, video games, movies and TV. These findings were all integrated into the AIM model which proposes that content needs to cycle through the following stages: Attract, Engage, Empower and Extend. 
Mechanics were another critical theme that needs to be carefully thought out when considering a VR/AR/MR attraction. The key point is that Theme Park industry will need to provide better entertainment experiences than people will be able to get at home. To stay ahead of the home market, Theme Parks will need to use their proven ability to maximize physical spaces in addition to augmenting theme with digital content. If the description of what constitutes VR widens from just Head Mounted Displays, there are lots of solutions already proven to work in Theme Parks. Mixed Reality will likely continue to grow and the focus areas will become offering interactivity, delivering repeatable rides and creating interesting experiences. The interviews continually pointed to the fact that most people were most excited about the future potential of Augmented Reality within Theme Parks. Though many insiders believed it will still be a few years before it will be possible to use AR Glasses in theme parks, they offered some of the most potential in terms of transforming ride experiences. There will likely be a growing level of experimentation across the various ride categories and systems. Any use of HMD's within Theme Parks will need to consider issues such as sanitation, safety, durability, quality, operation costs and minimizing simulation sickness. The important thing will be to ensure that new attractions focuses more on enhancing the experience while attempting to not get too wrapped up in the technology.

The investment in a new, technologically enabled attraction must have a compelling business case. New attractions should be linked to a revenue strategy including increasing number of visitors coming to the Theme Park, increasing per capita spending within the park, increasing the length of peoples visits, increasing peoples' frequency of visits and through cannibalization (Younger, 2016). In order to successfully integrate VR, AR and MR into attractions some challenges include: making sure that the ongoing cost of personnel doesn't make the new attraction uneconomical and ensuring that the high development cost is offset by a revenue growth strategy.

Given the inherent risk risks of implementing a VR/AR/MR attraction, a good strategy includes leveraging physical spaces in combination with digital elements to maximize the guest experience. Though hype surrounding how cool technologies such as VR and MR will be, attraction designers should focus more on maximizing their experience to ensure it is a lasting part of the attraction mix. Even as the goal posts seem to be moving from a technology 
perspective, it is important to remember to use the technology as a tool to help achieve better guest experiences with Theme Park Attractions. 


\section{Appendices}

\section{A.1. Theme Park Operators and Location Based Entertainment Companies}

Growth at Theme Parks

The top 25 Theme Parks have been growing in terms of attendance. Top attraction operators have grown over 7\% in 2015 (Au et al., 2016). The growth was largely fueled by large Asian and American operators including Chimelong, SongCheng, Disney and Universal (Au et al., 2016). Attendance at the top 25 parks has grown considerably over the last ten years going from 187 million in 2006 to 236 million in 2015 (Au et al., 2016). Growth is expected to continue to be robust, especially in Asia, where the middle class is growing rapidly and their disposable income growing even more rapidly.

The Theme Park industry is becoming increasingly popular on the global stage. North American Theme Parks attract 47\% of the guests, Asia Pacific has $42 \%$ and Europe, Middle East and Africa (EMEA) has 11\% (Au et al., 2016). In 2006, North America had 52\% of the guests, Asia-Pacific had 35\% and EMEA had 13\% (Au et al., 2016). In 2005, it was estimated that there were 362 Theme Parks in the world (Clavé, 2007). Of these, $35 \%$ were in Asia, $31 \%$ were in the USA and Canada and altogether, they represented 606 million visits annually (Clavé, 2007). Table 2 lists the top Theme Park operators and the growth in attendance of 2015 versus 2014. The growth of the three Chinese parks is highlighted.

Table 13 - Top Ten Global Theme Park Operators

\begin{tabular}{|c|l|c|c|c|}
\hline Rank & Theme Park Operators & \% Change & $\begin{array}{c}\text { Attendance } \\
\mathbf{2 0 1 5}\end{array}$ & $\begin{array}{c}\text { Attendance } \\
\mathbf{2 0 1 4}\end{array}$ \\
\hline 1 & Walt Disney Attractions & $2.7 \%$ & $137,902,000$ & $134,330,000$ \\
\hline 2 & $\begin{array}{l}\text { Merlin Entertainment } \\
\text { Group }\end{array}$ & $0.2 \%$ & $62,900,000$ & $62,800,000$ \\
\hline 3 & $\begin{array}{l}\text { Universal Parks and } \\
\text { Resorts }\end{array}$ & $11.8 \%$ & $44,884,000$ & $40,152,000$ \\
\hline 4 & OCT Parks China & $7.8 \%$ & $30,180,000$ & $27,990,000$ \\
\hline 5 & Six Flags INC. & $11.4 \%$ & $28,557,000$ & $25,638,000$ \\
\hline 6 & $\begin{array}{l}\text { Cedar Fair Entertainment } \\
\text { Group }\end{array}$ & $4.9 \%$ & $24,448,000$ & $23,305,000$ \\
\hline 7 & Chimelong Group (China) & $26.4 \%$ & $23,587,000$ & $18,659,000$ \\
\hline 8 & Fantawild (China) & $77.4 \%$ & $23,093,000$ & $13,020,000$ \\
\hline 9 & $\begin{array}{l}\text { Seaworld Parks \& } \\
\text { Entertainment }\end{array}$ & $0.3 \%$ & $22,471,000$ & $22,399,000$ \\
\hline
\end{tabular}




\begin{tabular}{|c|l|c|c|c|}
\hline 10 & $\begin{array}{l}\text { Songcheng Worldwide } \\
\text { (China) }\end{array}$ & $53.4 \%$ & $22,338,000$ & $14,560,000$ \\
\hline & Total & & 420,000 & \\
\hline
\end{tabular}

**Numbers from Global Attractions Attendance Report by TEA and AECOM

With the rapid globalization of the global economy and current Theme Park related infrastructure already in place, investment from large park operators will include a mix of new park developments, upgrades to current parks and current park upkeep and maintenance (Clavé, 2007).

\section{Table 14 - Top Theme Parks Profiles and VR/AR Business Strategies}

\begin{tabular}{|c|c|}
\hline Disney Parks & $\begin{array}{l}\text { Disney is the leader of the Theme Park Industry with the most powerful } \\
\text { brand, highest attendance, revenue per capita and highest ticket prices in the } \\
\text { industry (Blooloop, 2016). Disney is known for its incredible arsenal of } \\
\text { intellectual property including their Lucasfilm, Pixar, Marvel, Avatar, The } \\
\text { Muppets in addition to their classic characters such as Mickey Mouse. They } \\
\text { currently operate } 6 \text { Theme Parks in the US and } 3 \text { abroad. In 2016, they } \\
\text { opened a new park called Shanghai Disney Resort (Blooloop, 2016). } \\
\text { Their major future developments will involve adding to current parks and } \\
\text { adding new themed sections of existing parks such as the upcoming Star } \\
\text { Wars additions in Anaheim. "Due to the intangible assets it develops, its } \\
\text { ability to create new, imaginative media consumption products and its } \\
\text { sophisticated "Imagineering" skills, Disney has become the park operator } \\
\text { par excellence. Due to its vast resources, its financial capacity, its ability to } \\
\text { recruit the top professionals and its commitment to high levels of quality and } \\
\text { customer service, it has become, furthermore a reference for the rest of the } \\
\text { industry" (Clavé, 2007). }\end{array}$ \\
\hline $\begin{array}{c}\text { Merlin } \\
\text { Entertainment } \\
\text { Group }\end{array}$ & $\begin{array}{l}\text { In terms of attendance, Merlin is the second largest Theme Park operator. In } \\
2015 \text {, they operated } 111 \text { Theme Parks in over } 23 \text { different countries. Merlin } \\
\text { also operates "Midway" attractions such as Madame Tussauds wax } \\
\text { museums, Sea Life Aquariums and Legoland Discovery Centers. A large } \\
\text { driver for growth at Merlin is opening new Legolands including Legoland } \\
\text { Dubai, Legoland Japan, Legoland South Korea and Legoland China } \\
\text { (Blooloop, 2016). } \\
\text { Madame Tussauds partnered with The Void and Sony Pictures to create the } \\
\text { Ghostbusters Dimension - A Hyper Reality Experience. It is a a free- } \\
\text { roaming mixed reality experience which overlays digital worlds on top of } \\
\text { physical spaces and allows users to become Ghostbusters in the Virtual } \\
\text { World (NA, 2016d). }\end{array}$ \\
\hline
\end{tabular}




\begin{tabular}{|c|c|}
\hline & $\begin{array}{l}\text { At Alton Towers, a Merlin Park, they converted an old roller coaster into a } \\
\text { VR Coaster. On the three-minute ride, VR HMDs provide guests a space } \\
\text { journey which is synched with the roller coaster's twists, turns and falls } \\
\text { (Kelion, 2016). } \\
\text { At Thorpe Park, Merlin created the Derren Browne Ghost Train Experience. } \\
\text { The ride is vintage style physical train in a giant warehouse suspended in the } \\
\text { air. Guests enter the train for a 13-minute VR enabled thrill ride. The train } \\
\text { can carry } 60 \text { passengers at a time and each user wears a HTC Vive headset. } \\
\text { The experience includes 4D effects, illusions, special effects and an } \\
\text { immersive virtual narrative (NA, 2016b). }\end{array}$ \\
\hline $\begin{array}{c}\text { Universal } \\
\text { Studios }\end{array}$ & $\begin{array}{l}\text { The third largest Theme Park in terms of attendance is Universal Studios. } \\
\text { Universal Studios is a subsidiary of NBCUniversal which is a wholly owned } \\
\text { subsidiary of Comcast Corporation. Universal currently has } 3 \text { owned parks } \\
\text { and } 3 \text { operated parks under joint ventures. Universal Studios has access to a } \\
\text { large collection of film and media assets which it leverages throughout its } \\
\text { parks including titles such as Harry Potter, Transformers, Jurassic Park, } \\
\text { Despicable Me, The Simpsons, Shrek, The Walking Dead, Dr. Seuss, The } \\
\text { Fast and the Furious, Marvel Entertainment and Nintendo. In addition to } \\
\text { expanding Universal Studios in Hollywood and Orlando with new themed } \\
\text { lands and attractions there is also proposed new parks in Moscow and } \\
\text { Beijing (Blooloop, 2016). } \\
\text { Universal Studios Japan converted their ride Space Fantasy into a VR } \\
\text { experience. It is a spinning indoor coaster starring the Japanese fashion } \\
\text { model and singer Kyary Pamyu Pamyu. The new ride blends Japanese } \\
\text { anime, manga and pop culture with the singer's music (MacDonald, 2016). }\end{array}$ \\
\hline Six Flags & $\begin{array}{l}\text { Six flags owns and operates } 11 \text { large scale amusement parks throughout } \\
\text { North America. Six Flags though traditionally known for its roller coasters } \\
\text { also has exclusive licenses for Theme Park usage of IP from Warner } \\
\text { Brothers (including Looney Tunes, DC Comics and Hanna Barbera). Six } \\
\text { Flags is planning on opening more parks in Dubai and China through Joint } \\
\text { Venture partnerships (Blooloop, 2016). } \\
\text { Six Flags has equipped } 9 \text { aging roller coasters with VR headsets. Three of } \\
\text { the VR Coasters are Superman themed and the other } 6 \text { are futuristic alien } \\
\text { adventures (MacDonald, 2016). Five other VR Coasters are planned to be } \\
\text { implemented with the Alien story line. }\end{array}$ \\
\hline $\begin{array}{c}\text { Cedar Fair } \\
\text { Entertainment } \\
\text { Company }\end{array}$ & $\begin{array}{l}\text { Cedar Fair owns and operates } 11 \text { large scale amusement parks in North } \\
\text { America. A notable example of Cedar Fair's intellectual property strategy is } \\
\text { their partnership with video game company Electronic Arts. in 2016, new } \\
\text { ride experiences will be created using Mass Effect IP (Electronic Arts) and } \\
\text { Plants vs. Zombies (Electronic Arts) (Blooloop, 2016). } \\
\text { Cedar Fair has been working on interactive dark rids branded "Amusement } \\
\text { Dark" at all of their locations featuring custom IP which revolves around a } \\
\text { theme of different creatures living under each park. The theming will allow }\end{array}$ \\
\hline
\end{tabular}




\begin{tabular}{|c|c|}
\hline & $\begin{array}{l}\text { flexibility for refreshes of IP (Blooloop, 2016). } \\
\text { Cedar Fair plans to put VR on two rides for the summer of 2016. One at } \\
\text { Canada's Wonderland on the Thunder Run Coaster and the other at Cedar } \\
\text { Point USA on the Iron Dragon VR coaster. If the pilot is successful, they } \\
\text { will put it on other rides in at their other parks. }\end{array}$ \\
\hline Songcheng & $\begin{array}{l}\text { Songcheng Group is a Theme Park company based in Hangzhou, China. } \\
\text { They develop their own branded Songcheng cultural tourist attractions and } \\
\text { are best known for their Romance Show. They operate } 6 \text { parks around } \\
\text { China and have plans to develop } 3 \text { more parks over the next several years } \\
\text { (adding parks in Taishan, Wuyishan and Shilin). Additionally, they are } \\
\text { diversifying their business to produce movies and shows (Blooloop, 2016). } \\
\\
\text { Songcheng recently announced a joint venture partnership with the VR } \\
\text { startup Spaces. SPACES a virtual-and mixed-reality company based in Los } \\
\text { Angeles, CA that was founded by members of DreamWorks Animation's } \\
\text { Dreamlab (Anita Busch, 2016). }\end{array}$ \\
\hline $\begin{array}{c}\text { Compagnie des } \\
\text { Alpes }\end{array}$ & $\begin{array}{l}\text { Compagnie des Alpes is one of the biggest European Theme Park operators } \\
\text { with } 8 \text { amusement parks. Their business interests include a wide range of } \\
\text { entertainment options. Though they aren't well known for licensing IP, they } \\
\text { recently did put in a 5D attraction in partnership with videogame developer } \\
\text { Ubisoft called Raving Rabbits (Blooloop, 2016). }\end{array}$ \\
\hline Fantawild & $\begin{array}{l}\text { Fantawild is a Chinese based amusement park developer and operator. They } \\
\text { operate } 14 \text { smaller parks with several types of high tech rides such as } 4 \mathrm{D} \\
\text { theaters, flying theaters and simulators. They have an arsenal of IP which is } \\
\text { quite popular in China including Boonie Bears, Chicken Stew, Kung Fu } \\
\text { Masters of the Zodiac Series and Conch Bay. They plan to develop more } \\
\text { parks in China in the coming years ideally reaching } 19 \text { by } 2016 \text { (Blooloop, } \\
\text { 2016). }\end{array}$ \\
\hline $\begin{array}{c}\text { Wanda } \\
\text { Entertainment }\end{array}$ & $\begin{array}{l}\text { Beijing Wanda Cultural Industry Group is one of the biggest Theme Park } \\
\text { companies in China. They are involved with many mega projects which will } \\
\text { be coming out in China soon. Some of their major attractions include } \\
\text { Wuhan Movie Park and The Han Show. Wuhan Central Cultural District is } \\
\text { a USD } 8.1 \text { billion development. the theming at all their "Cultural Tourism } \\
\text { Cities" includes internally developed material (Blooloop, 2016). }\end{array}$ \\
\hline Paramount & $\begin{array}{l}\text { London Paramount is a Theme Park project which is expected to open in } \\
\text { 2021. The park will have a Theme Park, giant theater, waterpark, event } \\
\text { space and hotels. The IP will come from Paramount Pictures, BBC } \\
\text { Worldwide, Aardman Animations and the British Film Institute (Blooloop, } \\
\text { 2016). }\end{array}$ \\
\hline Fox Parks & $\begin{array}{l}\text { Fox has two Theme Parks in development, one in Dubai and the other in } \\
\text { Malaysia. The parks feature licensed IP from 20th Century Fox including } \\
\text { Ice Age, Rio, Planet of the Apes, Aliens, Predator, Night at the Museum, } \\
\text { Titanic, The Simpsons and Sons of Anarchy. The attractions include a mix } \\
\text { of dark rides and thrill rides (Blooloop, 2016). }\end{array}$ \\
\hline
\end{tabular}


Table 15 - Top VR/AR Location Based Entertainment Companies

\begin{tabular}{|c|c|c|}
\hline Name & Location & Description \\
\hline The Void & $\begin{array}{l}\text { New York, USA } \\
\text { Unannounced }\end{array}$ & $\begin{array}{l}\text { Madame Tussauds Ghostbusters Experience Live } \\
\text { Representing one of the most advanced out of home } \\
\text { VR installations is The Void at Madame Tussauds. } \\
\text { Using VR, real time interactive effects and physical } \\
\text { set, this is an experience based off of the popular new } \\
\text { movie Ghostbusters. In this installation, three people } \\
\text { can go in at a time and blast through a ghost infested } \\
\text { apartment with a proton pack and gun. } \\
\text { This is The Void's first partnership with the movie } \\
\text { studios but they have plans to expand to different } \\
\text { locations with different types of IP going forward. } \\
\text { The Void revealed that in the short term they are } \\
\text { already working on } 10 \text { other locations but in the next } 5 \\
\text { years they hope to be live in around } 230 \text { locations } \\
\text { across the US and internationally. } \\
\text { Shanda and The Void Announce Partnership } \\
\text { Top gaming company Shanda Group, for instance, } \\
\text { also plans to create a VR Theme Park in partnership } \\
\text { with The Void LLC, a United States-based } \\
\text { entertainment company. Shanda has pledged \$350 } \\
\text { million in the overall VR space as their company } \\
\text { diversifies away from mobile gaming. Partnering with } \\
\text { an industry leader like the Void will likely position } \\
\text { this operation as a leading experience in Location } \\
\text { Based Virtual Reality. }\end{array}$ \\
\hline HTC Vive & $\begin{array}{l}\text { Various Locations } \\
\text { around China }\end{array}$ & $\begin{array}{l}\text { HTC which manufactures the Vive Headset recently } \\
\text { announced plans to open over 10,000 out-of-home VR } \\
\text { installations throughout China. This will be done in } \\
\text { partnership with Chinese electronic retailers Suning } \\
\text { Commerce Group and Gome Electrical Appliances } \\
\text { Holding Ltd as a major push to provide people with } \\
\text { their first experiences with high end VR. }\end{array}$ \\
\hline
\end{tabular}




\begin{tabular}{|c|c|c|}
\hline $\begin{array}{l}\text { Spaces and } \\
\text { Songcheng }\end{array}$ & China & $\begin{array}{l}\text { A new VR Theme Park startup called Spaces has also } \\
\text { made the news recently. With former executives from } \\
\text { DreamWorks Animation, Spaces has been able to } \\
\text { secure } \$ 30 \text { million in seed funding with plans to bring } \\
\text { virtual reality into China's most popular Theme Parks. } \\
\text { Songcheng and Spaces announced a partnership to } \\
\text { bring VR to their theme parks. The joint venture will } \\
\text { be based in Hangzhou, China and co-managed from } \\
\text { it's headquarters in Los Angeles. }\end{array}$ \\
\hline $\begin{array}{l}\text { Bandai Namco - } \\
\text { VR Zone: Project } \\
\text { i Can }\end{array}$ & Tokyo, Japan & $\begin{array}{l}\text { The large facility will act as a VR research center } \\
\text { where Bandai Namco can test and gain feedback from } \\
\text { users to further develop offerings for virtual reality. } \\
\text { The VR Zone will likely only operate on a temporary } \\
\text { basis and only through appointments. } \\
\text { Some of the games people can experience at VR Zone: } \\
\text { Project i Can include a Fear of Heights experience, a } \\
\text { skiing game, a driving game, an escape room } \\
\text { experience, a train experience and a robot battle } \\
\text { experience. }\end{array}$ \\
\hline VRCade & Milpitas, USA & $\begin{array}{l}\text { VRCade is another leader in the Location Based } \\
\text { Entertainment Sector. VRCade's product is a } \\
\text { warehouse scale version of laser tag using their own } \\
\text { integrated VR technology set ups. They have an arena } \\
\text { scale game for } 12 \text { users and an arcade offering for } 6 \\
\text { users. } \\
\text { VRCade has over a dozen live installations of their } \\
\text { Arcade offering with } 6 \text { in Dubai and a number of new } \\
\text { facilities being put in in China. They have opened at } \\
\text { Dave and Busters in a California location and have } \\
\text { ambitions to grow rapidly through strategic } \\
\text { partnerships including their partnerships with } \\
\text { Simuline, a Korean motion simulator company and } \\
\text { Smartlaunch, a Denmark based Arcade service } \\
\text { provider. }\end{array}$ \\
\hline
\end{tabular}




\begin{tabular}{|c|c|c|}
\hline Zero Latency & $\begin{array}{l}\text { Melbourne, } \\
\text { Australia } \\
\text { Tokyo, Japan }\end{array}$ & $\begin{array}{l}\text { Zero Latency is a popular Melbourne based company } \\
\text { creating a high end free roam virtual reality game. } \\
\text { They have already opened an experience at Sega Japan } \\
\text { and plan to open more in the US, Australia and in } \\
\text { China. The experience is } 45 \text { minutes long and is } \\
\text { meant for } 6 \text { players. Zero Latency has been in beta } \\
\text { testing mode only accepting appointments, charging at } \\
\text { their head facility and then refining their product when } \\
\text { the facility is closed to the public. However, going } \\
\text { forward they plan to expand across Australia as well } \\
\text { as abroad with lots of interest in growing their } \\
\text { business. Tickets for their experience costs } \$ 88 \text { and } \\
\text { can be signed up for on their website. }\end{array}$ \\
\hline $\begin{array}{l}\text { Imax and } \\
\text { Starbreeze }\end{array}$ & Unannounced & $\begin{array}{l}\text { Imax announced a recent partnership with Starbreeze a } \\
\text { Swedish independent creator, publisher and distributor } \\
\text { of high end VR entertainment content. With Imax's } \\
\text { large global reach, connection to the Hollywood } \\
\text { Studios and Starbreeze's expertise in creating content, } \\
\text { they plan to roll out an out of home VR offering that } \\
\text { will be at multiplexes, malls, and other commercial } \\
\text { destination. }\end{array}$ \\
\hline Star Core & Shanghai, China & $\begin{array}{l}\text { Star Core has been the first VR-based Theme Park in } \\
\text { Shanghai involving a variety of VR experiences for } \\
\text { guests to enjoy. } \\
\text { Star Core partnered with Mili Pictures to create the } \\
\text { content for the various experiences. The center } \\
\text { features three playrooms, where visitors can } \\
\text { experience various space-age story lines in the "Star } \\
\text { Core" universe. } \\
\text { Star Core is set up as an entertainment facility aiming } \\
\text { to provide people with exposure to new VR } \\
\text { technologies who haven't tried them. }\end{array}$ \\
\hline $\begin{array}{l}\text { Guizhou Theme } \\
\text { Park }\end{array}$ & Guizhou, China & $\begin{array}{l}\text { There is a plan for a Virtual Reality Theme Park in } \\
\text { Guizhou. It is part of a larger 1.3-square-kilometer, } \\
\text { 10-billion-yuan ( } \$ 1.52 \text { billion) project being } \\
\text { developed by the Shenzhen-listed Oriental Times } \\
\text { Media Corp's animation unit. This is also an R\&D } \\
\text { based VR strategy similar to others in this space. }\end{array}$ \\
\hline
\end{tabular}




\section{A.2. Questionaires}

\section{Theme Park Attraction Manufacturers and Operators Questionnaire}

\section{General}

- What is your current focus, how did your career lead you to this type of work?

- What is your ultimate vision for where you think VR will ultimately be? What are your predictions for where it will be 5 years from now and 10 years from now from an entertainment perspective?

- What type of clients do you typically work with?

- What are some of the most interesting examples of Theme Park VR/AR experiences from your perspective (live and in development projects)?

- Which technology AR/VR do you think could have a more influential impact on the next generation Theme Park Rides? Why?

- Do you think disruptive technologies such as increasingly powerful home based entertainment, mobile or VR/AR could potentially displace Theme Parks as a provider of entertainment? Do you think Theme Park Operators are doing enough to combat this threat?

- What do you think the next wave of innovation will bring into the VR/AR Theme Park market?

\section{Mechanics}

- What your opinion on Head Mounted Displays within a Theme Park Setting?

- What do you think are key considerations that designers need to make to create great VR experiences?

- What experiences have you seen make people want to get out of their homes to experience something?

- What are some cool innovations regarding AR/VR which may soon be in theme parks in the short term?

- What design strategies do you think will help VR seem less isolating and more of a social experience?

- What types of game mechanics do you think pair well within a theme park context?

- Based on the current state of theme parks, do you think VR and AR provide a solutions or innovative experiences to some of the problems around theme parks? (i.e. improving 
experience in lines, making rides with multiple experiences in one, improving level of immersion?)

\section{Content}

- Within the VR/AR medium, what is your company's approach to creating compelling content and repeatable game mechanics?

- Do you find certain types of content more popular in creating blockbuster attractions (i.e. branded content vs. non-branded)?

- What is the future vision for the next generation for out of home immersive entertainment?

\section{Economics}

- Do you find theme parks are willing to take risks with new technologies (like VR/AR)?

- What do you make of all the media buzz and analyst expectations about VR and AR from your experience within the industry? Do you think its going to be as big as analysts expect?

- What are some of the biggest challenges will be for companies operating in the Out of Home Immersive Entertainment Sector?

- Do you think Technology Changes have made VR a more viable opportunity for Theme Parks to implement?

- Do you think Technology Changes have made AR a more viable opportunity for Theme Parks to implement?

- What are some of the biggest risks in implementing VR or AR in a theme park attraction based on current available technology?

- With increasingly powerful technology coming available in the home, how do you investing in Out-of-Home vs. home-based VR? Do you think their will be a sustainable market for both?

\section{Industry Analyst Questionnaire}

\section{General}

- After doing such an extensive analysis of the VR industry, from an entertainment perspective, what companies do you find most compelling?

- What are the top Location Based VR companies from your perspective?

- Do you feel VR is a viable technology for theme parks to implement?

- What were some of the different strategies of top entertainment companies working on VR? 
- What is the ultimate potential for VR in terms of what it might be able to enable from an entertainment perspective?

\section{Economics}

- How large do you think the VR Industry will be by 2020 ?

- What will be the key drivers to VRs growth?

- What will be the key barriers preventing VRs growth?

- Do you agree with industry reports stating that by 2020 , VR will be as big as a $\$ 110$-billiondollar market making it bigger than TV?

- What countries do you think will be the first movers from a consumer perspective?

- What are the most technologically advanced global regions from a development perspective?

\section{Mechanics}

- When conducting analysis on the VR industry, what entertainment use cases did you see and what do you think might be developed and released over the next 5 years?

- How do you view the maturity of VR against AR? Which do you think would have better use cases within an entertainment context?

\section{Content}

- What companies do you think will be leading the VR industry from an entertainment perspective ( 3 years from now, 5 years from now)?

- What do you think the killer app for VR will be?

\section{VR/AR Game Companies Questionnaire}

\section{General}

- What is your current role? How did you initially get involved with VR?

- Do you think Technology Changes have made VR a more viable opportunity for Theme Parks to implement?

- Which technology AR/VR do you think could have a more influential impact on the next generation Theme Park Rides? Why?

- What are some innovations that are available which you are most excited about? 
- Do you think disruptive technologies such as increasingly powerful home based entertainment, mobile or VR/AR could potentially displace Theme Parks as a provider of entertainment? Do you think Theme Park Operators are doing enough to combat this threat?

- What is your ultimate vision for out of home VR experiences and the types of experiences that they will be able to provide guests with? What do you think is more realistic things to see at theme parks in the short term?

\section{Mechanics}

- From your experience in designing out of home VR experiences, what do you think are key considerations that a designer needs to make to create great VR experiences?

- What is your companies approach to creating repeatable game mechanics?

- What gaming genres do you think could work well in theme park experiences which are typically designed for high throughput?

- What are some of the other dimensions to make VR game play compelling? What do you think the top 3 focus areas are for creating compelling VR gameplay?

- Based on the options available out of home for enhancing VR experiences, which gameplay mechanics have you seen which you think are cool? What do you think we can expect from this sector going forward based on the design affordances of VR and potentially available technology?

\section{Content}

- What is your companies approach to creating compelling content?

- What design strategies do you think will help VR seem less isolating and more of a social experience?

- From a content perspective, do you think branded content or custom is better for VR experiences?

\section{Economics}

- With increasingly powerful technology coming available in the home, how does your company view investing in Out-of-Home vs. home-based VR? Do you think their will be a sustainable market for both? Which segment is your company targeting?

- What do you think the killer app for VR could be? 
- What do you make of the growing Analyst expectations and VC interest within VR and AR? Do you think the valuations of some of these companies (like Magic Leap or Oculus) are high? Do you think there could be a bit of a bubble similar to the dot com bust?

- Globally, which countries do you think are leading from a VR development perspective? 


\section{Glossary}

Though the following list is a glossary of technical terms used throughout this paper to describe technologies associated with Virtual Reality, Augmented Reality and Mixed Reality.

Table 12- Typical Definitions of VR and AR Terms

\begin{tabular}{|c|c|}
\hline Technology & Description \\
\hline $\begin{array}{l}\text { VR Head Mounted } \\
\text { Display }\end{array}$ & $\begin{array}{l}\text { A head-mounted display (HMD) is a computer display device that is worn } \\
\text { on the head. The display immerses the user in an experience and changes } \\
\text { the content based on how a user's head turns, much like the real world. A } \\
\text { VR based head mounted display will immerse a user in a } 360 \text { interactive } \\
\text { virtual environment. Benefits of high end head mounted displays include } \\
\text { wide field of view, high resolution and high frame rate. }\end{array}$ \\
\hline $\begin{array}{l}\text { Smartphone based } \\
\text { Head Mounted } \\
\text { Display }\end{array}$ & $\begin{array}{l}\text { By putting a smartphone in a specialized HMD unit, users can experience } \\
\text { VR. For this to work, a specialized app needs to be downloaded that } \\
\text { splits the screen providing each eye with a 2D projection which the brain } \\
\text { reconstructs into a 3D experience. Smartphone based VR leverages the } \\
\text { phone's built in sensors including the gyroscope, magnetic compass and } \\
\text { accelerometer to allow head tracking within the virtual environment. } \\
\text { VR Coasters leverage this technology for their experiences. }\end{array}$ \\
\hline Computer & $\begin{array}{l}\text { A gaming computer is designed for performing computationally } \\
\text { demanding computer operations such as operating a video game or } \\
\text { immersive VR experience. A gaming computer will have a high end } \\
\text { graphics cards and processor installed which enables the complex } \\
\text { computational operations inherent in creating Virtual Reality. }\end{array}$ \\
\hline Game Engine & $\begin{array}{l}\text { A game engine is a type of software used for creation and development of } \\
\text { video games and VR experiences. }\end{array}$ \\
\hline 3D Audio & $\begin{array}{l}\text { Virtual Reality requires sound which immerses a user much like the real } \\
\text { world involving } 360 \text { degrees of sound sources to be simulated around a } \\
\text { user. This involves the virtual placement of sound sources anywhere in } \\
\text { three-dimensional space, including behind, above or below the listener. }\end{array}$ \\
\hline $\begin{array}{l}\text { Networked } \\
\text { Environment }\end{array}$ & $\begin{array}{l}\text { Virtual Reality relies on complex interconnected networks in order for } \\
\text { multiple people to enjoy an experience at once. This problem can be } \\
\text { solved with computer clusters. Networked Environments or Computer } \\
\text { Clusters have each node performing the same task which is controlled and } \\
\text { scheduled by software. } \\
\text { In the case of free-roaming VR experiences, this typically involves a } \\
\text { series of laptops worn on users backs which are wirelessly connected to a } \\
\text { centralized system. }\end{array}$ \\
\hline
\end{tabular}




\begin{tabular}{|l|l|}
\hline $\begin{array}{l}\text { Positional } \\
\text { Tracking }\end{array}$ & $\begin{array}{l}\text { Positional tracking is a mix of hardware and software which is able to } \\
\text { detect the absolute position of an object. When using VR, the physical } \\
\text { space that the user is in can be tracked with cameras or infrared sensors } \\
\text { which can detect movement within a given area. Positional Tracking is } \\
\text { important in virtual reality because it allows position and movement of } \\
\text { any body part or prop that marked to move dynamically in the virtual } \\
\text { environment. } \\
\text { This enables a lot the unique gameplay that is inherent in many VR } \\
\text { experiences. }\end{array}$ \\
\hline Mobile AR & $\begin{array}{l}\text { Hardware components required to produce AR include processor, display, } \\
\text { sensors and input devices. Mobile devices such as smartphones and } \\
\text { tablets now have these and others such as cameras MEMS sensors, } \\
\text { accelerometers, GPS units and solid state compasses which all enable AR } \\
\text { technology to work. }\end{array}$ \\
\hline AR Head Mounted \\
This is the technology that VR Coasters use and Augmented Reality \\
Games throughout theme parks.
\end{tabular}




\begin{tabular}{|l|l|}
\hline 3D Projection & $\begin{array}{l}\text { Projection Mapping is also sometimes referred to video mapping or } \\
\text { spatial augmented reality. It relies on projection technology that turns } \\
\text { objects, often irregularly shaped, into a display surface for video } \\
\text { projection. These objects can be complex industrial landscape such as } \\
\text { buildings, small indoor objects or stages. }\end{array}$ \\
& $\begin{array}{l}\text { This is a popular technology used in a lot of Media Based Attractions and } \\
\text { Dark Rides being introduced over the coming years. }\end{array}$ \\
\hline
\end{tabular}




\section{References}

Anita Busch. (2016, June). Former DreamWorks Animation Execs’ New Company To Bring Virtual Reality To China's Theme Parks. Deadline. Retrieved from http://deadline.com/2016/06/virtual-reality-china-theme-parks-spaces-former-dreamworksanimation-execs-1201768560/

Au, G., Chang, B., Cheu, L., Finney, B., LaClair, K., Lock, J., ... Yoshii, C. (2016). TEA/AECOM 2015 Theme Index and Museum Index: The Global Attractions Attendance Report.

Blooloop, E. (2016). Global Attraction Landscape. ECA-Blooloop Global Attractions Landscape. Boshoff, C. (2006). A proposed instrument to measure the customer satisfaction of visitors to a theme park. Management Dynamics, 15(3), 2. JOUR.

Clavé, S. A. (2007). The global theme park industry. BOOK, Cabi.

Craig, A. B., Sherman, W. R., \& Will, J. D. (2009). Developing Virtual Reality Applications Foundations of Effective Design. Multiple: Morgan Kaufmann Publishers.

Dolan, D., \& Parets, M. (2016, January). Redefining the Axiom of Story: The VR and 360 Video Complex. Tech Crunch.

Etherington, D. (2016). Pokemon Go crosses \$200M in Global Revenue One Month into Launch. Retrieved August 22, 2016, from https://techcrunch.com/2016/08/07/pokemon-gocrosses-200m-in-global-revenue-one-month-into-launch/

Forni, A., \& Vandermeulen, R. (2016). Gartner's 2016 Hype Cycle for Emerging Technologies Identifies Three Key Trends That Organizations Must Track to Gain Competitive Advantage. Stamford, Conneticut. Retrieved from http://www.gartner.com/newsroom/id/3412017

Jenkins, H. (2006). Convergence culture: Where old and new media collide. NYU press.

Jones, B. (2016). What is projection mapping?

Kelion, L. (2016, January). Alton Towers to open virtual reality rollercoaster. $B B C$. Retrieved from http://www.bbc.com/news/technology-35290384

Kim, J., Cho, Y. M., Park, F. C., \& Lee, J. M. (2003). Design of a parallel mechanism platform for simulating six degrees-of-freedom general motion including continuous 360-degree spin. CIRP Annals-Manufacturing Technology, 52(1), 347-350. JOUR.

Kipper, G., \& Rampolla, J. (2012). Augmented Reality: an emerging technologies guide to AR. 
BOOK, Elsevier.

Lazzaro, N. (2004). Why we play games: Four keys to more emotion without story. JOUR.

Lehu, J.-M. (2007). Branded entertainment: Product placement \& brand strategy in the entertainment business. BOOK, Kogan Page Publishers.

Llamas, S. (2016). Virtual Reality \& the Next Killer App.

MacDonald, B. (2016, March). Virtual reality coasters to take theme parks by storm this summer. LA Times. Retrieved from http:/www.latimes.com/travel/themeparks/la-trbvirtual-reality-coasters-20160304-story.html

Matney, L. (2016, June). HTC Vive announces \$10 billion VR Venture Capital Alliance. Tech Crunch.

Merel, T. (2016). Augmented/Virtual Reality revenue forecast revised to hit $\$ 120$ billion by 2020. Retrieved from http://www.digi-capital.com/news/2016/01/augmentedvirtual-realityrevenue-forecast-revised-to-hit-120-billion-by-2020/\#.V4ZVcJMrKgQ

Milgram, P., Takemura, H., Utsumi, A., \& Kishino, F. (1995). Augmented reality: A class of displays on the reality-virtuality continuum. In Photonics for industrial applications (pp. 282-292). CONF, International Society for Optics and Photonics.

Milman, A. (2001). The future of the theme park and attraction industry: a management perspective. Journal of Travel Research.

Murphy, M. (2016, March). Top Six Firms Inventing Virtual-Reality Tech. Tech World.

NA. (2016a). Looking inside an HTC Vive game using a green screen. Retrieved August 8, 2016, from https://www.youtube.com/watch?v=BjdzsVFs2C0

NA. (2016b). UK's Thorpe Park Unveiled Derren Brown's Ghost Train VR Experience Launching in Spring 2016. Virtual Reality Reporter.

NA. (2016c). Virtual Reality: What does it look like today, what will lead to it's adoption? Retrieved from http://www.lek.com/sites/default/files/Virtual-RealityAdoption_ExecutiveInsights_Spotlight3.pdf

NA. (2016d, May). The Void to Power New Ghostbusters VR Experience at Madame Tussauds NY. Road to VR.

Orland, K. (2014). Facebook purchases VR headset maker Oculus for $\$ 2$ billion [Updated]. ARS Technica. Retrieved from http://arstechnica.com/gaming/2014/03/facebook-purchases-vrheadset-maker-oculus-for-2-billion/ 
Ranj, B. (2016, January). Goldman Sachs says VR will be bigger than TV in 10 years. Business Insider. Retrieved from http://www.businessinsider.com/goldman-sachs-predicts-vr-will-bebigger-than-tv-in-10-years-2016-1

Rebori, S. J. (1993). Theme parks: an analysis of Disney's planning, design and management philosophies in entertainment development. University of Tennessee.

Schell, J Shochet, J. (2001). Designing interactive theme park rides. Computer Graphics and Applications, IEEE, 21(4), 11-13. JOUR.

Schell, J. (2014). The Art of Game Design: A book of lenses. CRC Press.

Tim Merel. (2016, May). The reality of augmented and virtual reality venture capital. Tech Crunch. Retrieved from http://techcrunch.com/2016/05/24/the-reality-of-augmented-andvirtual-reality-venture-capital/

Torrado A, S. A. (1995). Parques tematicos: la atraccion del siglio (Planeta Ba). Anuario de los temas.

Wi, J. H. (2009). Innovation and strategy of online games (Vol. 14). BOOK, World Scientific.

Wong, K. K. F., \& Cheung, P. W. Y. (1999). Strategic theming in theme park marketing. Journal of Vacation Marketing, 5(4), 319-332. JOUR.

Yang, B. (2016). Practical VR for Disney Theme Parks. Game Developer Conference. Retrieved from https://www.youtube.com/watch?v=JEp1rq7VaiU

Younger, D. (2016). Theme Park Design \& The Art of Themed Entertainment (71.75). Lightning Source. 